\title{
THE INTERNAIIONAL
}

REVIEW OF RESEARCH IN

OPEN AND DISTANCE LEARNING

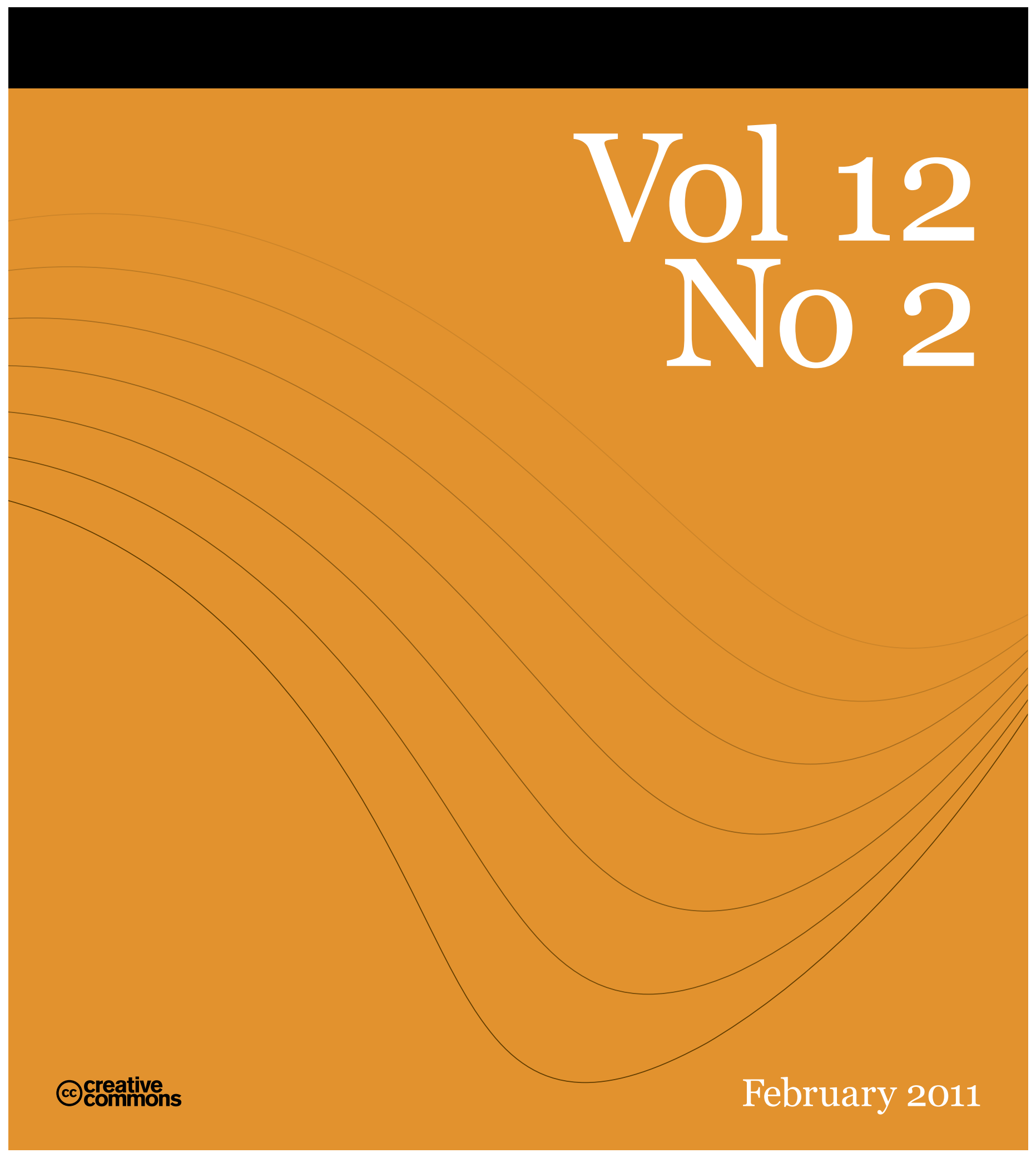




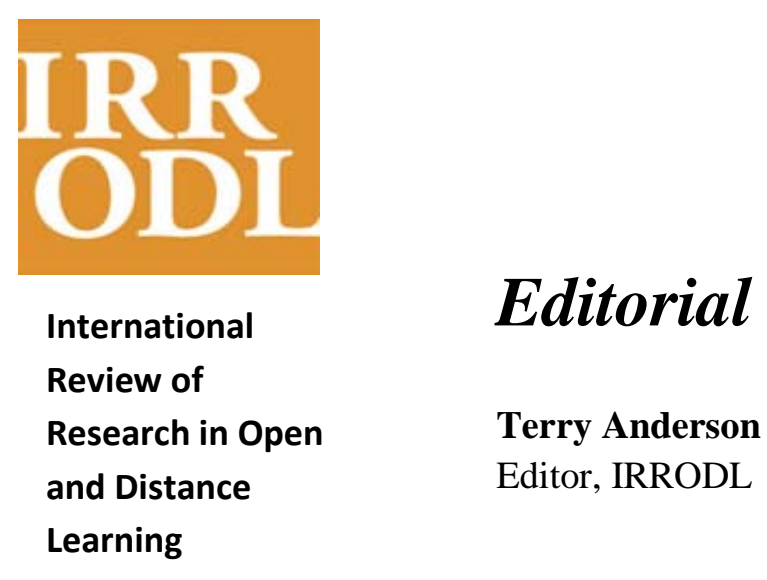

Vol. 12.2

February - 2011

We are pleased to present another general issue of IRRODL to our research community, distance educators, and general readers throughout the world. This delightful general issue has a variety of themes, including instructional design for distance education, support for distributed adjunct faculty, and mobile learning.

The first research article by Simon Paul Atkinson presents a new and, I think, a very practical instructional design model for online education. His article, "Embodied and Embedded Theory in Practice: The Student-Owned Learning-Engagement (SOLE) Model,” describes the rationale for, and a good description of, a toolkit that is designed to help instructors and designers create online courses that make the most of both the technical and pedagogical affordances of the Web.

Our second research article challenges us to look beyond the hype and sales talk too often associated with online learning and to confront the challenges of high dropout and low prestige and lack of acceptance by mainstream academics. In "Head of Gold, Feet of Clay: The Online Learning Paradox," researchers Thomas Michael Power and Anthony Morven-Gould propose a way out of John Daniel's iron triangle of cost, accessibility, and quality by combining both synchronous and asynchronous models to create "blended" online learning design (BOLD).

Many models of distance education achieve their economy of scale and reduce costs by employing part-time adjunct faculty. Thus, they are a critical and arguably the most important component of any distance education system. However providing adequate training and support to these distributed educators has long been a challenge to distance education systems. We are pleased to publish two articles that investigate ways to support adjunct faculty. The first by Julie Shattuck, Bobbi Dubins, and Diana Zilberman is titled "Maryland Online's Inter-Institutional Project to Train Higher Education Adjunct Faculty to Teach Online," and it evaluates a program designed to help adjunct faculty become highly effective online teachers. The lessons learned and the interventions developed and piloted in Maryland and described in this article will be useful in guiding professional development and support units across the world. The second by Vera Dolan 
is titled “The Isolation of Online Adjunct Faculty and its Impact on their Performance.” It presents the results of a grounded theory study of adjunct faculty with specific focus on the value of occasional face-to-face interactions with administrators and colleagues at the institution where they are employed. As noted above the study also reveals the need for quality professional development and support. The two articles together overview the need and present solutions to supporting these important workers in our distance education systems.

The fifth research article, "A Pedagogical Framework for Mobile Learning: Categorizing Educational Applications of Mobile Technologies into Four Types” by Yeonjeong Park, presents a pedagogical model for designing, developing, and marketing different types of mobile learning activities. The article picks up on Moore's familiar transactional distance model and uses it to categorize the many different types of instructional activities that can be developed for mobile learning. I think all of us struggle with ways to meaningfully employ these increasingly ubiquitous tools in our work, and this article will help us develop applications that understand and maximize the technical affordances offered.

The final research article, "Delimiting the Prospect of Openness: An Examination of Initial Student Approaches to E-Learning” by Christopher Naughton, Juliette Smeed, and John Roder, reports on a study conducted in New Zealand, which shows the indifference of students to online forums when the assessment model remains individualistic and competitive. The article encourages us to consider new forms of assessment that demonstrate the value of student engagement in the learning process.

We have one Field Notes article in this edition that again focuses on mobile learning but this time with a geographic focus - Malaysia. Tina Lim, Mansor Fadzil, and Norziati Manso present a case study of the effective use of mobile learning to enhance programming in one of the world's megauniversities. In "Mobile Learning via SMS at Open University Malaysia: Equitable, Effective, and Sustainable," the authors demonstrate that SMS technologies have a critical role to play in the matrix of technologies and human resources needed to support effective and efficient distance education delivery.

The issue includes a book review by Wolfram Laaser of the Economics of Distance and Online Learning: Theory, Practice and Research, edited by W.J. Bramble \& S. Panda. Economics and cost effectiveness have always been of concern to distance educators and thus this edited book is of special relevance. The summary and the critical review of the 15 chapters in this book highlight the variability and different models of distance education delivery that compete for our attention and funding in current times.

The issue concludes with two technical reviews by graduate students in Athabasca University's Master's of Distance Education program. The first by Tanya Elias overviews important "Universal Instructional Design Principles for Mobile Learning." The second, "Online Videoconferencing Product Update” by Douglas Burton and Tim Kitchen updates earlier IRRODL reviews on online web conferencing products. Four new products are overviewed and 
compared, thus providing invaluable information for those wishing to add a synchronous component to their distance delivery.

We trust you will enjoy these articles, pass the links and a free subscription suggestion to your colleagues, and have an opportunity to thank the many who bring you IRRODL without charge through their gifts and skills of sponsorship, scholarship, review, editing and production.

\section{Athabasca University $\mathbf{a}$}

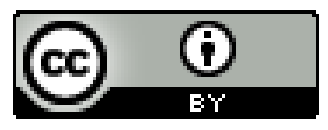




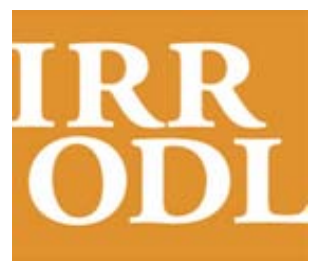

International

Review of

Research in Open

and Distance

Learning

Vol. 12.2

February - 2011

\section{Embodied and Embedded Theory in Practice: The Student-Owned Learning-Engagement (SOLE) Model}

Simon Atkinson

London School of Economics and Political Science, UK

\begin{abstract}
The demands on academic staff in all sectors to adopt best ODL practices to create effective and efficient models of learning in the face of increasing external pressures show no signs of abating. The massification of higher education, diversified access, and pressures to meet institutional visions and research objectives demand of teaching staff an increasingly public design process subject to peer review in numerous forms. Expectations of systematized pedagogical planners and embedded templates of learning within the institutional virtual learning environments (VLEs) have, so far, failed to deliver the institutional efficiencies anticipated. In response, a new model of learning design is proposed with a practical, accessible, and freely available "toolkit" that embodies and embeds pedagogical theories and practices. The student-owned learningengagement (SOLE) model aims to support professional development within practice, constructive alignment, and holistic visualisations, as well as enable the sharing of learning design processes with the learners themselves.
\end{abstract}

Keywords: Learning design; constructive alignment; pedagogical planners; toolkit 


\section{Why a Learning Design Model?}

The rich traditions of ODL, particularly those in distance and more recently online provision, are being drawn upon by an increasing number of institutions as they engage with some form of online support for learning. Academic staff are increasingly encouraged, or coerced, into the move towards blended modes of delivery with the same instance of a course being delivered to several cohorts simultaneously in both contact and distance mode or towards wholly online delivery modes. Staff unfamiliar with the intricacies and complexities of ODL provision find themselves, often for the first time, in an environment where the learning design process is more transparent, no longer delivered behind closed doors and often more complex as the contextual parameters prove new and unpredictable.

The conceptual work presented here, the SOLE model and its associated toolkit, is based on ten years of heuristic development in an academic professional context in explicitly ODL institutions (Open University, UK), majority campus-based provision (University of Hull, UK) and emerging blended institutional models (Massey University, NZ). The aim of the SOLE work has been to make pedagogical theory accessible to staff, to support their ability to visualise novel and effective ways for learners to engage remotely, and to avoid the danger of having staff develop materials in addition to those they have traditionally delivered in a face-to-face context, resulting in workload management difficulties for staff and students. The resulting SOLE model is grounded in professional practice and has produced a practical toolkit currently being implemented and evaluated. The aim of the toolkit is to support staff in designing learning and to share ownership of learning with the learner.

It is the author's intention, as an educational developer, to support both individual and collective professional development processes. In order to do so, one must recognise that place, time, and motivation will be significant factors for academic staff. As Knight, Tait, and Yorke suggest,

How do we make workplaces evoke learning? Firstly, spaces need to be found for this activity, for the creation of shared meaning. Secondly, power relationships within activity systems need to encourage collegiality and participation. Thirdly, appropriate procedures and practices are needed; in higher education this is often represented by the capricious notion of reflection.” (2006, p. 332)

It is suggested that professional development must be situated within practice to be truly effective, must fit within the practical activity of staff in designing support for their practice, must encourage collegial participation, and must establish opportunities for negotiated and shared procedures.

The response to the challenge of the massification of higher education has, in part, been to raise the profile of scholarship of teaching and learning (SoTL) as a recognisable and reward-worthy activity for academic staff. Beyond specialism within a knowledge domain, the ability to support 
learning in that domain becomes a pursuit in its own right. Shulman's oftquoted suggestion that "we develop a scholarship of teaching when our work as teachers becomes public, peer-reviewed and critiqued [and] exchanged with members of our professional communities so they, in turn, can build on our work” (Shulman, 2000, p. 50), still suggests the primacy of fellow teaching academics as peers, rather than the majority of those actively engaged in the learning experience, namely the learners. Nonetheless, Shulman invites us to consider the dynamic nature of the teaching experience, suggesting, "We can treat our courses and classrooms as laboratories or field sites in the best sense of the term, and can contribute through our scholarship to the improvement and understanding of learning and teaching in our field” (Shulman, 2000, p. 50). We might also consider the advantages of engaging the learners themselves in this scholarship of teaching and learning process, making the learning design process and implementation a transparent and reflective experience for the teacher and learner.

\section{Supportive Models}

Models, frameworks, and toolkits serve to support staff in a myriad of ways. Much of the work behind the development of learning design models has sought to support course developers, teaching academics, and instructional designers alike in producing well-structured, balanced, and effective learning opportunities for students. A model serves to instil in the design process agreed parameters for a course of study such as the total student workload, shape of assessment strategy, and range, or nature, of learning activities. Recent work in the United Kingdom has invested significantly in the creation of pedagogical planners such as the work derived from JISC Design for Learning (JISC, 2006) and the successor to the Phoebe and London Pedagogical Planner projects, the Learning Design Support Environment (LDSE, 2010). These initiatives have produced largely web-based applications to assist staff in creating and structuring learning activities, which are then shareable and reusable. Much of this work has emphasised the costeffectiveness and efficacy of technology-enhanced learning in meeting the increasing demands on higher education for expanding and widening participation with static or diminishing financial resources. Meeting this challenge will require innovative approaches to teaching and learning, to the use of technology enhanced learning, and to the means which ensure that institutions are able to support staff in their practice (Laurillard \& Masterman, 2010).

Despite the promise of the learning objects movement, of the availability of open educational resources (OERs) that have flourished in recent years, and of the commercial responsiveness of many publishers, the bulk of development still rests in context with individual academic staff. Whilst there is undoubtedly value in the sharing of templates of activity and patterns of learning,

Learning design is a complex activity that is influenced by a wide range of factors such as: the prior experience and background of the designer (or design team); the nature of the target group for which the learning product is being designed; the designer's understanding of cognition, pedagogy and epistemology; and, of course, various technological factors relating to the use of media and the properties they possess. (Barker, 2008, p. 128) 
Funding agencies are often attracted to the notion of a definable product, but staff themselves, and their institutional support structures, have a very limited capacity to engage meaningfully with new tools. Academic staff frequently cite a lack of time as well as a lack of fundamental support as reasons why they do not use the myriad of tools provided.

Laurillard makes it clear that technology is potentially a solution to much of the inconsistency in the quality of learning design, but also represents part of the problem facing higher education (Laurillard, 2008). Its constant evolution and disruptive impact require a level of institutional preparedness that few have been able to live up to. There is much that is exciting about the recent development of individual learning design tools and pedagogical planners, but the emphasis remains on tools to retain levels of academic control; effective use of technology is represented as "essential if the academic community is to both maintain control of the new pedagogies, and find the most creative and effective ways of exploiting what the technology offers" (Laurillard, 2008, p. 149).

\section{Learning Engagement: Constructive Alignment}

The United States National Survey of Student Engagement (NSSE) defined student engagement as "the time and energy students devote to educationally sound activities inside and outside the classroom, and the policies and practices that institutions use to induce students to take part in these activities” (NSSE, 2007, p. 3).

This definition is significant in taking into account the world outside the classroom as one that academic staff would be wise to account for in their models of learning engagement. When this is considered alongside Professor John Biggs' seminal work on the constructive alignment of learning, a powerful notion of the whole life-cycle of learning emerges. Biggs takes Bloom's taxonomy of educational objectives (Bloom, 1964) and constructs a neat model of integrated and interdependent processes for curriculum designers that seek to align learning outcomes and assessment, as well as associated learning activity (Biggs \& Collis, 1982). Biggs argues that, having decided on well-articulated verbs for the learning outcome in question (for example, "learners will be able to evaluate the underlying social prejudices influencing media criticality in contemporary news programming"), associated assessment might be expected to enable students to demonstrate they have met that outcome ("learners will be assessed on their ability to evaluate the underlying social prejudices influencing media criticality in contemporary news programming”). As a consequence, the teaching method, which Biggs clearly prefers to call teaching \& learning activity (TLA), will also activate that verb, so one could expect to see the teaching and learning itself evaluating, examining social prejudices, exploring notions of influence unpacking the notion of "media criticality," and establishing a context for news programming (Figure 1). If the teaching and learning activities do not activate the verb, one cannot be sure learners will experience that which they are expected to evidence to demonstrate attainment of the learning outcomes. 


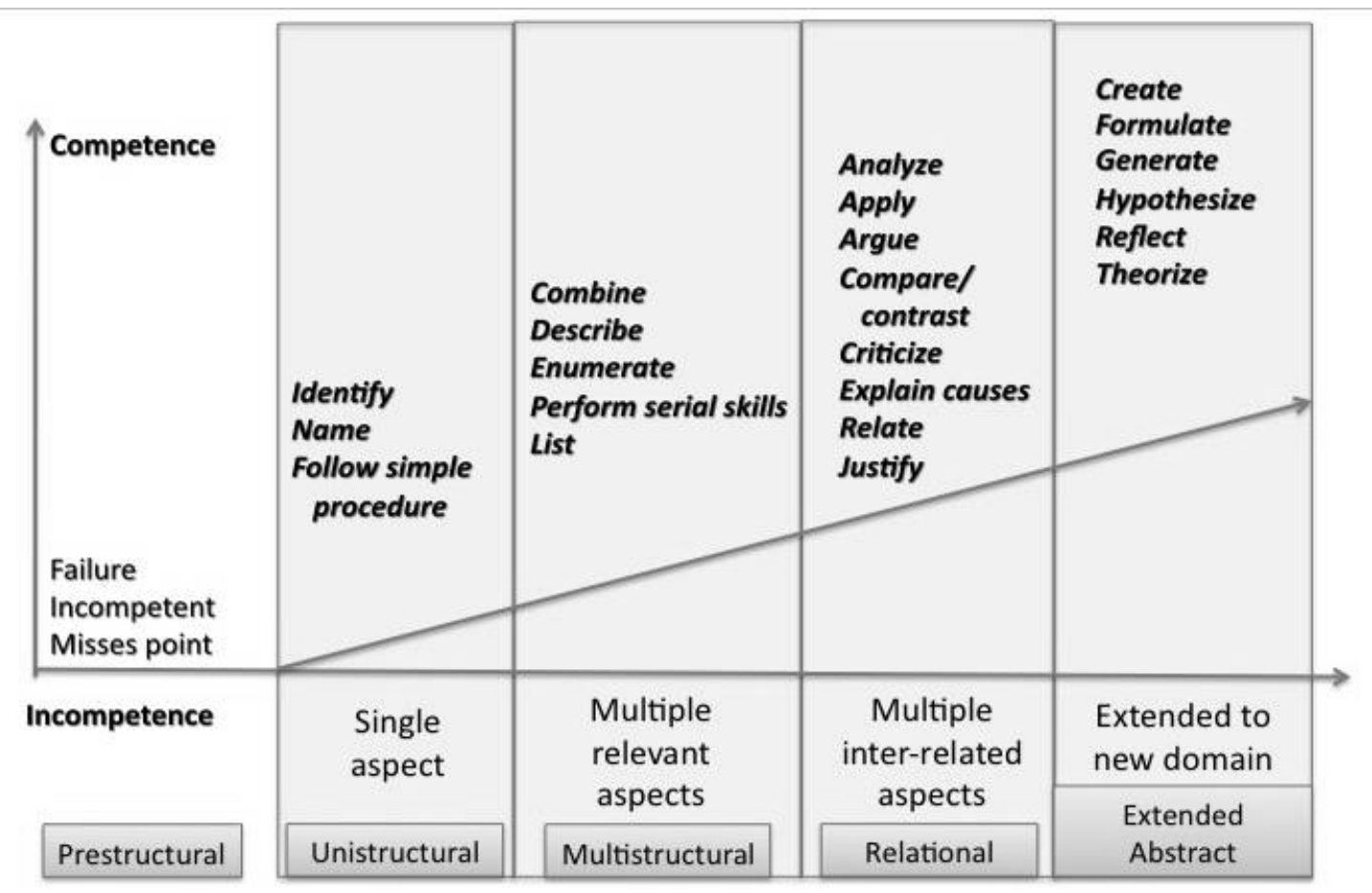

Figure 1. Constructive alignment (Biggs \& Tang, 2007).

Also significant in any consideration of learning design model is the ability to express a range of existing theoretical models and their evidenced practice. To this end, Laurillard's conversational framework (Laurillard, 2002) is significant, in that it illustrates very effectively the way in which emerging $20^{\text {th }}$-century learning theories and approaches have subsumed, rather than crudely displaced, each preceding one. Socio-cultural learning does not displace notions of social constructivism, but simply absorbs and extends its reach. The NSSE definition cited above represents a culmination of that subsuming approach to theory.

\section{Why a Student-Owned Learning-Engagement Model?}

SOLE stands for student-owned learning-engagement. All these terms are contested within education, but the emphasis is clearly on students being conscious of the learning design and learning processes and of the desire to optimise appropriate and effective learning engagement opportunities.

The SOLE model's (Atkinson, 2010) original development goals were threefold:

1. to embed pedagogical guidance regarding constructive alignment (Biggs \& Tang, 2007) inside a learning design tool easily accessible to staff;

2. to produce a practical model that captured the lessons to be learnt from Laurillard's representations of conversational learning processes (Laurillard, 2002);

3. to enable the development of a practical toolkit which would make patterns of learning design shareable and transparent to students and colleagues (Conole \& Fill, 2005). 
The SOLE model was borne out of a desire to make the learning design process transparent to students, to encourage staff to share patterns of learning with each other, and to provide a basis for self-evaluation and development of specific learning designs.

It is no coincidence that the SOLE model places the intended learning outcomes (ILOs) at the centre. In each constructively aligned course or unit of learning, the resulting pattern of activity will be different because the learning outcomes, the assessment designed to elicit evidence of attainment, and the patterns of teaching required to support that process will each be different. The SOLE model is, therefore, explicitly a model, not a template. The model can, and should, be adapted by staff to suit the particular approach to learning required by their students in any given context. The resulting pedagogical patterns should reflect the nature of their discipline, students' existing context, and the specific teaching environment.

The model seeks not to restrict, but rather to illuminate, the practices of staff, and so encourage effective practices. The model is not concerned with the design of specific learning activities, although it provides references to effective resources, but the model does advocate, as appropriate, a balance between the different modes of student engagement. The model is not prescriptive, and its associated toolkit is therefore open and flexible. It is possible for course design or teaching teams to change and modify any aspect of the toolkit, a simple spreadsheet, to suit their needs. The priority, however, is to provide staff with a model of effective practice so that one might be justifiably concerned about the quality of the student learning experience if the toolkit illustrated a consistently unbalanced approach. As Dick et al. suggest, "Instructional design models are based, in part, on many years of research on the learning process. Each component of the model is based on theory and, in most instances, on research that demonstrates the effectiveness of that component.” (2004, p. 14). An imbalance in the elements of the model requires attention.

The SOLE model is, then, a visual representation of the different modes of learning engagement that one might be expected to promote for a holistic learning experience. The model provides a conceptual map of learning engagement aligned to learning outcomes and assessment. The associated toolkit produces a visual representation of these elements of learning engagement for diagnostic, developmental, descriptive, and evaluative purposes.

At the heart of each unit of learning is the graduate profile wrapped in the articulated programme outcomes, and subsequent course outcomes, all of which should be able to demonstrate some form of alignment.

The model illustrates nine elements of learning engagement. These are visually represented in a uniform way and reflect the underlying premise that a balanced approach to learning engagement is preferable. However, it is recognised that each instance of learning design will produce a different representation of the learning experience. The associated toolkit illustrates this notion of balance further. 
It is also worth noting that the traditional attitudes of students might be to focus on assessment "Assessment defines what students regard as important, how they spend their time and how they come to see themselves as students and then as graduates” (Brown, Bull, \& Pendlebury, 1997, p. 7) - and so effectively work their way counter-clockwise through this model's elements from assessment. This is significant because the traditional staff design approach has often been content focussed, beginning with learning materials and working clockwise through a comparable design process. This is important to understanding the means by which students engage with a conceptualisation of learning as presented to them (in a model or a toolkit). To secure learners' engagement with the learning process itself, it is necessary not only for some degree of transparency to be present but also for ownership to be transferred. It is certainly true that students demand evidence of value and that staff engagement is deemed evidence of value or at least of commitment on behalf of the institution to the learning process; however, we should be aware of the evidence on surface and deep learning from Gibbs and others. This research suggests that relatively high contact hours, excessive course material, and lack of choice (amongst other factors) promote surface learning (Gibbs, 1992, p. 9). Conversely, intrinsic motivation of wanting to know, learner activity, interaction, and well-structured content (related to actual experience and logically consistent within itself) encourage deeper learning (Gibbs, 1992, p. 11).

This anomaly, of students' counter-clockwise conceptualisation versus staff's clockwise process, is one of the things the model seeks to expose and mitigate. The transparency of the design process and the clear delineation of the learning experience as one supported by the academic but owned by the student are intended to promote deeper learning. The SOLE model attempts to capture the intrinsic motivation of assessment and encourage its effective use in the learning design by highlighting feedback as an identifiable category to which staff assign student time and commitment. Whilst the toolkit does not enforce a model of negotiated assessment, marking activity, or peer-designed rubrics, it does encourage, and support through annotation, a greater degree of consideration of this important aspect of students' motivation (Rust, 2002, p. 153).

The identification of feedback as a distinct element is significant. Rather than subsuming feedback within assessment or reflection, the SOLE model aims to raise students' metacognition by promoting self-measurement of achievement and articulating at each opportunity the drivers and constructive alignment of the learning experience. 


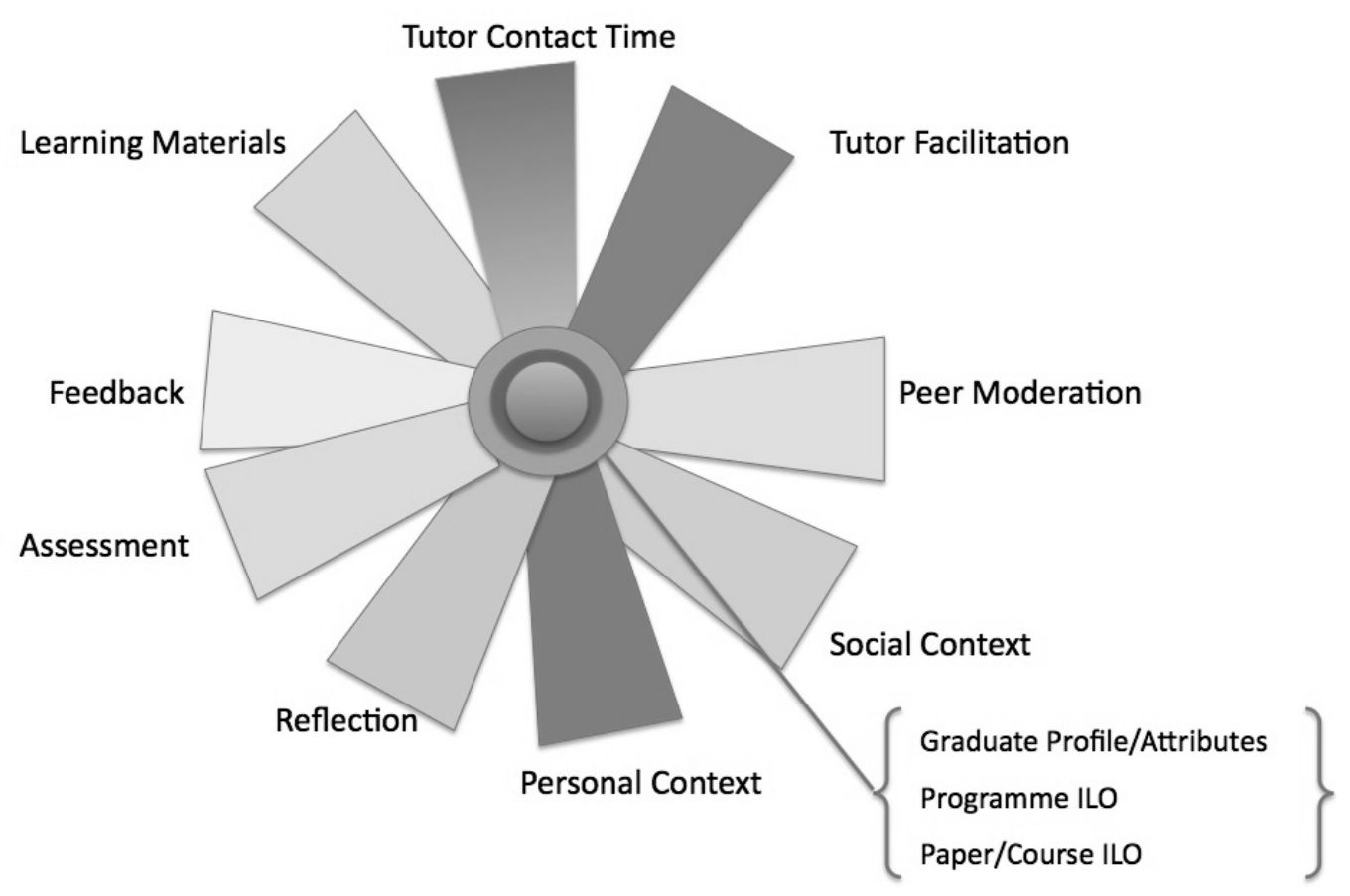

Figure 2. The SOLE model.

Developing a model of engagement from both a teacher and learner perspective is challenging. The SOLE model describes the nine elements of the model (a) and, in the associated toolkit, provides pedagogic guidance (b) supported with references to resources and literature (not detailed here) for design purposes as follows:

1. Feedback

a. Supportive guidance on quality and level of evidence being demonstrated in achievement of the learning outcomes.

b. Feedback could be self-generated, peer-generated, or teacher-focused. What opportunities exist for feedback within your given teaching context? Will students see you each week, for how long, and are class sizes such that feedback will necessarily be peer provision? Would learning sets or group strategies support more effective feedback? If you are teaching online, or supporting the learning online, is there an opportunity for personalised feedback?

2. Assessment

a. Both formative and summative assessment.

b. Assessment could be for the purposes of evaluating progress against achievement of the learning outcomes (formative) or for demonstration of that progress for evaluative and credit purposes (summative); what is the balance within your course? Have you provided opportunities for engagement with the marking rubrics? Have you optionality or negotiated assessment possibilities in your course? Are there opportunities for students to relate assessment tasks to prior learning, to other pre-requisite courses? Does assessment design give the students anything to take away of practical benefit to their future learning career of life- 
work?

3. Reflection

a. Identified as a reflection-on-action to reflection-in-action process through the course life-cycle.

b. What opportunities exist to capture the reflection on feedback and assessment? What artefacts might be stored for later consideration? What occasions exist to engage in the individual's social context and with peers to evaluate the learning in progress?

4. Personal Context

a. The individual life context, which the learner occupies, is a source of real-world activity we can build on in our learning design.

b. Is the learner face-to-face or online? Are they working part-time or full-time, studying for a professional degree, trade or craft, or some life-work as yet illdefined? Is this something that can be developed as a theme for personal reflection? What prior-learning, pre-requisites, or co-requisites might be drawn on in the learning design?

\section{Social Context}

a. The non-course context in which the learner lives is a source of real-world activity we can build on in our course design.

b. Is the cohort a homogenous or heterogeneous group? What external social contexts can we reference in our learning design; are students working and could contexts be cited? Are there diversities in life contexts which afford opportunities to encourage contextual learning, and can learners be asked to share social differences? What learning might occur with other non-peers, elders, siblings, or social or leisure contexts?

6. Peer Moderation

a. The direct engagement with fellow students on the same learning cycle that can be reasonably directed.

b. What opportunities exist for in-class, or online, exchange of views, coconstruction, and co-resolution? What opportunities for negotiation, sharing, joint inquiry, or critical-friends exist within the course? Is collaboration, critique, or inquiry an identified learning outcome? Are there reasons why group work would contribute to the ILO; are there skills to be learnt through particular forms of collaboration?

7. Tutor Facilitation

a. Time and activity allocated to asynchronous engagement involving the teacher.

b. What level of direct engagement with learner activity is required of you to support and progress student learning? What degree of online intervention is commensurate with your learning design; are students online and requiring your guidance? To what extent is your presence required and motivational? What periodic interventions might you make to contemporise the learning context, drawing on current literature or social contexts to make the learning real-world relevant? 
8. Tutor Contact Time

a. Time and activity allocated for real-time synchronous engagement.

b. What balance of face-to-face, or virtual contact time, is appropriate throughout the course? Does institutional timetabling allow variance throughout the course; might you choose to engage to a greater extent at the outset of the learning process and again for summative purposes? If learning materials are supporting domain knowledge acquisition, what is the most effective use of your time?

9. Learning Materials

a. The materials provided, usually in advance, to support domain knowledge acquisition.

b. What pre-existing material exists? Have you explored existing Open Educational Resources (OER) that could be adapted to suit your learners' needs? Would a single set-reading be a helpful reference point? What capacity for deep engagement with resources exists? Are seminal texts identified to students as such, and if not, are they truly necessary? What opportunities exist for learners to assist in developing and refining the creation of learning materials, for example in the joint creation of an online glossary or a shared annotated bibliography?

These nine elements of the SOLE model are designed to reflect a comprehensive consideration of the students' learning experience which, if properly populated, would afford an effective balance of activity, learning ownership, and opportunities for higher-order thinking and deep learning.

\section{From Model to Toolkit: Supporting Theory-In-Action}

As the early iterations of the SOLE model were explored with academic colleagues, the original goals were revised in response to the demand to actualise the model in some meaningful way. The embodying of theory within a model became a quest to embed the theoretical principles within a practical manifestation of the model.

Revised development goals were therefore

1. to embody pedagogical guidance and learning theory within an accessible and transparent model shared by students and teachers;

2. to embody best practices regarding constructive alignment (Biggs \& Tang, 2007) inside a learning design model easily accessible to, and shared by, staff and students;

3. to produce a practical model that captured the lessons to be learnt from Laurillard's representations of conversational learning processes (Laurillard, 2002), whilst taking an inclusive approach to alternative conceptualisations of learning;

4. to enable the development of a practical toolkit that would make patterns of learning design shareable and transparent to students and colleagues (Conole \& Fill, 2005).

While the theoretical debate around conversational, or dialogic, learning and constructive alignment is of interest to many in the education disciplines, the model is intended for use across 
HE subject areas. A visual representation is still not sufficient to make the model live for most academic staff. The opportunity certainly exists for professional development engagements around a presentation of the model itself, and these have been successfully undertaken, but the intention has been to make the model as accessible as possible. As Conole suggests, "the development of toolkits provides a way for non-specialists to engage with such theories in a manner which supports careful design and prompts productive reflection and engagement” (Conole, Dyke, Oliver, \& Seale, 2004, p. 18).

The model has a number of underlying theoretical constructs informing its design, but it is not intended to enforce a rigid pedagogical theoretical framework. A teacher may choose to continue to teach in exactly the same way s/he always has; the model simply illustrates that process to colleagues and, more importantly, to students. Indeed, as Conole and colleagues identify,

Toolkits are designed to facilitate the identification of implications or recommend suitable approaches based on the information and assumptions elicited from the user. They provide a structured guiding framework, whilst also enabling flexibility and local contextualisation. Therefore rather than the toolkit deciding on the best approach on behalf of the user, the practitioner uses these interferences to make informed, professional decisions about whether certain changes would be appropriate. (2004, p. 22)

The model, without the associated toolkit, is in itself a team discussion tool, a course-based instrument for planning and development, and a means of visualising one's practice and assumptions about that practice. The toolkit provides much the same opportunities but also allows the academic, and ultimately the student, to work within a learning design, diagnosing expected activity, adjusting the balance of engagement through the development process, describing (as an advanced organiser) what the learning might look like, and providing opportunities for ongoing evaluation. The first version of the toolkit, as an Excel 2007 Spreadsheet, was shared with staff in a series of workshops in May and June 2010 at Massey University, New Zealand (see Figure 3). 


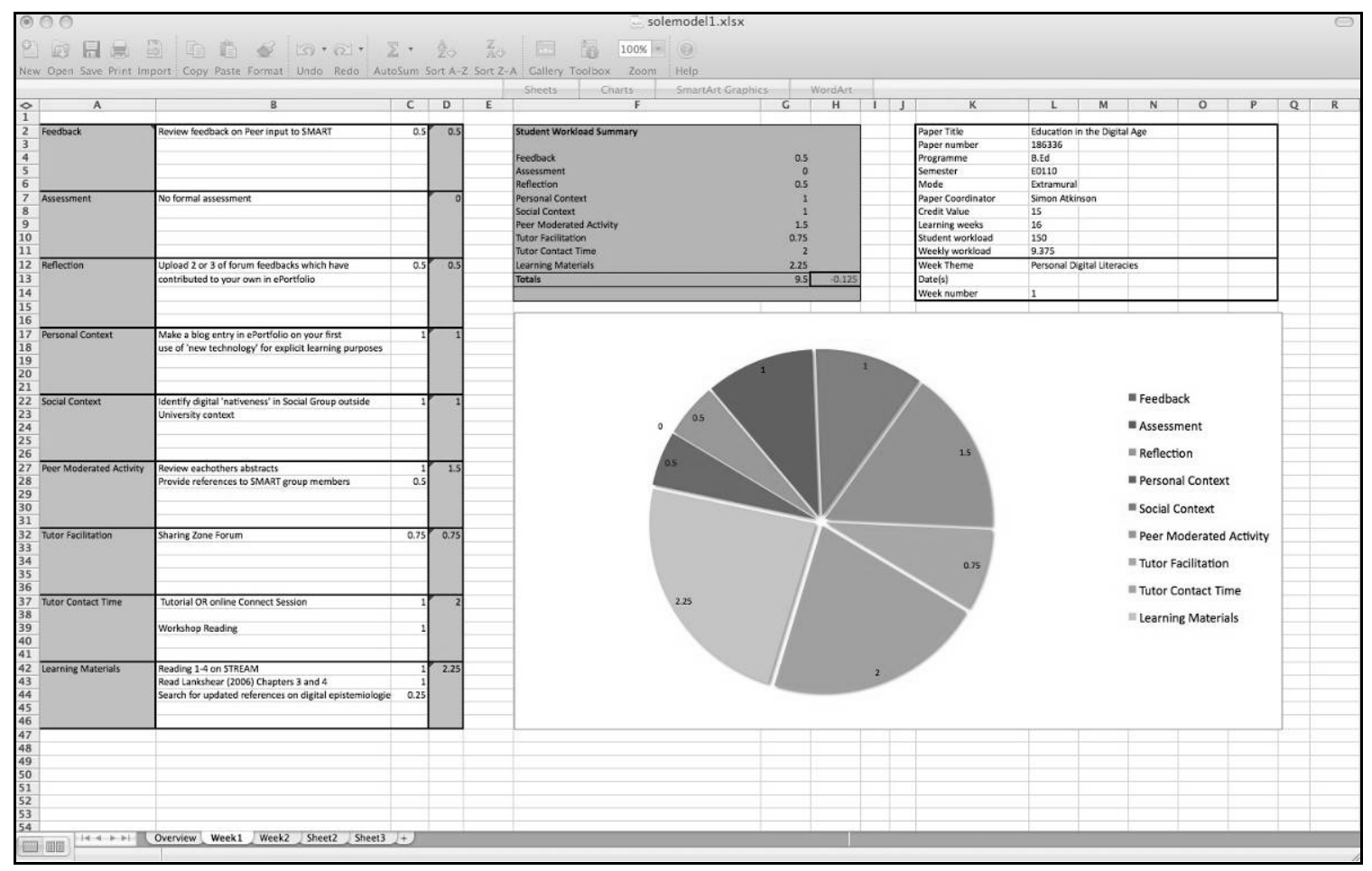

Figure 3. The SOLE toolkit (Version 1.1)

The focus of the toolkit developed for the workshops was to support staff in student workload planning, seeking to make transparent the activities in which students were being encouraged to engage (Atkinson, 2010). Version 1.1 of the toolkit, released online in May 2010, had a number of features intended to be of use to academic staff and students.

- An initial overview sheet contains summary data which need be entered only once (total hours, number of weeks, course descriptions, learning outcomes) and which is then populated across subsequent unit views.

- A summary table on each unit view pulls data from the overview and displays calculations of student time in each engagement area.

- The time allocations are summed and displayed clearly, including whether, in that unit, time is ahead or behind the norm or allocated amount.

- An automatically generated pie chart provides quick visual information to a student to remind them that there is a balance of activity with which to engage.

It is hoped that staff will share their resulting patterns as models of pedagogical approaches. It is also anticipated that staff would, in many cases, leave the spreadsheets open for students to complete with actual details of activity and time recorded. In both cases, this offers the prospects of ongoing evaluation and development of learning designs through "shareable representations of beliefs and of practice" (Conole et al., 2004, p. 18). The intention is that the spreadsheet toolkit will produce a clear visual representation that is given to the student to form an advanced organiser. A review of the completed spreadsheets would perhaps then act as a useful evaluation 
exercise, identifying activities that were particularly beneficial or making clear a learning designer's unrealistic expectations.

Further iterations of the toolkit have followed, and in September 2010 version 1.2 was released on the Internet, expanding the toolset for staff and students. As well as a revised explanatory worksheet that detailed the nine effective elements of the model with extensive guidance (see Figure 4), and questions and prompts towards effective practice, an option was included to allow for the actual time spent to be recorded by students on a distributed version of the toolkit as a spreadsheet rather than as a PDF for printing. The pedagogical guidance embedded in the toolkit is intended to be layered, so that in column $\mathrm{C}$ of the spreadsheet a cell with a detailed description of an element has an embedded comment associated with it, in column $\mathrm{D}$ each guiding question to support reflection also has an embedded comment, and individual resources in column $\mathrm{E}$ can support institutionally contextualised guidance (as illustrated in Figure 4).

Staff are also provided with the opportunity to detail the assessment requirements and provide students with a repeated sense of the effective alignment of learning outcomes, assessment, and teaching and learning activities.

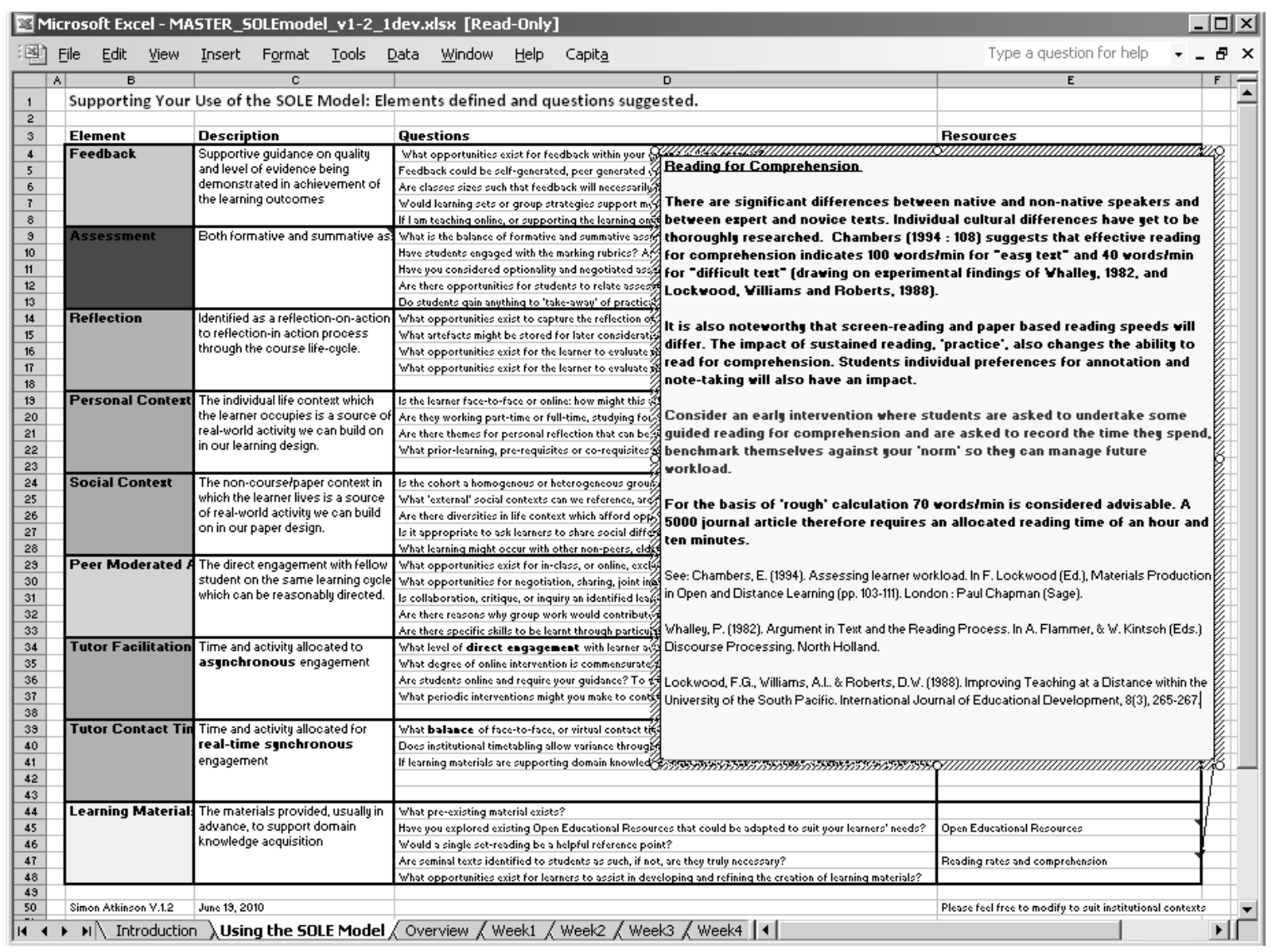

Figure 4. Version 1.2 with pedagogical guidance associated with each of the nine elements of the SOLE model. 
One of the reasons for choosing to adopt a familiar desktop spreadsheet application as the basis for a toolkit was to avoid any need for students to download any additional software, and to see the toolkit as something adaptable, personalised, and shareable. For the majority of students, the software is expected to be familiar, but for those who have not engaged with spreadsheets before it can be argued that to do so would have beneficial consequences. Spreadsheets, it is suggested, can still provide a rich and meaningful environment in which students can take ownership of information (Conole, de Laat, Dillon, \& Darby, 2008).

\section{Diagnostic, Descriptive, Developmental, and Evaluative}

The SOLE toolkit has evolved to have four particular functions in the full life-cycle learning design process. The toolkit has a diagnostic function in asking the academic to envisage a full course cycle, with planned or predicted learning engagement on the part of the learner. The academic is recognised as being restricted by institutional guidelines and each instance will be different; however, in assigning a time allocation across the duration of the course, the academic as designer is constantly reminded of the holistic nature of the learner experience, core learning outcomes, and assessment within realistic time frames. The result is a visual representation that is descriptive, which provides a representation of the learning experience (and expectations) as moving beyond the immediate relationship between teacher and student. The toolkit might be shared with learners as a print-out so the learner has a visual representation of what is anticipated of them, holistically. Early evidence suggests this act alone has impact on learners' perceptions of their role and ownership of the learning process. The notion that they draw directly on personal context, and use earlier feedback, as an articulated learning activity is a novel concept for many. The toolkit is also developmental, and the academic may choose to invite feedback from learners on their engagement with the model and adjust the balance of activities appropriately.

The learner might be given the toolkit in its spreadsheet form and, as such, can interact with it, recording (in version 1.2) the actual balance of time they applied to the designated learning activity. As well as the developmental feedback available to teachers, this also provides evidence for the final dimension of the model, evaluation. Evidence from students of actual time spent and the degrees of engagement achieved will provide useful re-design opportunities for academic staff. In contexts where the development and maintenance of learning portfolios is appropriate, students might be asked to make their engagement with the toolkit a submissible artefact.

Both the developmental and evaluative aspects of the toolkit provide opportunities for peer support and extensive sharing. Engagement with the toolkit quickly provides evidence that no single model of practice is being enforced. One would anticipate that the visualisation generated by the toolkit would reflect a pattern of learning that differs from course to course. One also identifies quickly how the ideal pattern of learning modulates from week to week within a course. In the first week of an undergraduate course, one might expect to see significantly more teachercenteredness than in the twelfth week of the same course. A course based around an inquiry model of learning at postgraduate level would be expected to have a different pattern again. The visualisation will differ; the patterns can be expected to reflect different levels of engagement. 
It is a curious fact of higher education that, despite all we know about learning styles and dependencies, we continue to timetable activity (often determined by contact-hours) evenly or uniformly through a semester. By making clear that not all learning is teacher-dependent, it becomes easier to visualise how the teacher, reflecting on their changing inputs and recognising institutional systems and constraints, might manipulate profitably the balance of activity.

\section{Conclusion}

The SOLE model has originated from 10 years of academic development practice in the United Kingdom and New Zealand. Development workshops with practitioners have provided support for the effectiveness of the model as a visualisation of interrelated learning theory. Workshops have also indicated support for the role of the toolkit as an embodiment and embedding of theory into practice. The model and nascent toolkit were presented in April 2010 at the Distance Education Association New Zealand (DEANZ) 2010 conference in Wellington and again in July 2010 at the European LAMS Learning Design Conference in Oxford. Several individual academic staff are in the process of applying the SOLE Toolkit to their learning design processes, and documenting that experience, to enable the author to validate the model and toolkit and make enhancements where deemed appropriate. One notable aspect of the feedback from internal staff presentations between March and June 2010 has been the suggestion that the toolkit provide a degree of holistic visualisation, which they welcomed. This transparent practice aspect of the toolkit is central to the notion of staff's responsibility for creating a full life-cycle experience of learning for the student.

As these early action research projects come to fruition, it is anticipated that there will be further refinements based on the practical implementation of the toolkit in contexts in which learners can take ownership of the learning process. Students' recognition of their metacognitive development, and consequent self-adjustments for effective learning through engagement with the toolkit representations, will demonstrate the SOLE model's ultimate value.

After the success of the DiAL-e framework in encouraging a transformative learning experience for academic staff with respect to the deployment of digitised resources for learning (Burden \& Atkinson, 2009), the need to provide a more generic learning design tool, beyond engaging content, became evident. Subsequent personal experience with many educational technology design tools and academic colleagues' resistance to learning new tricks suggested that a solution that relied on familiar desktop applications, with no need for additional software installations, specialised training, or support, had real potential. The SOLE model is an attempt to provide course designers with the benefit of embodying pedagogical theory and reflecting this directly in practice through a freely available and accessible toolkit that is diagnostic, descriptive, developmental, and evaluative.

\section{Acknowledgements}

Whilst a decade in gestation, the development work for the SOLE model was undertaken primarily in 2009-2010 whilst the author was employed at the College of Education at Massey 
University, New Zealand. The work was influenced, though not directly supported, by the award in 2009 of a Massey FIET grant, and benefitted from presentations to, and professional conversations with, staff in the College of Education and the Centre for Academic Development and eLearning (CADeL). The SOLE model also draws on work undertaken jointly with Kevin Burden (University of Hull) in support of the DiAL-e Project funded by JISC in 2006. 


\section{References}

Atkinson, S. (2010). SOLE learning design. Educational technologies to enable social change [Web log post]. Retrieved from http://spatkinson.wordpress.com/sole-learning-design/

Barker, P. (2008). Re-evaluating a model of learning design. Innovations in Education and Teaching International, 45(2), 127. doi:10.1080/14703290801950294

Biggs, J., \& Collis, K. (1982). Evaluating the quality of learning: The SOLO taxonomy (structure of observed learning outcome). New York: Academic Press.

Biggs, J., \& Tang, C. (2007). Teaching for quality learning at university (3rd ed.). Milton Keynes: Open University Press.

Bloom, B. (1964). Taxonomy of educational objectives. New York: McKay.

Brown, G. A., Bull, J., \& Pendlebury, M. (1997). Assessing student learning in higher education (1st ed.). London and New York: Routledge.

Burden, K., \& Atkinson, S. (2009). Personalising teaching and learning with digital resources: DiAL-e Framework case studies. In J. O'Donoghue (Ed.), Technology supported environment for personalised learning: Methods and case studies. Hershey, PA: IGI Global.

Conole, G., Dyke, M., Oliver, M., \& Seale, J. (2004). Mapping pedagogy and tools for effective learning design. Computers \& Education, 43(1-2), 17-33.

Conole, G., \& Fill, K. (2005). A learning design toolkit to create pedagogically effective learning activities. Journal Article. Retrieved from http://oro.open.ac.uk/11725/

Conole, G., de Laat, M., Dillon, T., \& Darby, J. (2008). Disruptive technologies, pedagogical innovation: What's new? Findings from an in-depth study of students' use and perception of technology. Computers and Education, 50, 511-524.

Dick, W. O., Carey, L., \& Carey, J. O. (2004). The systematic design of instruction (6th ed.), Boston: Allyn \& Bacon.

Gibbs, G. (1992). Improving the quality of student learning. Bristol (United Kingdom): Technical \& Educational Services Ltd.

JISC. (2006). Design for learning. Retrieved from http://www.jisc.ac.uk/whatwedo/programmes/elearningpedagogy/designlearn.aspx 
Knight, P., Tait, J., \& Yorke, M. (2006). The professional learning of teachers in higher education. Studies in Higher Education, 31(3), 319-339.

Laurillard, D. (2002). Rethinking university teaching: A conversational framework for the effective use of learning technologies (2nd ed.). London: RoutledgeFalmer.

Laurillard, D. (2008). The teacher as action researcher: using technology to capture pedagogic form. Studies in Higher Education, 33(2) 139-154.

Laurillard, D., \& Masterman, E. (2010). TPD as online collaborative learning for innovation in teaching. In J. Ola Lindberg \& A. D. Olofsson (Eds.), Online learning communities and teacher professional development (pp. 230-246). Hershey, PA: IGI Global.

LDSE. (2010). LDSE. Learning design support environment. Retrieved from https://sites.google.com/a/lkl.ac.uk/ldse/

NSSE. (2007). Experiences that matter: Enhancing student learning and success (Annual Report). Bloomington, IL: Center for Postsecondary Research.

Rust, C. (2002). The impact of assessment on student learning. Active Learning in Higher Education, 3(2), 145-158. doi:10.1177/1469787402003002004

Shulman, L. (2000). From Minsk to Pinsk: Why a scholarship of teaching and learning. Journal of the Scholarship of Teaching and Learning, 1(1), 48-53.

\section{Athabasca University $\mathbf{a}$}




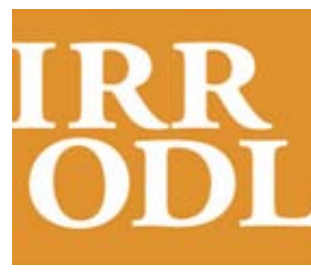

International

Review of

Research in Open and Distance

Learning

Vol. 12.2

February - 2011

\section{Head of Gold, Feet of Clay: The Online Learning Paradox}

\author{
Michael Power and Anthony Gould-Morven
}

Laval University, Canada

\begin{abstract}
Although online learning (OL) is becoming widely accessible and is often viewed as cuttingedge, the actual number of regular faculty participating in this form of teaching remains small. Moreover, OL, despite its growing recognition, is often associated with high rates of student dissatisfaction and isolation, withdrawal, and attrition. Furthermore, although administrators typically champion support of OL, they often seem unable or unwilling to marshal the necessary financial, human, and technological resources to produce high-quality course materials and to effect efficient course delivery. In short, online learning seems paradoxically to be both booming and busting simultaneously. It is expanding supply yet hitting similar obstacles that distance education encountered generations earlier. Under these circumstances, OL is unlikely to become mainstream without a major redirection. This article applies economic principles and concepts to OL. The revised conceptualization posits that an understanding of stakeholder priorities is the key to improved online course design and delivery.
\end{abstract}

Keywords: Online learning; core faculty; obstacles; push and pull; blended online learning design 


\section{Introduction}

Online learning has a "head of gold" and is sometimes touted as the key to better higher education (HE). This image comes mostly from its potential for large numbers of low unit-cost enrolments (Duderstadt, Atkins, \& Van Houweling, 2002; Pittinsky, 2003). On the other hand, online learning appears to have what we describe as "feet of clay" because it has not been widely embraced by mainstream academia. The reasons for low levels of uptake of this form of course delivery appear to center on perceptions of quality (Carr-Chellman, 2005; Noble, 2001) although they may be more complex. Nonetheless, in the face of such disparate influences, online learning is creeping into many centers of HE (Allen \& Seaman, 2008), although much of this growth is being managed by using contract faculty or adjuncts (Bedford, 2009; Sammons \& Ruth, 2007), whereas the majority of core faculty continue to deliver courses using a conventional lecture-hall format (OECD, 2005). This article is about paradoxes in online learning. It associates the major issues in OL with the main stakeholders and addresses perceptions of accessibility, quality, and efficiency, proposing a new way of reconciling the competing priorities of various stakeholders.

\section{From Distance Education to Online Learning: Stakeholder Perspectives}

Distance education, as a field, was founded for the purpose of creating and promoting greater social justice and equity. (Burge, 2008)

Distance education (DE) has a long and noble past. Some suggest that Saint Paul was one of the first-documented distance educators with his Corinthian correspondence. In more modern times, Pitman's "penny post" initiative in the mid-1800s and the University of London's correspondence education starting in 1858 are often seen as the modern beginning of this form of learning (Moore \& Kearsley, 2005). In the 20th century, DE made progress in adapting to learner needs and prevailing social and technological conditions. It has greatly influenced developments in educational technology and has emerged as a credible strategy for making learning more efficient and accessible without compromising quality (Bertrand, 2009; Daniel, Kanwar, \& UvalicTrumbic, 2009).

Online learning (OL), be it in the form of a new generation of DE (Anderson, 2008), a departure from DE (Garrison, 2009) or even a new paradigm for teaching and learning (Harasim, Hiltz, Teles \& Turoff, 1995), is advancing rapidly (Allen \& Seaman, 2008). For current purposes, we define OL as an essentially Internet-based, asynchronous type of distance education (Maeroff, 2003). It typically entails institutions providing instructional materials and support to students who are involved in flexible learning on a 24/7 basis (Bullen \& Janes, 2007; Collis \& Moonen, 2002).

The watershed U.S. Department of Education (2009) meta-analysis study reasserted the growing popularity of OL and provided empirical evidence of its relative effectiveness compared to traditional education. The report emphasized, in particular, the effectiveness of blended learning approaches that create complete and rich learning environments and compel students to learn. Despite such potential, OL is often developing, at the university level, without the full 
involvement of regular, core faculty (Sammons \& Ruth, 2007; Bedford, 2009), highlighted by the tendency to use contract faculty to deliver courses online. "As tenured or full-time faculty have been unable to fulfill these roles due to workload or resistance, organizations are more frequently turning to adjuncts to meet the needs of their online learners” (Bedford, 2009).

Stakeholders in the learning process, such as faculty, students and administrators, appear to have different reasons for adopting or resisting OL. For example, the huge increase in interest in OL has not always been synonymous with wide-scale adoption by HE institutions because of various hurdles and obstacles (Orr, Williams \& Pennington, 2009). Core faculty are often hesitant about participating because they fear it will add to their workload, diminish quality, or compromise intellectual property (Blin \& Munro, 2008; Maguire, 2005). Dreyfus (2001) refers to feelings of "disembodiment" and "alienation" on the part of faculty, whereas Shea, Fredericksen, Pickett, \& Pelz (2005) state that "[p]art of the explanation for the limited use of online teaching and learning is its incompatibility with the teaching styles of many professors.” Sammons \& Ruth (2007) add: "So the new 24/7 professor who is dragged from a traditional classroom into cyberspace may not be able to adjust."

Insofar as students are concerned, there has been a large increase in online course enrolments, especially in North America (OECD, 2005). However, there remains a fairly widespread perception that this form of course delivery is not only second-rate (Noble, 2001), but working against the democratization of HE (Carr-Chellman, 2005), and possibly representing a strategy for pushing a commercialization agenda (Bok, 2003). Furthermore, online students often feel alone and isolated, phenomena linked to unsustainably high rates of withdrawal and drop-out (Morgan \& Tam, 1999; Berge \& Huang, 2004). Research has highlighted other deficiencies of asynchronous courses. These include delayed feedback and lack of immediacy (Schullo et al., 2005), student isolation (Ludwig-Hardman \& Dunlap, 2003), inadequate social context (Vonderwell, 2003), and a lack of learner community support (Garrison \& Archer, 2007).

The third stakeholder in OL, administrators, is also often frustrated when faced with having to implement this form of course delivery (Gambescia \& Paolucci, 2009). They are typically willing to promote OL in order to garner its financial and image-related benefits, typically viewing OL as a panacea to their problems (Wilson, 2001). However, they have found it difficult to marshal the financial, human, and technological resources required to produce high-quality learning material for online courses (Tallent-Runnels et al., 2006). In the following section, we describe in more detail the limitations of online learning in the modern era. We also present a conceptual framework which can be used to develop a strategy to address these problems.

\section{Information and Communication Technology, Online Learning, and the Dual-Mode University}

In the 1980s, traditional universities, especially in Canada and Australia, started experimenting with newly-available educational technology (Burge, 2008; Campion, 1990; Evans \& Nation, 1993). Their need was urgent and immediate: both were large countries with vast distances between population and education centers. The challenge was to increase accessibility to 
university programs in order to stimulate economic growth and improve industrial competitiveness (OECD, 2005). As personal computer-based instruction became viable and increasingly powerful, information and communication technologies (ICTs) proliferated. As a result of such online learning implemented, the potential for widespread and transformative innovation within universities became apparent (Bates, 1995, 2005; Evans \& Nation, 1993). Yet, in retrospect, this potential has not been fully realized (Guri-Rosenblit, 2009; Zemsky \& Massy, 2004).

Undergraduate OL has already emerged as a noticeable trend over the past two decades (Allen \& Seaman, 2008). However, the overall aim has, typically, been to free up space on campus, boost student enrolments, and achieve lower per-unit costs. In pursuing these objectives, OL has come to be viewed as a way of subsidizing costly on-campus instruction (Thompson, 2005). However, it has also been plagued by a reputation for low quality and, mostly for this reason, been resisted by university faculty (Zemky \& Massy, 2004; Guri-Rosenblit, 2009). Faculty attitudes towards OL are discussed by Power (2009) in a series of case studies, revealing that faculty view OL in its asynchronous form as being unsustainable, because it takes too much time to design and develop courses. Furthermore, it requires that faculty spend long hours typing on a keyboard, a task several view as "boring," "hell," and wasted time (Power, 2009). Others emphasize the futility of investing in high-level, upfront course design because frequent redesign is required (Twigg, 2003). Yet, despite this and again reinforcing the fundamental paradox that is OL, faculty in dualmode universities will likely have to become major OL providers in light of a widening gap between supply and demand in HE (Daniel et al., 2009; Olcott, 2008). Indeed, according to GuriRosenblit (2009),

The new technologies have actually turned dual-mode provision into a leading model in most HE institutions worldwide, as many conventional universities decided to adopt them for offering various forms of distance education through online provision. Many studies indicate that the future belongs to dual-mode institutions which are likely to thrive in the coming decade. (p. 126)

\section{A Critique of Distance Education, Online Learning, and Blended Learning}

As noted, a key reason DE/OL have not gone mainstream is low-level commitment from faculty. Indeed, the impetus for creating the British Open University (BOU) was a strong political will to break the monopoly of the upper-class-dominated established institutions. The BOU's explicit mission was, and continues to be, to make higher education in the UK more accessible (Perry, 1976). As a result, a dichotomy of choices appeared: either a student studied on campus or at a distance. However, when traditional universities (TUs) in Australia and Canada started adopting DE on a large scale (Evans \& Nation, 1993), these institutions began a metamorphosis and became dual-mode universities (DMUs), thereby opening up more options for students. The advent of OL deepened this trend, multiplying OL models and offerings (Guri-Rosenblit, 2009; 
Power, 2005; 2008a). Yet still, core faculty remain aloof from OL as they have from DE, thus severely limiting program offerings.

Blended learning (BL) was consolidated in the latter years of the '90s as a trade-off between completely on-campus and completely online courses (Garrison \& Kaunuka, 2004; Garrison \& Vaughan, 2008; Mortera-Gutierrez, 2006). The University of Lancaster's definition of BL is adopted here: BL occurs "where traditional forms of teaching and learning (i.e., classrooms, books, etc.) are used in conjunction with e-learning to deliver the full student experience" (see www.uclan.ac.uk/information/services/sss/quality/glossary_of_terminology.php). Usually an administration-led strategy, BL has allowed universities to rapidly-with little investmentenhance their enrolment capacity by having students spend one week on campus and one week online at home (Pullen \& Snow, 2007). BL has generally been viewed positively by faculty because it has created economies which enable them to reduce and or better manage their workload (Garrison \& Vaughan, 2008; Mortera-Gutierrez, 2006). Students also appear to see benefit in BL. Like faculty, they often view it as capable of freeing them from their weekly schedule of on-campus courses without any noticeable loss in quality (Rovai \& Jordan, 2004). However, since BL requires that students spend at least some amount of time on campus, it cannot be successful in solving the accessibility dilemma for the typical, off-campus DE student. Rather, by being marketed to students as a flexibility enhancement initiative, it has mostly been seen as a new way for administrators to expand university enrolments (Cook, Owston, \& Garrison, 2004).

\section{Addressing Accessibility, Quality, and Cost-Effectiveness in Online Learning}

In this section, we shift emphasis from understanding why distance education and the current form of OL have not met expectations and consider how a new form of DE/OL might be implemented to simultaneously increase accessibility, improve quality, and enhance costeffectiveness in HE at the graduate level. This is a problem that Kanuka \& Brooks (2010) have considered unsolvable: "[D]istance education can achieve any two of the following: flexible access, quality learning experience and cost-effectiveness - but not all three at once” (p. 69).

Sir John Daniel, a pioneer of DE, also emphasizes the virtual impossibility of universities simultaneously attaining these three goals by referring to them as the "Iron Triangle" (Daniel, Kanwar, \& Uvalic-Trumbic, 2009). He suggests that the sides of a hypothetical triangle could be considered to represent the key vectors of university course delivery: access, quality, and cost. From a strategic standpoint, Daniel considers that such a triangle has two characteristics. First, it may be distorted in different ways. Distortions represent trade-offs amongst the three key elements. Second, the triangle has a fixed-length perimeter. In practice, this means, for example, that one can only increase access to a given course under circumstances where one lowers its level of quality. Such a zero-sum view of service delivery gives rise to the reference to "iron." Daniel then argues that DE is a way of breaking out of the iron triangle, because it lowers cost while maintaining quality and increasing accessibility. As a result, the overall fixed-length perimeter can be extended, allowing the accessibility and quality sides of the triangle to be extended without a corresponding increase in the size of the cost vector. According to Daniel, DE 
allows for improvements in accessibility and quality, as well as economies of scale that traditional universities simply cannot attain. In Figure 1, a graphic representation of Daniel's thesis is presented.

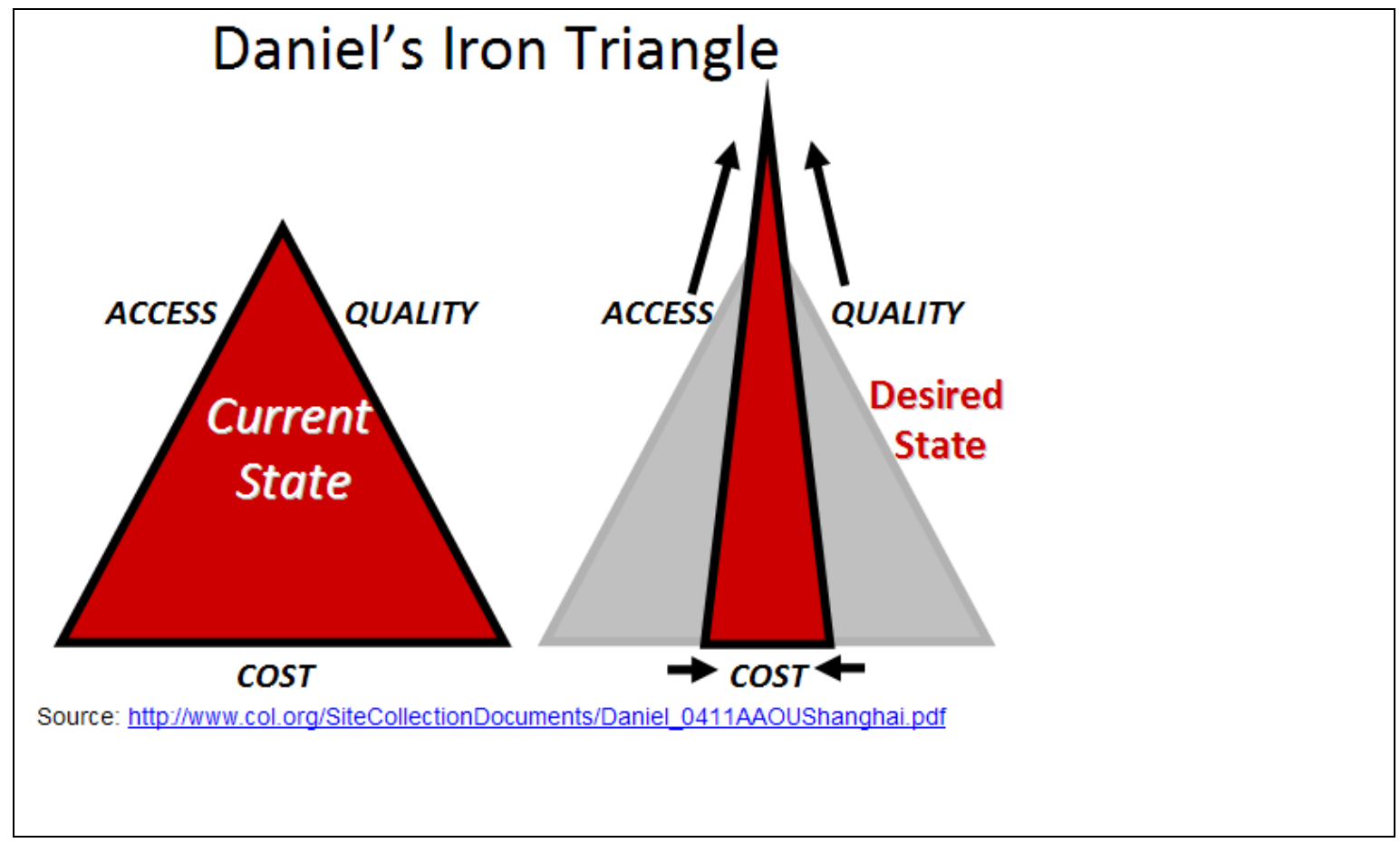

Figure 1. Daniel's iron triangle, presenting both the current state of affairs and the desired state made possible by universities implementing wide-scale distance education.

As noted earlier, despite high growth in the 1970s and 1980s, DE has not been adopted by mainstream universities (Bates, 2005). Indeed, from its outset, DE has been vigorously resisted by faculty in traditional universities (Perry, 1976). Now, under its new guise as OL, DE has only been partially and begrudgingly embraced by regular university faculty (Mitchell \& Geva-May, 2009). In light of these trends, we view Daniel's iron-triangle framework as dated and fundamentally unworkable, an industrial solution in a post-industrial period. Indeed, the iron triangle theory implicitly suggests that universities will inevitably evolve of their own accord to embrace DE/OL, because taking such a step liberates universities from the zero-sum paradigm. Yet this has not occurred. In short, had DE been such an obviously viable solution, it would likely already have been implemented.

It is therefore necessary, in our view, to understand why stakeholders have not broken out of Daniel's Triangle, when doing so seems so predictable and so beneficial to all. To address this problem, we have expanded upon the triangle concept. Our conceptualization presents OL as a strategic choice associated with defined benefits. It also considers obstacles to the transition process from a stakeholder perspective. We believe there is indeed a way out of the iron triangle which does involve OL-but it is not OL as we currently know it. In the following section, we 
will argue in favour of a form of OL that meets or exceeds the needs and expectations of key stakeholders in HE: faculty, students, and administrators.

\section{Revisiting the Iron Triangle}

As mentioned above, Daniel speaks of three vectors as the sides of the iron triangle: access, quality, and cost. Yet he does not associate vectors with specific stakeholders' groups, nor does he discuss how the needs of faculty, students, and administrators may differ. Research suggests that there are specific stakeholder groups and that they are likely not equally interested in each of Daniel's vectors (Duderstadt, Atkins, \& Van Houweling, 2002; Kampov-Polevoi, 2010; Schullo et al., 2005). We introduce the term priorities as an alternative to Daniel's vectors to take this phenomenon into account. This change in terminology emphasizes that the points of the triangle are influenced by who, in the teaching and learning processes, is assessing the situation.

Figure 2 represents our revision of Daniel's iron triangle concept, in which we propose two major changes. Firstly, as indicated above, we replace vectors with priorities, and, secondly, we modify the names of these priorities. Hence, cost is removed as a vector and replaced with costeffectiveness as a priority, namely because cost-effectiveness is seen as being a more complete and significant indicator than is cost alone. By doing this, we have three positives or elements that would be beneficial to increase, rather than two positives and a negative (i.e. in Daniel's view, that cost must be decreased). This change thereby allows us to work with positives alone, thereby making our analysis more transparent. We also do this in order to portray cost as a necessary ingredient in the DE/OL mix, rather than something to be avoided. Likewise, we have replaced access, which we consider too general a term, with accessibility, which we define narrowly here as the act of increasing access for students to DE/OL programs and courses.

Figure 2 presents our previously-identified priorities as the corners of a triangle. Each priority is associated with a stakeholder. In this diagram, we posit that students are naturally most concerned about accessibility. On the other hand, faculty are typically defenders of quality, whereas administrators are tasked with assuring system cost-effectiveness. We further suggest that each stakeholder group is naturally inclined to promote its own priority, thereby bringing the parties into conflict. However, we argue that for DE/OL to succeed, each stakeholder group should have its needs met to an acceptable threshold level. Our revised conceptualization of Daniel's IT concept establishes the corners of a triangle as more important than its sides. In passing, we note that the student stakeholder group may be considered as a more disembodied influence, something akin to market forces. We mention this because student needs are not always viewed as monolithic. On the other hand, for current purposes, we continue to refer to students as a stakeholder group, a term we consider most appropriate because it identifies whose priority is being considered and who is "pushing" for increased accessibility. 


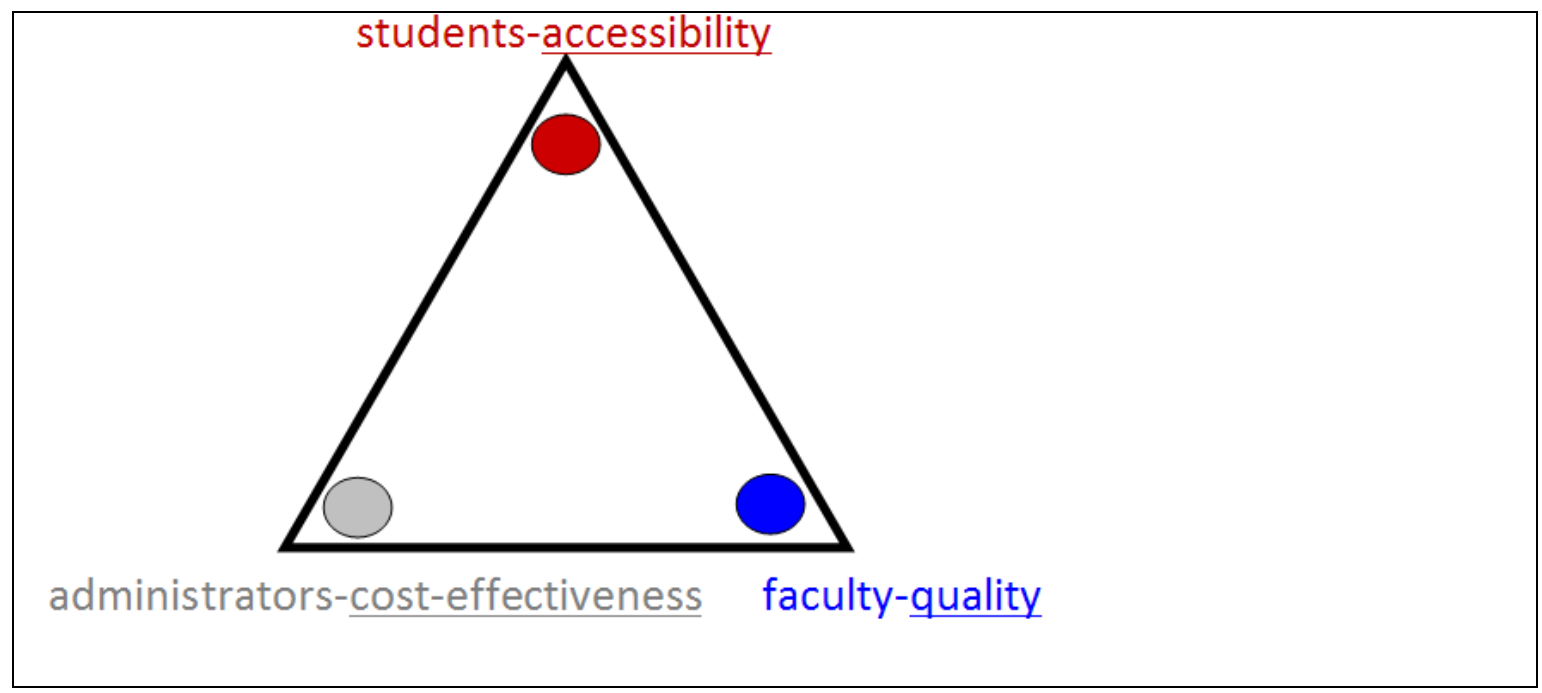

Figure 2. The Power-Gould revised iron triangle associating stakeholders and stakeholder priorities.

Figures 3A \& 3B further develop the three stakeholder - three priorities idea which is implicit in our modified iron triangle. Specifically, it indicates how parties interact to advance their agendas. For example, when students "push" accessibility (meaning that they demand access to more courses), the likelihood of "pull” at the faculty end (meaning that faculty will respond to this demand through increasing their involvement in OL) will depend on the extent to which the respective priorities of these two stakeholder grouper are in alignment. Hence, a situation is created whereby one stakeholder group will respond to the priority of another, but only insofar as such a response does not impede the pursuit of their own priority. Ideally, this dynamic would lead to a state of equilibrium and a balancing of priorities between the two stakeholder groups. However, should increasing accessibility lead to a state of worsening quality (i.e. worsening working conditions, fewer qualified students, less support for faculty, etc.), then these two stakeholder groups would have overtly non-aligned priorities, resulting in a lower probability of pull at the faculty end. Under these circumstances, we posit that faculty "pushback" would likely occur (i.e. resistance to increasing accessibility). Built into this conceptualization is the notion of a threshold, defined here as a theoretical point of equilibrium whereby all three stakeholder groups attain an acceptable level of satisfaction of their priorities. We believe that our conceptualization explains why some attempts at expanding accessibility to DE/OL in the past have failed. 


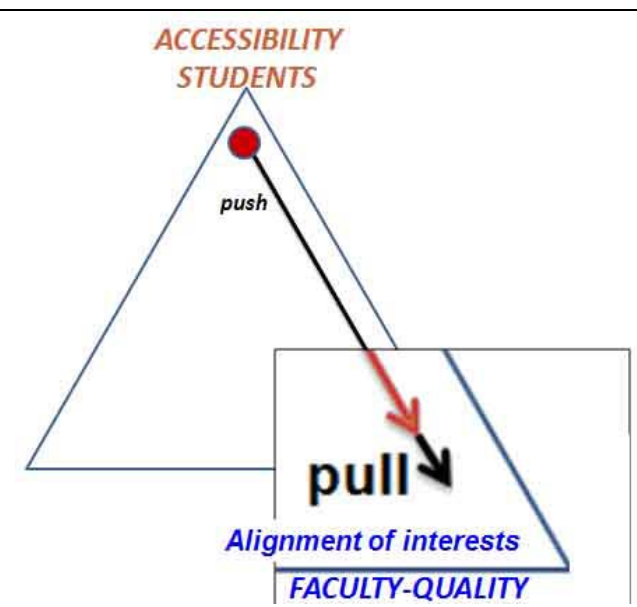

Figure 3A: Student push, faculty pull, and alignment of priorities.

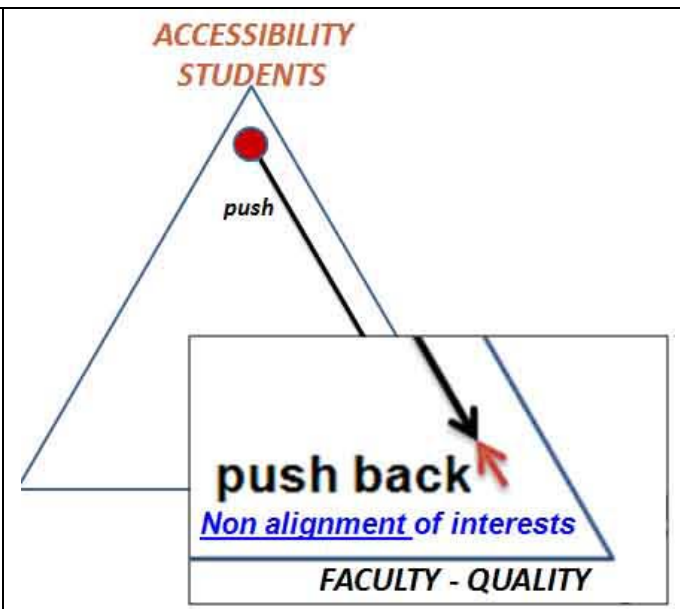

Figure 3B: Faculty push-back due to a non alignment of priorities.

The logic of Figures $3 \mathrm{~A}$ and $3 \mathrm{~B}$ can be extended to understanding the student-administration interface. This dynamic is depicted in Figures 4A and 4B. Here, one might expect administration pull as a response to a student-initiated accessibility push. Insofar as a student agenda of this kind does not impede higher levels of cost-effectiveness (C-E), such as more enrolments, higher professor-student ratios, more prepared applicants, and so on-administrators would likely accommodate this priority through a pull response. On the other hand, if increased accessibility were to lead to lesser levels of C-E (i.e., higher costs because of more services required, more upfront investment in systems or infrastructure, more faculty training, etc.), then a non-alignment of student/administrator priorities would probably emerge. Under these circumstances, administrators would likely push back in order to continue to pursue their cost-effectivenessrelated priority. Such a state of affairs would possibly result in less accessibility than desired by the student stakeholder group.

\begin{tabular}{|l|l|}
\hline STUDENTS \\
Figure 4A: Student push, administrator pull, \\
and alignment of priorities.
\end{tabular}

We also apply the logic of Figures 3A, 3B, 4A, and 4B to faculty and administrator priorities. Specifically, faculty promote (push) quality and students welcome (pull) quality, insofar as it does not interfere with their priority. Indeed, students may welcome quality in cases where it promotes accessibility and possibly heightened degree prestige. However, if accepting (pulling) quality were to lead to lower levels of accessibility (i.e., diminishing opportunities or more work), 
then students would likely react negatively (push back) in the face of overtly non-aligned priorities. Such push-back would likely be commensurate with the degree of misalignment.

An implication of our modified iron triangle is that sometimes the priorities of stakeholder groups can be somewhat broad. This state of affairs tends to create more opportunities to align priorities. For example, if faculty were to push the quality agenda and such a push coincidently led to higher levels of cost-effectiveness, (say, more prestige for their institution, better opportunities for attracting high-performing faculty, etc.), then there would likely be an enthusiastic pull of this agenda on the part of administrators. In other cases, quality might be interpreted more narrowly. For example, faculty might demand more support, more resources, or a reduced workload in order to achieve their definition of quality. Such an agenda, despite potential long-term costeffectiveness, would likely raise short-term costs and thus ultimately be unacceptable to administrators, probably resulting in a pushback from them.

Finally, to complete the analysis, were administrators to promote new cost-effectiveness measures or standards of DE/OL, there would likely be pull on the part of students, insofar as heightened C-E leads to increased accessibility. There would also likely be pull on the part of faculty, insofar as improved C-E leads to better quality. However, once again, were administrators to impose C-E measures or standards without considering their impact on accessibility and quality, then pushback would most likely ensue. Such pushback could come from one or both of the other stakeholder groups.

Unless there is an acceptable level of alignment of priorities amongst the three stakeholder groups, we posit that accessibility to HE via DE/OL will be constrained and its quality and costeffectiveness limited. Hence, we argue that alignment of priorities is the key to breaking out of the iron triangle. Our conceptualization has five key elements:

1. The three identified stakeholder groups should each be actively involved in overall DE/OL deployment. The priorities of each group should be harmoniously integrated into an overall strategy;

2. The right amount and kind of push can result in pull on the part of other stakeholders, but the key to achieving such a coordinated effort is the notion of priority or interest alignment;

3. Any major push by one of the three stakeholders will likely result in a state of disequilibrium and elicit a push-back by either one or both of the other stakeholders;

4. Priorities may be viewed broadly or narrowly by stakeholders. A broad, system-wide interpretation is likely to have greater implications for a pull reaction on the part of other stakeholders;

5. Each stakeholder group, in promoting and managing its respective priorities, should develop an understanding of and appreciation for the priorities of the other stakeholder groups. 


\section{Breaking out of the Iron Triangle}

We argue that breaking out of the iron triangle requires that $\mathrm{DE} / \mathrm{OL}$ be revised and redefined. As noted previously, for decades DE and now OL have been developed without full faculty influence. Rather, development has been mostly driven by university administrators responsible for perpetuating their institutions by promoting increased cost-effectiveness. As we have seen, faculty intent on maintaining qualitative standards have allowed this to happen, perhaps blissfully unaware of how DE and OL are fundamentally reshaping their Academy. Finally, students (i.e. market forces) are using their purchasing clout to bring about increased accessibility without necessarily considering the long-term consequences of such an agenda.

We consider that DE/OL has substantial untapped potential. Yet such potential will likely not be realized unless and until acceptable trade-offs between stakeholder priorities can be achieved. Success in doing so will translate into harmonious human and technological resource deployment, thereby creating a sustainable online teaching and learning environment. In our view, the hallmarks of this new educational environment will be sufficient ubiquity and user-friendliness to assure improved levels of accessibility; sufficient technological sophistication to allow for a quality online teaching and learning environment; and sufficient cost-effectiveness to meet university resource limitations. In the final section, we describe just such a new online teaching and learning environment that, based on current exploratory evidence-based data, balances stakeholder priorities and offers the prospect of virtually unlimited growth for universities, specifically in the field of graduate studies.

\section{Blended Online Learning Design (BOLD)}

Power (2008b, 2009) and Power \& Vaughan (2010) have described the blended online learning design (BOLD) in earlier publications. In a nutshell, BOLD is a combination of BL (blended learning) and OL. It implements a fully online, combined synchronous- and asynchronous-based learning environment with advanced knowledge-sharing and -creation tools. This hybrid online environment allows users access to a community learning experience as well as 24/7-accessible resources. A BOLD course brings graduate students and faculty together on a regular basis in real time, to debate, critique, and consult one another-implementing both spontaneous and differed modes of learning. In Figure 5, BOLD unites the synchronous, dialogue-based tradition of the campus-based university and the asynchronous, structure-based tradition of the distance education university (Power, 2002; Power \& Vaughan, 2010). 


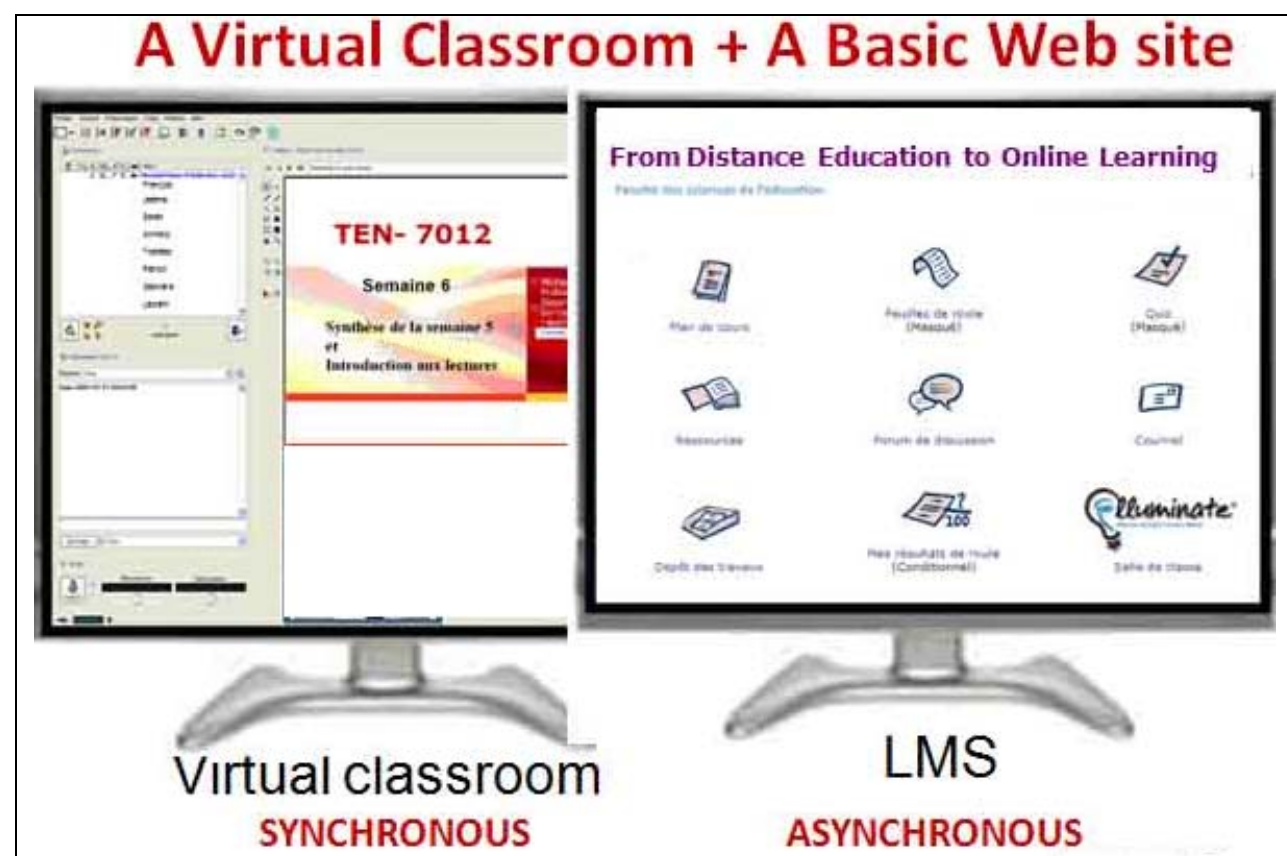

Figure 5. BOLD, a combined-technology approach to the design and delivery of university graduate studies.

BOLD emphasizes the fundamental need for a combination of, on the one hand, a basic, userfriendly learning management system (LMS) and, on the other, a virtual classroom (a.k.a. a synchronous desktop conferencing platform). As such, BOLD can be seen as bridging both asynchronous and synchronous forms of instruction, thereby creating a new form of OL. This new space for OL is illustrated in Figure $6{ }^{1}$. Here, various university-level design and delivery models are situated on a Cartesian plane. They are differentiated according to their teaching mode (synchronous or asynchronous) and their design and delivery mode (on-campus versus online). Figure 6 embodies several ideas. In its lower left-hand quadrant, traditional $H E$ is located. This strategy is the perennial, mainstream, on-campus design and delivery and professor-led, processbased, synchronous-mode teaching. To the right of traditional HE is videoconferencing. This mode of teaching stretches towards the "online space" (in implementing technology) but is also campus-based because it uses satellite campuses. Hence, it is depicted in Figure 6 as straddling the line. Above, traditional HE are library-type resources, which represent course-associated materials that are not available online but are generally accessed asynchronously on campus. In the upper right-hand quadrant, online learning is located. This is characterized by a systemmanaged, product-based, asynchronous teaching mode in the DE tradition. As such, it is seen as being the antithesis of traditional HE. On the other hand, blended learning is a form of teaching that combines both campus-based and OL activities. It is depicted in Figure 6 as a trade-off model, in that it draws on and amalgamates some of the strengths of other design and delivery modes while having the weakness (for off-campus learners) of still requiring some degree of student presence on campus. Finally, BOLD is located in the entire right half of the diagram. This mode is characterized by an optimal blend of, on the one hand, synchronous and asynchronous

\footnotetext{
${ }^{1}$ For a more complete explanation of Figure 6, please see Power, 2008a.
} 
activities and, on the other, faculty-led and system-led activities. It must be emphasized that BOLD is very much a trade-off model, in that it allows for spatial freedom (reaching out to offcampus learners) but not for temporal freedom (in that seminars are scheduled at set times, as they are on campus).

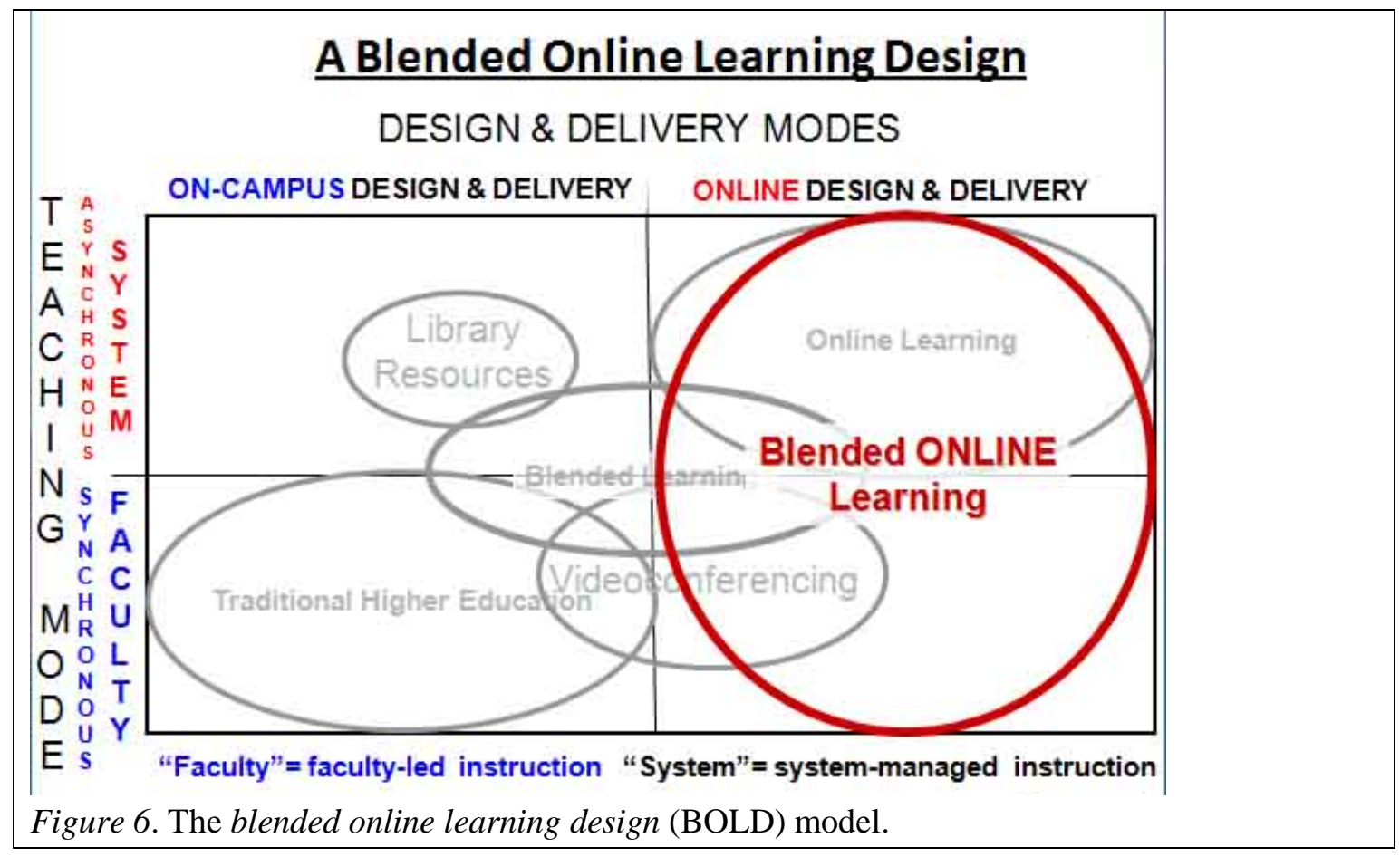

As we have seen previously, Traditional Universities (or TUs), whether they implement DE, OL, or BL, fail to address at least one and, at times, two of the three stakeholder priorities to an acceptable threshold level, thereby resulting in limited successful deployments of alternative course delivery modes. BOLD, on the other hand, appears to better harmonize the priorities of all three stakeholder groups, based on current data (Power \& Vaughan, 2010). It overcomes the shortcomings of DE, OL and BL in the following ways:

- BOLD offers a higher level of accessibility to graduate seminars than those offered by TUs implementing BL, in that students attend a BOLD seminar completely online. It thus achieves enhanced spatial freedom for both faculty and students by removing the oncampus requirement. Student accessibility is further enhanced through access to recordings of weekly classes whenever and as often as they like. This is especially important in the case of second-language students (Moore \& Kearsley, 2005). Faculty experience a pull reaction to BOLD in that they can work with students wherever they may be located geographically. Indeed, faculty report that BOLD-enhanced accessibility allows them to maintain teaching commitments while taking advantage of increased opportunity for off-campus research and fieldwork, making BOLD highly attractive to them. Administrators also experience a pull reaction vis-à-vis BOLD because, using already available infrastructure (existing institutional computer network and faculty equipment) and offsetting expenses (students use their equipment and their own Internet 
connection), they can increase enrolments without any "bricks-'n-mortar” investment, thereby achieving increased cost-effectiveness. In a nutshell, from an economic perspective, administrators are quick to realize that increased accessibility allows traditionally low-enrolment graduate courses to quickly become viable.

- Compared to DE and OL, BOLD improves quality, because faculty find transition to a BOLD environment more engaging and rewarding than to DE (increased level of dialogue with students) and less taxing than to OL (less front-end design, hence less time commitment and less effort). Some even allude to "higher touch" (proximity to students) while simultaneously experiencing "higher tech" (state-of-the-art virtual classroom), concepts once considered diametrically opposed (Naisbitt, Naisbitt, \& Philips, 2001). BOLD thus represents a trade-off between the costly front-end design associated with asynchronous OL courses and the highly inaccessible TU classroom-based seminars. It strikes this balance because real-time, online dialogue compensates for lower front-end design. Hence, faculty are reporting that designing and developing a BOLD course requires a similar time commitment to a TU seminar. As we have seen, such equivalence is achieved thanks mostly to the synchronous component. But the asynchronous component - a basic course website - also contributes to it. Leaner than that of a standalone OL course, the website is developed and updated on an ongoing basis by faculty, but often supplemented by the graduate students themselves. Increased quality is also reported in reference to dialogue in the virtual classroom which successfully approximates the on-campus experience. Students report pull as they are given the opportunity to interact in real-time with their professors and peers, a benchmark for quality in TUs. BOLD, as opposed to DE/OL, affords them a more quality experience and, as opposed to $\mathrm{BL}$, they have the "group experience" without having to come to a university campus. Students also report that gaining access to previously unavailable seminars improves the overall quality of their programs and degrees. Moreover, faculty who implement BOLD report experiencing less of a workload as compared to teaching asynchronous OL courses, while enjoying a similar level of direct interaction with students (compared to TU seminars). Finally, administrators also report pull, not only because of heightened student satisfaction levels, but also because of increased core faculty engagement with OL and added prestige to their institution for effectively contributing to outreach, factors that augur well for future large-scale OL deployment.

- BOLD also seems to improve cost-effectiveness in that it requires no substantial investment or costly incentive system. It enables administrators to "top up" lowenrolment seminars, or even launch entirely new ones as they would TU seminars, on a per-demand basis. BOLD requires much lower start-up costs (due to lower front-end design levels and on-the-fly enrolment) than rival approaches (DE, OL, and BL) and creates expanded outreach possibilities (any online student who accepts the temporal limitation can enrol). Moreover, as the potential pool of students expands, possibilities emerge for offering seminars or full programs for which there may be little or even no local demand, but for which substantial national or international demand exists. By maintaining on-campus course scheduling (courses are "slotted" in the same way they are 
for TU seminars) and faculty workloads (a BOLD course is accounted for in the same way as a regular seminar), administrators avoid the pitfalls commonly associated with OL. These include the issues of faculty transition to OL, hiring adjunct faculty, and providing high-level technical support for faculty. Furthermore, BOLD removes intellectual property as an obstacle to faculty online engagement because, simply put, there is none, as such. Faculty, in launching a BOLD course, use the virtual classroom as they would their campus classroom. They interact in real-time with their graduate students. Such interaction does not produce intellectual property which may be contested. BOLD courses focus on processes and on human resource deployment (like TU seminars) rather than on products and costly didactic material design and delivery (as is common in DE-OL). In 2010, content is no longer king (Odlyzko, 2001) or as much of an issue as it was in 1994, when OL started. Virtually unlimited resources are now available online, waiting only to be harnessed by faculty and students alike. Hence, faculty implement BOLD to teach an augmented form of their TU seminars enhanced by online resources, a form of delivery that may be described as an augmented webinar. Each course is as unique as any TU seminar. Its nature and character are influenced by the issues raised and discussed synchronously or asynchronously, or both, as well as by the personalities and idiosyncrasies of graduate students as well as their professors.

\section{Conclusion}

Further research is required to ascertain with any degree of certitude the applicability of blended online learning design (BOLD) in various situations. Indeed, a number of international pilot projects are currently underway. When completed, these will shed more empirical light on the theory presented in this article. In the meantime, we consider that BOLD offers enormous potential in meeting the needs of faculty, students, and administrators because it harmonizes disparate priorities. A strategic perspective on these issues is timely because the sector has grown rapidly but, at this stage, with mixed results and, at times, lacklustre support from key stakeholders.

This paper has focused on blending synchronous- and asynchronous-mode teaching and learning strategies and technologies in higher education. We have argued that BOLD has the potential to enhance accessibility while maintaining quality and cost-effectiveness in graduate studies. Results may interest faculty, administrators, and instructional designers, as well as educational researchers who are engaged in TU teaching, learning, DE, OL, or BL research. BOLD represents a departure from the DE-inspired, industrial-based, single-mode university instructional design model still prevalent in asynchronous-mode, online learning today and proposes, in its stead, a post-industrial, faculty practice-related, dialogue-rich design model. We deem BOLD a more suitable model for dual-mode universities than rival strategies. It brings together separate but complementary conceptual frameworks, such as distance education, online learning, blended learning, faculty development, instructional design, and educational technology. 


\section{References}

Allen, I. E. and Seaman, J. (2008). Staying the course: Online education in the United States. Needham, MA: Sloan Consortium.

Anderson, T. (Ed.). (2008). Theory and practice of online learning. Athasbasca, AB: Athabasca University.

Bates, A. (1995). Technology, open learning and distance education. London/New York: Routledge.

Bates, A. (2005). Technology, e-learning and distance education. London/New York: Routledge.

Bedford, L.A. (2009). The professional adjunct: An emerging trend in online instruction. Online Journal of Distance Learning Administration, 12 (3). Retrieved from http://www.westga.edu/ distance/ojdla/browsearticles.php

Berge, Z. \& Huang, Y. (2004). A model for sustainable student retention: A holistic perspective on the student dropout problem with special attention to e-learning. DEOSNEWS, 13 (5). Retrieved from http://www.ed.psu.edu/acsde/deos/deosnews/deosnews13_5.pdf

Bertrand, L. (2009). Réinventer l'université. Québec, QC: Presses de l’Université Laval.

Blin, F. \& Munro, M. (2008). Why hasn't technology disrupted academics' teaching practices? Understanding resistance to change through the lens of activity theory. Computers \& Education, 50, 475-490.

Bok, D. (2003). Universities in the marketplace: The commercialization of higher education. Princeton, NJ: Princeton University Press.

Bullen, M. \& Janes, D. (Eds.). (2007). Making the transition to e-learning: Strategies and issues. Hershey, PA: Information Science Publishing.

Burge, L. (2008). 'Crafting the future': Pioneer lessons and concerns for today. Distance Education, 29 (1), 5-17.

Campion, N. (1990). Post-fordism and research in distance education. In T. Evans (Ed.), Research in distance education. Geelong, Australia: Deakin University.

Carr-Chellman, A. A. (Ed.). (2005). Global perspectives on e-learning: Rhetoric and reality. Thousand Oaks, CA: Sage Publications.

Collis, B. \& Moonen, J. (2002). Flexible learning in a digital world. Open Learning: The Journal of Open and Distance Learning, 1469-9958, 17(3), 217-230. 
Cook, K., Owston, R. D., \& Garrison, D. R. (2004). Blended learning practices at COHERE Universities. Institute for Research on Learning Technologies. Technical Report No. 2004-5. Toronto, ON: York University.

Daniel, S. J., Kanwar, A., \& Uvalic-Trumbic, S. (2009). Breaking higher education's iron triangle: Access, cost, and quality. Change, March-April,

Dreyfus, H. L. (2001). On the internet. London: Routledge.

Duderstadt, J. J., Atkins, D. E., \& Van Houweling, D. (2002). Higher education in the digital age: Technology issues and strategies for American colleges and universities. Connecticut: Greenwood Publishing.

Evans, T., \& Nation, D. (1993). Reforming open and distance education. London: Kogan Page.

Gambescia, S. F. \& Paolucci, R. (2009). Academic fidelity and integrity as attributes of university online degree program offerings. Online Journal of Distance Learning Administration, 12(1), Spring. $\quad$ Retrieved from http://www.westga.edu/ distance/ojdla/spring121/gambescia121.html

Garrison, D. R. (2009). Implications of online learning for the conceptual development and practice of distance education. Journal of Distance Education/Revue de l'éducation à distance, 23(2), 93-104.

Garrison, D. R., \& Vaughan, N. (2008). Blended learning in higher education. San Francisco: Jossey-Bass.

Garrison, D. R., \& Archer, W. (2007). A community of inquiry framework for online learning. In M. Moore (Ed.), Handbook of distance education (pp. 77-88). New York: Erlbaum.

Garrison, D. R., \& Kanuka, H. (2004). Blended learning: Uncovering its transformative potential in higher education. Internet and Higher Education, 7, 95-105.

Guri-Rosenblit, S. (2009). Digital technologies in higher education: Sweeping expectations and actual effects. New York: Nova Science.

Harasim, L., Hiltz, S. R., Teles, L., \& Turoff, M. (1995). Learning networks: A field guide to teaching \& learning online. Cambridge: MIT Press.

Kampov-Polevoi, J (2010). Considerations for supporting faculty in transitioning a course to online format. Online Journal of Distance Learning Administration, 13(2). 
Kanuka, H. \& Brooks, C. (2010). Distance education in a post-fordist time: Negotiating difference. In M. F. Cleveland-Innes \& D. K. Garrison (Eds.), An introduction to distance education: Understanding teaching and learning in a new era. New York \& London: Routledge.

Ludwig-Hardman, S. \& Dunlap, J. C. (2003). Learner support services for online students: Scaffolding for success. The International Review of Research in Open and Distance Learning, 4(1). Retrieved from http://www.irrodl.org/index.php/irrodl/article/view/131/602

Maeroff, G. I. (2003). A classroom of one: How online learning is changing our schools and colleges. New York: Palgrave Macmillan.

Maguire, L. L. (2005). Literature review-Faculty participation in online distance education: Barriers and motivators. Online Journal of Distance Learning Administration, 8(1). Retrieved from http://www.westga.edu/ distance/ojdla/spring81/maguire81.htm

Mitchell, B. \& Geva-May, I. (2009). Attitudes affecting online learning implementation in higher education institutions. Journal of Distance Education/Revue de l'éducation à distance, 23(1), 71-88.

Moore, M. G. \& Kearsley, G. (2005). Distance education. A systems view (2nd ed.). Belmont, CA: Thomson Wadsworth.

Morgan, C. K. \& Tam, M. (1999). Unravelling the complexities of distance education student attrition. Distance Education, 1475-0198, 20(1), 96-108.

Mortera-Gutiérrez, F. (2006). Faculty best practices using blended learning in e-learning and face-to-face instruction. International Journal on E-Learning, 5(3), 313-337. Chesapeake, VA: AACE.

Naisbitt, J., Naisbitt, N., \& Philips, D. (2001). High tech/high touch: Technology and our accelerated search for meaning. London: Nicholas Brealey Publishing.

Noble, D. F. (2001). Digital diploma mills: The automation of higher education. New York: Monthly Review Press.

OECD (2005). E-learning in tertiary education: Where do we stand? Paris: OECD, Centre for Educational Research and Innovation.

Odlyzko, A. (2001). Content is not king. First Monday, 6(2-5). Retrieved from http://firstmonday.org/htbin/cgiwrap/bin/ojs/index.php/fm/article/view/833/742 
Olcott, D. (2008, November). Going global: Opportunities and challenges for open and distance learning. ACU Conference of Executive Heads, Hyderabad, India.

Orr, R., Williams, M. R., \& Pennington, K. (2009). Institutional efforts to support faculty in online teaching. Innovative Higher Eucation, 34(4),

Perry, W. (1976). Open university: A personal account by the first vice-chancellor. Milton Keynes, UK: The Open University Press.

Pittinsky, M. S. (Ed.). (2003). The wired tower: Perspectives on the impact of the internet on higher education. Upper Saddle River, NJ: Prentice Hall.

Power, M. \& Vaughan, N. (2010). Redesigning online learning for international graduate seminar delivery. Journal of Distance Education/Revue de l'éducation à distance, 24(2). Retrieved from http://www.jofde.ca/index.php/jde/issue/view/59

Power, M. (2009). A designer's log: Case Studies in instructional design. Athabasca, AB: Athabasca University Press. $\quad$ Retrieved from http://www.aupress.ca/index.php/books/120161

Power, M. (2008a). The emergence of blended online learning. Journal of Online Learning \& Teaching, 4(4). Retrieved from http://jolt.merlot.org/vol4no4/power_1208.htm

Power, M. (2008b). A dual-mode university instructional design model for academic development. International Journal for Academic Development, 13(1), 5-16. Retrieved from http://dx.doi.org/10.1080/13601440701860185

Power, M. (2005). Le design pédagogique dans un contexte de bimodalisation de l'enseignement supérieur: Une étude multi-cas. Faculté des sciences de l'éducation, Université Laval. Unpublished doctoral dissertation. Retrieved from http://www.theses.ulaval.ca/2005/23258/23258.html

Power, M. (2002). Générations d'enseignement à distance, technologies éducatives et médiatisation de l'enseignement supérieur. Journal of Distance Education/Revue de l'éducation à distance, 17(2). Retrieved from http://www.jofde.ca/index.php/jde/article/view/115

Pullen, J. M. \& Snow, C. (2007). Integrating synchronous and asynchronous internet distributed education for maximum effectiveness. Education and Information Technologies, 12, 137-148.

Rovai, A. P. \& Jordan, H. M. (2004). Blended learning and sense of community: A comparative analysis with traditional and fully online graduate courses. International Review of 
Research in Open and Distance Learning, 5(2). Retrieved from http://www.irrodl.org/index.php/irrodl/article/view/192/274

Sammons, M. C. \& Ruth, S. (2007). The invisible professor and the future of virtual faculty. International Journal of Instructional Technology and Distance Learning, 3(1),

Schullo, S., Barron, A. E., Kromrey, J. D., Venable, M., Hohlfeld, T., \& Hogarty, K. Y. (2005, April). Enhancing online courses with synchronous coftware: An analysis of strategies and interactions. Annual Meeting of the American Educational Research Association, Montreal, Canada.

Shea, P., Fredericksen, E., Pickett, A., Pelz, W.. (2005). Increasing access to higher education: A study of the diffusion of online teaching among 913 college faculty. International Review of Research in Open and Distance Learning, 6(2). Retrieved from http://www.irrodl.org/index.php/irrodl/article/view/238/493

Tallent-Runnels, M. K., Thomas, J. A., Lan, W. Y., Cooper, S., Ahern, T. C., Shaw, S. M., et al. (2006). Teaching courses online: A review of the research. Review of Education Research, 76(1), 93-35.

Thompson, K. (2005). Constructing educational criticism of online courses: A model for implementation by practitioners. Unpublished doctoral dissertation. University of Central Florida: Orlando, FL.

Twigg, C.A. (2003). Improving learning and reducing costs: New models for online learning. EDUCAUSE Review, 38(5), 29-38.

U.S. Department of Education (2010). Evaluation of evidence-based practices in online learning: A meta-analysis and review of online learning studies. Office of Planning, Evaluation, and Policy Development: Washington, D.C. Retrieved from http://www.ed.gov/rschstat/eval/tech/evidence-based-practices/finalreport.pdf

Vonderwell, S. (2003). An examination of asynchronous communication experiences and perspectives of students in an online course: A case study. Internet and Higher Education, 6(1), 77-90.

Wilson, G. (2001). The promise of online education: El dorado or fool's gold? Educational Technology Journal, 11(1).

Zemsky, R. \& Massy, W.F (2004). Thwarted innovation. What happened to e-learning and why? Retrieved from http://www.irhe.upenn.edu/Docs/Jun2004/ThwartedInnovation.pdf 


\section{Athabasca University $\mathbf{Z}$}

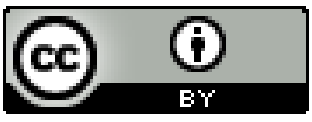




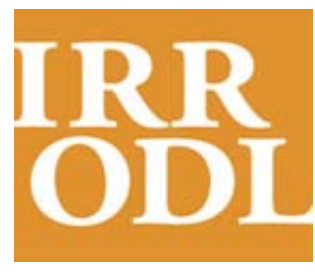

International

Review of

Research in Open

and Distance

Learning

Vol. 12.2

February - 2011
MarylandOnline's Inter-

Institutional Project to Train

Higher Education Adjunct Faculty

to Teach Online

Julie Shattuck

Frederick Community College, USA

Bobbi Dubins

Allegany College of Maryland, USA

Diana Zilberman

Baltimore City Community College, USA

\begin{abstract}
This article reports on an inter-institutional project to design, develop, pilot, and evaluate a statewide online training course for higher education adjunct faculty who are preparing to teach their first online course. We begin with a brief literature review to contextualize the stated problem the project sought to address: the need for quality, accessible training for online adjunct faculty. We then give background information to describe the environment in which the project was situated before detailing the process of designing and piloting the first iteration of the Certificate for Online Adjunct Teaching (COAT) course. Using a mixed-methods approach (surveys and reflection journals), data were collected from the adjunct faculty who took the COAT course, the COAT instructor, and the COAT design team. The results indicate that the pilot COAT course did meet the perceived needs and expectations of the course participants. We finish by discussing our plans for the next phase of this project.
\end{abstract}

Keywords: Adjunct faculty; online teaching; professional development; online learning 


\section{Introduction}

Research has highlighted that different roles and competencies are needed for online teaching than for traditional, on-campus instruction (Berge, 1995; Goodyear, Salmon, Spector, Steeples, \& Tickner, 2001; Ragan, 2009; Smith, 2005; Varvel, 2007). Using Berge's (1995) four instructor roles for moderating online discussions, Morris and Finnegan (2008-2009) found that novice online instructors "enacted a management role to a limited degree, and rarely posted a comment classified as 'pedagogical'” (p. 61); however, experienced online instructors "enacted multiple roles - social, managerial, and pedagogical - to engage students and increase student persistence and success” (p. 61). To assist novice online instructors in becoming competent in all four of Berge's online roles, higher education institutions may offer some form of training in online teaching. However, this training may not be available to all instructors, particularly part-time, adjunct faculty who have limited access to on-campus training opportunities, and the training may not be sufficient to adequately prepare instructors to effectively teach online.

This article focuses on an ongoing project in Maryland, United States, which began in 2008 when MarylandOnline (MOL), a statewide consortium of higher education institutions, funded an exploratory research project to see if there was interest in a shared training program to prepare adjunct faculty to teach online. The research indicated that there was a need for such a program, and this article focuses on describing the second phase of the project: the development, delivery, and evaluation of a pilot Certificate for Online Adjunct Teaching (COAT) course. The article begins with a brief literature review to contextualize the stated problem the project seeks to address: the need for quality, accessible training for online adjunct faculty. We then give background information to describe the environment in which the project is situated before detailing the process of designing and piloting the first iteration of the COAT course. Evaluation data from the pilot course are presented and analyzed before we discuss our recommendations for future iterations of the COAT course.

\section{Problem: The Need for Quality, Accessible Training for Online Adjunct Faculty}

A recent report focused on online learning in the United States found that "online enrollments have continued to grow at rates far in excess of the total higher education student population" (Allen \& Seaman, 2010, p. 1), and comparative enrollment trends for community colleges from fall 2007 to fall 2008 "reported a 22\% increase for distance education enrollments" (Instructional Technology Council, 2010, p. 2). Tipple (2010) highlighted that this increase in online enrollment is inter-related with a second trend: "the significant increase in adjunct (part-time) faculty" (para. 1). The Center for Community College Student Engagement (2009) found that 67\% of all community college instructors taught part-time (p. 18), and Seaman (2009), surveying instructors employed at four-year institutions in the United States, discovered that "part-time faculty are more likely to engage in online learning than their full-time counterparts, with $32.4 \%$ of part-time faculty currently teaching online compared to $22.2 \%$ of full-timers” (p. 15). 
Kanuka, Jugdev, Heller, and West's (2008) exploratory study focusing on academics who worked from home (of which $66.5 \%$ were adjunct faculty) concluded that new instructors should be provided with "an option for sustained early training in distance-delivered online teaching" (p. 162), and that such training should be delivered online. However, recent studies suggest that professional development opportunities focusing on helping instructors become familiar with online teaching roles and competencies may not be available for all instructors. For example, Allen and Seaman (2010) found that "19\% of institutions with online offerings report that they have no training or mentoring programs for their online teaching faculty” (p. 3). Pagliari, Batts, and McFadden's (2009) research into desired versus actual training for online instructors showed that over $40 \%$ of surveyed online instructors had not accessed any training in the past year.

For institutions that do provide training for instructors transitioning to online teaching, the training may not be offered in a format that is easily accessible for adjunct faculty. Allen and Seaman (2010) found that "the most common training approaches...are internally run training courses (65\%) and informal mentoring (59\%)” (p. 3), but details were not provided on the structure or format of the trainings. It is likely that adjunct and full-time faculty training needs vary, with online adjuncts less able to attend on-campus workshops or participate in mentoring if it occurs through informal face-to-face meetings.

Two recent doctoral dissertations have focused on the training needs of online adjunct faculty. Biro (2005) conducted qualitative research that explored, among other topics, online adjuncts' perceptions of their preparation to teach online. Biro concluded that "instructional teams comprised of faculty, administrators, technologists, and instructional design specialists work best when helping faculty prepare to teach online” (2005, p. 90), and that this team-based training "must encourage and facilitate critical-thinking opportunities for faculty who teach online so they can reflect on their decisions as educators and on their learning as students" (2005, p. 93). Blodgett (2008) performed an exploratory, descriptive study of adjuncts’ professional development experiences and preferences to prepare them to teach online. Blodgett's study addressed "the lack of information regarding professional development of part-time/adjunct faculty in preparation for online teaching from the perspective of such faculty” (2008, p. 7). Her research found that adjuncts' perceived needs and preferences for training included (a) the use of online formats to provide flexible access, (b) the provision of the experience of being online students, and (c) the offer of mentoring for continued support. Blodgett gave three recommendations based on her research findings, the first being that "universities should develop formalized, yet flexible faculty development programs for adjunct faculty who are hired to teach online courses” (2008, p. 88).

To summarize, with the increase in online enrollments and the number of adjuncts teaching online courses comes a need for quality training that is accessible to adjunct faculty. Recent research recommends that this training should be designed by teams of faculty, administrators, instructional designers, and technologists, and that the training should be offered in an online format that gives instructors the experience of being online students. The next section discusses how the problem contextualized in this brief literature review-namely, the need for quality, 
accessible training for new online adjunct faculty—is being addressed within a specific context: higher education institutions in Maryland.

\section{Context and Background: Project Purpose and History}

This section begins by introducing two groups involved in online learning in Maryland: MarylandOnline (MOL) and the Instructional Design Affinity Group (IDAG). IDAG received MOL grants in 2008 and 2009 to initiate the COAT project. The COAT initiative has been a collaborative project involving a number of individuals from both MOL and IDAG. A list of major project contributors can be found on the COAT Web site (COAT Project, 2010a).

\section{MarylandOnline}

MarylandOnline is a consortium of independently governed higher education institutions in Maryland. MOL's mission states that it is

a statewide, inter-segmental consortium, dedicated to championing distance learning in Maryland. Through collaboration among Maryland community colleges, colleges, and universities, MarylandOnline facilitates students' access to articulated courses, certificates, and degree programs offered via distance; and promotes excellence in Web-based learning in the physical as well as in the virtual classroom. With strategic partners, MarylandOnline enhances the quality and availability of higher education for the citizens and employers of Maryland and for students worldwide. (MarylandOnline, 2010)

MarylandOnline was established in 1999 and is considered by its member institutions to be innovative and progressive in its approach to championing the cause of distance education. This was reinforced in 2003 by the awarding of a U.S. Department of Education Fund for the Improvement of Postsecondary Education (FIPSE) grant. The chief goal of the grant was the development of a "replicable pathway for inter-institutional quality assurance and course improvements in online learning” (Quality Matters, 2010, para. 1). The product of the FIPSE grant, Quality Matters, has since become nationally recognized for its faculty peer review certification process for online courses.

\section{Instructional Design Affinity Group}

IDAG, an affinity group of the Maryland Distance Learning Association, is primarily comprised of instructional designers working in higher education contexts. The stated mission of IDAG is to promote "the use of instructional design for learning activities that are mediated by technology" (Instructional Design Affinity Group, 2010, para. 1). IDAG’s goals include supporting Maryland distance learning programs and fostering partnerships through collaboration. The project 
described in this paper came about through IDAG collaboration focused on perceived training needs for preparing instructors to teach online.

In 2008, IDAG applied for a grant from MOL in order to conduct research on how interested Maryland institutions might be in the development of a state-wide online teaching certificate for instructors in higher education. As instructional designers at Maryland institutions, many IDAG members were responsible for providing training for instructors at their institutions in the areas of pedagogy and technologies used for online teaching. It became apparent that many instructional designers within the group were developing similar training sessions for instructors at their respective institutions. It was felt that the creation of a training course that could be shared among institutions might reduce this duplication of effort while also expanding the number, quality, and consistency of trainings offered to online instructors within Maryland's higher education community.

Many institutions were also grappling with the task of how to properly prepare new instructors how to teach online. With the success of MOL's Quality Matters project (Quality Matters, 2010) and its impact on defining and certifying the quality of course design, institutions were turning their attention to the quality of the delivery of those courses.

Instructors themselves seemed interested in obtaining some type of formal designation indicating they had a certain level of online teaching expertise. Adjunct instructors, who often teach for multiple institutions, were sometimes required to complete potentially identical training at each institution. In contrast, some adjunct instructors did not have access to training at all because their institution did not offer it or did not offer it in a format or time frame that was convenient for them. It was envisioned that the creation of a sharable training course would increase the availability of training to instructors. It could also potentially increase the pool of trained adjunct faculty for institutions to draw upon. Hence, it was envisioned that the project could benefit MOL member institutions through (a) providing access to COAT course design and training materials, and (b) providing access to a pool of trained instructors. The project could benefit adjunct instructors through (a) providing access to training that is familiar to MOL institutions, (b) providing a proven method to document their skills, and (c) offering access to training that might not currently be available or easily accessible to them.

\section{Phase One: Research, 2008-2009}

MOL responded to IDAG's grant request by awarding an initial grant to the group in the fall of 2008. Primary purposes of the grant were identified as (a) to perform research on the training needs of Maryland's higher educational institutions, (b) to perform research on the level of interest Maryland's higher educational institutions may have in a shared training course/program, and (c) if there appeared to be sufficient interest, to recommend a program model(s) that might allow MOL to offer training sessions or certification courses as a state-wide group. The group first reviewed current literature on online teaching competencies and researched existing higher education training programs for online teaching (Dubins \& Graham, 2009). 
A survey was then conducted on the training needs of Maryland's higher educational institutions. The Maryland Higher Education Commission (MHEC) Web site (MHEC, n.d.) was used to identify higher education institutions in Maryland. Thirty-seven institutions were identified as having credit online course offerings or programs in place, and invitations to participate in the survey were sent via email to the distance learning administrators and instructional designers/faculty trainers of these 37 institutions. Multiple responses from institutions were permitted in order to collect more comprehensive data (i.e., the researchers saw a need for data collected from both administrator and instructional designer/faculty trainer perspectives). Respondents were required to identify themselves in order to detect duplicate responses from institutions.

The survey gathered information about faculty training/professional development sessions offered by institutions to their online instructors. Information gathered included (a) topics/competencies covered, (b) delivery mode, (c) identification of unmet training needs, and (d) reasons why unmet training needs were not being addressed. Finally, the survey included questions designed to gauge interest in training offered by a central Maryland organization and interest in a state-wide certification program for online instructors.

The survey response rate was 59\% with a total of 27 responses received from 22 institutions (five institutions provided responses from two different respondents). The majority of responses were received from distance learning directors/managers (13 responses) and instructional designers/technologists/faculty trainers (13 responses).

Selected results of the Maryland Faculty Training Needs Assessment Survey were as follows:

- Learning management system training appeared to be offered sufficiently by most institutions;

- Training was more readily available for course development than for teaching online;

- Less than half of respondents (44\%) offered training for teaching online;

- The most common reasons for not offering training were lack of staff (62\%) and lack of time (31\%);

- The majority (81\%) of individual respondents were personally interested in an online teaching certificate program;

- $71 \%$ of respondents indicated their institution was, or might be, interested in an online teaching certification program offered state-wide.

The results of the survey indicated there was supported interest by Maryland's higher education distance learning professionals to develop a state-wide training program focused on the competencies needed to teach online. The survey results also revealed which training topics 
institutions were currently offering (see Table 1) and which topics they felt needed to be offered but which were not currently available to their faculty. Responses to an open-ended question on what training they would like to offer, but currently did not, fell into the following categories: (a) teaching online (six responses); (b) pedagogy (two responses); (c) assessment (four responses); (d) managing online discussions (one response); (e) Americans with Disabilities Act (two responses); (f) copyright (two responses); (g) course design (two responses); and (h) technology (two responses).

Table 1

Survey respondents' responses to survey question: "Please use the list below to tell us about your current training for teaching online. Select all that apply”

\begin{tabular}{|l|c|c|}
\hline \multicolumn{1}{|c|}{ Teaching online training topic } & Do offer & Do not offer \\
\hline Online best practices & & \\
\hline Leading / managing / monitoring discussions & $78 \%$ & $22 \%$ \\
\hline Rubrics & $63 \%$ & $37 \%$ \\
\hline Creating engaging assignments & $59 \%$ & $41 \%$ \\
\hline Assessing assignments/discussions & $56 \%$ & $44 \%$ \\
\hline Copyright & $56 \%$ & $44 \%$ \\
\hline Learning styles (auditory, visual, kinesthetic) & $56 \%$ & $44 \%$ \\
\hline ADA guidelines & $37 \%$ & $63 \%$ \\
\hline Learning theories (behaviorism, cognitivism, constructivism) & $30 \%$ & $70 \%$ \\
\hline
\end{tabular}

The topics identified in Table 1, as well as the results of the literature review to identify online teaching competencies, were detailed in the report to MOL at the end of phase one. The report included recommendations that (a) the training should be delivered fully online, include formal assessment of core competencies, and focus on teaching online, not on course design; (b) an advisory board comprised of experienced online instructors, instructional designers, and distance learning administrators should be formed; and (c) the training should be available to both new and experienced instructors. The report also recommended course competencies that were incorporated into the COAT syllabus in phase two (COAT Project, 2010c).

\section{Proposed Solution: Phase Two - Certificate for Online Adjunct Teaching}

The phase one project report recommended that MOL fund a second phase of the project focused on the development and pilot offering of a training course aimed at preparing adjunct faculty to teach online. This section focuses on phase two of this project, which was completed in the academic year 2009-2010. The logistics of setting up an inter-institutional training course is first discussed. 


\section{Organizing the Project}

Preparation for phase two of the project necessitated first identifying major project tasks and determining a timeline for project activities. These activities reflected the main components needed in an instructional design plan as identified by Morrison, Ross, and Kemp (2007): learner characteristics, task analysis, instructional objectives, content sequencing, instructional strategies, designing the message, development of instructions, and evaluation instruments (p. 12).

August-September 2009

- Write course syllabus.

- Define module objectives.

- Form a project advisory board.

- Determine project timeline.

- Present detailed grant proposal to the MOL board of directors for approval.

October-November 2009

- Present at the Maryland Consortium for Adjunct Professional Development

- conference and gauge instructor interest in the project.

- Determine criteria for selection of the course development team and course facilitator.

- Recruit course development team members and course facilitator.

- $\quad$ Select a learning management system and host institution for the course.

- $\quad$ Determine course development standards.

December 2009-March 2010

- Design and develop the course.

- Develop a project Web site.

- Recruit and select pilot course participants. 
April-June 2010

- $\quad$ Run the nine-week pilot course.

- Compile and analyze course evaluation results.

- Solicit feedback from MOL Distance Learning Directors affinity group.

- Write final report, including recommendations for the next phase.

\section{Course structure and syllabus.}

The first task in designing the COAT course was to decide on the course structure and write the syllabus. Using the recommendations from phase one's research, it was decided to deliver the course completely online as a nine-week asynchronous course consisting of four modules. The modules encompassed the eight main competency areas: (a) orienting students to online learning; (b) technology skills; (c) learning management skills; (d) basic instructional design principles; (e) pedagogy and andragogy; (f) social process and presence; (g) managing assessment; and (h) legal and institution-specific policies and procedures (COAT Project, 2010b). The course description reflected elements from the community of inquiry framework (Garrison, Anderson, \& Archer, 2000) with a particular emphasis on social and teaching presences.

A primary objective for the paced COAT course structure was to provide instructors with the experience of online learning from the student's perspective. The concept of a group training experience led by an instructor, as opposed to self-paced study with no instructor, drew on Bandura's (1977) social learning theory, in particular on the idea of modeling. By participating in a well-designed online course facilitated by an experienced online instructor who modeled identified best practices, participants would benefit through observing the practical implementation of what they studied in the course.

The course syllabus gave a detailed course description, including teaching methods, learning objectives, and assessment methods (COAT Project, 2010c). Course design standards provided to the design team indicated that the course should include structured weekly content similar to what instructors would likely use in their own online courses, such as (a) using a textbook, articles, and Web sites as required readings; (b) viewing videos; (c) completing written and interactive exercises; (d) completing quizzes, self-checks, and self-reflection assignments; and (e) interacting with other participants in discussion boards and group activities.

\section{Project advisory board.}

The next task was to address any concerns of distance learning administrators at MOL-affiliated institutions. An advisory board was formed in August, 2009 and included representatives from a number of MOL-affiliated institutions and organizations. The advisory board initially focused on 
addressing areas of concern that had been expressed by some institutions. The first area of concern was the use of the word recognize in the proposed grant proposal for phase two: colleges would recognize the training. The project management team clarified that the intent of the project was to offer training with content that was familiar to MOL participating institutions. It was not to mandate the training to institutions or to require institutions to formally recognize it. Individual institutions were free to determine whether the training met or contributed to their training needs, and to what extent.

The second area of concern was the title of the project (i.e., Certificate for Online Adjunct Teaching). Some institutions were uncomfortable with using the word certificate in the title of the project, citing concerns that participants might misinterpret it to be a professional certificate or a credit-course certificate program. The advisory board was not able to come to consensus on this issue prior to the drafting of the phase two proposal to MOL, so it was agreed that the title of the project for phase two would be modified to the Online Adjunct Teaching project and that the group would revisit the title of the project upon completion of phase two.

The third area of concern was the target audience for the course. It was clarified that the course would be targeted toward adjunct instructors who were experienced face-to-face college teachers, but were new to teaching online.

Using the input provided by the advisory board, the project management team presented a detailed proposal for phase two of the project to the MOL board in September, 2009, which was subsequently approved. The advisory board was active throughout phase two of the project and offered input and advice on various facets of the project, including recommendations for continuing the project into phase three, with a project title of Certificate for Online Adjunct Teaching.

\section{Distance learning directors affinity group.}

In addition to the project advisory board, the project management team solicited input from the distance learning directors affinity group, which was comprised of directors of distance learning at MOL member institutions (or who had similar responsibilities). The course was showcased to the group in June 2010. Feedback regarding the course was excellent.

\section{Pilot Course Design and Development: Process and Product}

The COAT course was developed using a collaborative, inter-institutional team approach. Preparation for course design and development began in the fall of 2009 with the recruitment and selection of the course development team. The course development team included members from six Maryland institutions who were experienced online instructors (fulltime and adjunct), instructional designers, and/or distance learning administrators. All members had extensive experience in instructional design and were well-versed in the Quality Matters course design standards. 
With the exception of an initial team meeting, the team met and designed the course entirely online using Internet conferencing and collaboration tools. The team met on a weekly basis over a period of four months.

All team members were employed in positions at their respective colleges; thus, it was essential to maximize efficiency and effectiveness of the team. The initial team meeting was held face-toface in November 2009, at which time the project leaders outlined the major tasks of the design team and the project timeline. They also shared the roles they envisioned for each member of the team and gave each team member an opportunity to accept, decline, or modify their role and/or time commitment. Hence, at the conclusion of the initial meeting, each member had a clear idea of what was expected and was enthusiastic about his or her role on the team.

Also during the initial meeting, the project leaders distributed copies of the course syllabus and module objectives, which they had determined using the research conducted in phase one of the project and which were supported by the advisory board (COAT Project, 2010c). In addition, proposed course development standards were introduced in order to ensure coherence across course content and adherence to good instructional design standards and practices. Design and development of the course occurred from January through April 2010. Course design highlights included that the course

- $\quad$ be designed in module format;

- $\quad$ be designed with the foresight of migrating to multiple learning management systems;

- $\quad$ be designed using Quality Matters standards;

- be designed as a nine-week cohort course;

- emphasized the modeling of good teaching practices;

- contained multiple and varied assessments;

- considered different learning styles of participants; and

- made use of multiple resources/types of resources (textbook, PowerPoint presentations, SoftChalk lessons, videos, external Web sites, interactive software, etc.).

A design team survey, conducted at the conclusion of the course development, indicated that the team unanimously felt the inter-institutional, team approach to designing the course resulted in a course of much higher quality than one being designed by a one- or two-person team. They felt the team collaboration allowed for a more diverse pool of ideas, as well as a diverse pool of knowledge (i.e., each team member brought a different strength to the project). In addition, the inter-institutional approach to designing and developing the course resulted in a more comprehensive coverage of topics and issues that adjunct instructors from different institutions 
might encounter. Despite a heavy workload and unforeseen external demands on some team members, the team unanimously indicated they found the experience to be rewarding and were proud of the course they had produced. In addition, all team members noted that they felt they were given adequate license to be creative and innovative.

\section{Pilot Course Implementation}

Participants were recruited for the pilot course through (a) a COAT presentation at the 2009 Maryland Consortium for Adjunct Professional Development conference, (b) referrals from distance learning administrators, and (c) referrals from MOL board members. Of the 65 applicants for the online pilot course, 20 were chosen. Criteria for selection included (a) experienced adjuncts with no previous online teaching experience, (b) availability during the pilot course period of April through June 2010, (c) affiliation with an MOL member institution, and (d) teaching discipline. The 20 participants represented 10 Maryland institutions. Two of the participants withdrew from the course within the first week, citing personal reasons for their withdrawal (lack of sufficient time, lack of technical skills). Of the remaining 18 participants, 17 completed the course successfully. The pilot course was offered at no cost to participants.

\section{Evaluation Methods}

The purpose for evaluating the pilot course was to focus on how the participants and instructor perceived the effectiveness of the course content and design for preparing adjuncts to teach their first online course. When participants applied to take the course, they were informed that they would be asked to provide feedback on their experiences in the course, specifically on how the course could be improved for future participants. Participants were asked to give permission to use their course contributions (submitted assignments, discussion board postings, survey responses, etc.) for evaluation purposes. Participants were assured that their contributions would be presented anonymously and their evaluation comments would have no impact on their successful completion of the course. All participants voluntarily signed a permission form.

The evaluation approach was based within a social constructivist epistemology as defined by Koro-Ljungberg, Yendol-Hoppey, Smith, and Hayes (2009). Koro-Ljungberg et al.'s description of a social constructivist epistemology included the following: considering the researcher as having a multifaceted, participatory role; having research goals to "negotiate and transform the practice” (2009, p. 690); and viewing knowledge as being generated from participants. The researcher who conducted and analyzed the evaluations was a member of the COAT leadership team, but was not a member of the course design team. The aim of the research was to use course participants' feedback to make changes to the pilot course where necessary in order to improve the course for future offerings.

Evaluation data were collected from the participants in the pilot course using a mixed-methods approach: surveys (four module surveys and an end-of-course survey) and course documents (e.g., reflection journals). The surveys contained both Likert scale questions and open-ended questions in order to provide both quantitative and qualitative data. 


\section{Evaluation Results and Analysis}

\section{Participants’ perspective.}

Participants were asked to complete an online survey within the learning management system at the end of each module and an additional survey at the end of the course (a total of five surveys ranging from 17 to 34 questions in length). Participants were assured that their responses were anonymous and no response could be directly linked with a participant's name. Out of 17 participants, 16 completed the end-of-course and module 1 surveys, 15 completed the modules 2 and 4 surveys, and 14 completed the module 3 survey. The researcher tabulated the Likert scale questions and categorized the open-ended responses into common topics. Other members of the COAT team were asked to review the categories and make comments on whether the categories reflected the data in a way that would inform useful course redesign decisions. In the interest of space, only partial results of the surveys are given. Tables 2 and 4 show the compiled results for the four module surveys' closed response questions, Table 3 gives the results to the Likert scale questions in the end-of-course survey, and Table 5 shows the results from one of the open-ended response questions for the first module.

Table 2

Responses from the Four Module Surveys for the Three Questions Repeated across Surveys

\begin{tabular}{|c|c|c|c|c|c|}
\hline Question & $\begin{array}{l}\text { Strongly } \\
\text { agree }\end{array}$ & Agree & $\begin{array}{c}\text { Neither agree } \\
\text { nor disagree }\end{array}$ & Disagree & $\begin{array}{l}\text { Strongly } \\
\text { disagree }\end{array}$ \\
\hline $\begin{array}{l}\text { The module objectives were clearly } \\
\text { stated. }\end{array}$ & 35 & 23 & 1 & 1 & \\
\hline $\begin{array}{l}\text { The assignments and activities were } \\
\text { clearly explained. }\end{array}$ & 21 & 32 & 6 & 1 & \\
\hline $\begin{array}{l}\text { I found the content (textbook readings, } \\
\text { documents, audio, video, websites etc.) } \\
\text { in this module to be useful. }\end{array}$ & 27 & 30 & 3 & & \\
\hline
\end{tabular}

Table 3

Responses from the End of Course Survey for the Likert Scale Questions

\begin{tabular}{|l|c|c|c|c|c|c|}
\hline Question & $\begin{array}{c}\text { Strongly } \\
\text { agree }\end{array}$ & Agree & $\begin{array}{c}\text { Neither } \\
\text { agree nor } \\
\text { disagree }\end{array}$ & Disagree & $\begin{array}{c}\text { Strongly } \\
\text { disagree }\end{array}$ & N/A \\
\hline $\begin{array}{l}\text { Overall the course content met my } \\
\text { needs to prepare me to teach online. }\end{array}$ & 9 & 5 & 1 & 1 & & \\
\hline The course was well organized. & 9 & 5 & 2 & & & \\
\hline The structure/design of the course & 10 & 4 & 2 & & & \\
\hline
\end{tabular}




\begin{tabular}{|c|c|c|c|c|c|c|}
\hline contributed to my overall learning. & & & & & & \\
\hline $\begin{array}{l}\text { The structure/design of the course } \\
\text { helped me understand what a quality } \\
\text { online course can look like. }\end{array}$ & 11 & 4 & 1 & & & \\
\hline $\begin{array}{l}\text { The overall course objectives included } \\
\text { what I wanted to study in order to } \\
\text { prepare to teach online. }\end{array}$ & 5 & 9 & 1 & 1 & & \\
\hline $\begin{array}{l}\text { This course has helped me to } \\
\text { understand introductory concepts and } \\
\text { skills relevant to teaching online. }\end{array}$ & 10 & 6 & & & & \\
\hline $\begin{array}{l}\text { The required textbook was valuable in } \\
\text { contributing to my overall } \\
\text { understanding of the course content. }\end{array}$ & 5 & 5 & 3 & 3 & & \\
\hline $\begin{array}{l}\text { The introduction to the course } \\
\text { (syllabus, orientation area, introductory } \\
\text { video clips etc.) were useful in } \\
\text { understanding how the course would } \\
\text { be run. }\end{array}$ & 9 & 7 & & & & \\
\hline $\begin{array}{l}\text { Course content met the stated } \\
\text { objectives. }\end{array}$ & 12 & 3 & 1 & & & \\
\hline $\begin{array}{l}\text { I found the Blackboard course site easy } \\
\text { to navigate. }\end{array}$ & 9 & 3 & 1 & 3 & & \\
\hline $\begin{array}{l}\text { The workbook assignments were } \\
\text { useful. }\end{array}$ & 7 & 7 & 2 & & & \\
\hline $\begin{array}{l}\text { The group work provided me with a } \\
\text { good learning experience. }\end{array}$ & 4 & 5 & 5 & 2 & & \\
\hline $\begin{array}{l}\text { The weekly discussion board was an } \\
\text { important part of my learning } \\
\text { experience in this course. }\end{array}$ & 7 & 6 & 2 & 1 & & \\
\hline $\begin{array}{l}\text { I found the "Digging Deeper" sections } \\
\text { useful. }\end{array}$ & 4 & 7 & 4 & & & 1 \\
\hline $\begin{array}{l}\text { The media mix of text, video, and } \\
\text { audio accommodated my preferred } \\
\text { learning style. }\end{array}$ & 10 & 2 & 4 & & & \\
\hline $\begin{array}{l}\text { The amount of content covered each } \\
\text { week was reasonable. }\end{array}$ & 5 & 7 & 1 & 2 & 1 & \\
\hline $\begin{array}{l}\text { I found it challenging to keep up with } \\
\text { the workload. }\end{array}$ & 1 & 8 & 5 & 2 & & \\
\hline $\begin{array}{l}\text { The optional synchronous meetings } \\
\text { with the instructor through web- } \\
\text { conferencing software were useful for } \\
\text { me. }\end{array}$ & 4 & 1 & 4 & & & 7 \\
\hline I would recommend this 9-week cohort & 8 & 5 & 2 & 1 & & \\
\hline
\end{tabular}




\begin{tabular}{|c|c|c|c|c|c|}
\hline training to a colleague. & & & & & \\
\hline $\begin{array}{l}\text { I would have preferred to access this } \\
\text { training as four individual modules } \\
\text { rather than as a 9-week course. }\end{array}$ & & 1 & 5 & 7 & 3 \\
\hline $\begin{array}{l}\text { I would have preferred to take this } \\
\text { course as a self-paced study program } \\
\text { rather than as a paced, cohort, } \\
\text { collaborative course. }\end{array}$ & & 3 & 1 & 7 & 5 \\
\hline $\begin{array}{l}\text { The instructor provided a positive } \\
\text { model on how an online course should } \\
\text { be facilitated. }\end{array}$ & 10 & 5 & 1 & & \\
\hline $\begin{array}{l}\text { This course has helped me decide that } \\
\text { teaching online is something that I } \\
\text { want to do. }\end{array}$ & 5 & 8 & 3 & & \\
\hline
\end{tabular}

The data presented in Table 2 show that the majority of participants indicated that they either strongly agreed or agreed that the course content was clearly stated (97\% of responses), the assignments and activities were clearly explained (88\%), and the content useful (95\%). Highlights from the end-of-course survey responses were that the majority of participants strongly agreed or agreed that

- the course met their needs to prepare them to teach online (14 out of 16 respondents),

- the course helped them understand what a quality online course can look like (15 out of 16 respondents),

- they would recommend the nine-week cohort training to a colleague (13 out of 16 respondents),

- the instructor provided a positive model of how an online course should be facilitated (15 out of 16 respondents).

In addition, the majority of the participants strongly disagreed or disagreed that they would have preferred to access the training via four separate modules (10 out of 16 respondents), or as selfpaced individual study (12 out of 16 respondents). In response to one of the open-ended questions, "what did you like most about the course," seven responses included having the experience of being an online student. For example, one participant stated, "I liked most that I got to experience it as a student.” These results confirmed for the COAT team the value of having cohort-based, paced online training that positioned participants as online students.

One interesting development that the design team had not originally planned was the inclusion of two optional synchronous meetings using web-conferencing software. The course was designed as a completely asynchronous course, but the instructor suggested offering optional synchronous 
meetings. These meetings were well received by the attendees, with five participants strongly agreeing or agreeing that the synchronous meetings were useful.

The pilot course was designed with the expectation that participants would spend approximately four to five hours a week working on the course. Table 4 shows that module 2 had the heaviest workload in terms of how many hours participants felt they worked on course content ( 9 out of 15 respondents felt they worked seven or more hours a week on this module). In the end-of-course survey, 12 out of 16 respondents strongly agreed or agreed that the amount of content covered each week was reasonable, but 9 out of 16 strongly agreed or agreed that they found it challenging to keep up with the workload. A number of responses to the open-ended question on what participants liked least about the course suggested that the workload expectations could be revisited: "Sometimes having to read all of the discussion threads seemed overwhelming," and "a few of the weeks were challenging with the amount of perceived work." The course design team had been concerned about the amount of work in module 2, and so made module 2 a three-week rather than a two-week module (modules 1, 3, and 4 were two-week modules).

Table 4

Hours per Week Spent on Course

\begin{tabular}{|l|l|l|l|l|}
\hline $\begin{array}{l}\text { Hours per } \\
\text { week }\end{array}$ & $\begin{array}{l}\text { \# of respondents, } \\
\text { module 1 }\end{array}$ & $\begin{array}{l}\text { \# of respondents, } \\
\text { module 2 }\end{array}$ & $\begin{array}{l}\text { \# of respondents, } \\
\text { module 3 }\end{array}$ & $\begin{array}{l}\text { \# of respondents, } \\
\text { module 4 }\end{array}$ \\
\hline Less than 4 & 3 & 0 & 2 & 3 \\
\hline $4-6$ & 8 & 6 & 5 & 5 \\
\hline $7-10$ & 4 & 7 & 4 & 6 \\
\hline $\begin{array}{l}\text { More than } \\
10\end{array}$ & 1 & 2 & 2 & 1 \\
\hline
\end{tabular}

The open-ended questions were categorized into topics in an attempt to see if there were any clear patterns to the participants' responses. On the whole, it was found that the data collected in the open-ended questions, while very useful in painting a picture of individuals' experiences in the course, were not helpful for making course redesign decisions. For example, in Table 5, while two respondents found the SoftChalk lesson on instructional design basics useful, another participant highlighted the same lesson as not being useful. This was a trend throughout the openended questions responses: what one participant liked, another did not. The COAT team decided that the qualitative data gathered in the pilot course should be combined with data gathered in the next phase of the COAT project to see if increasing the sample size produces clearer, more distinct categories to inform major redesign decisions for future iterations of the training course. 
Table 5

Module One: Did any assignments stand out for you as being particularly useful, not useful? Do you have any comments you want to add about the assignments?

(Each response was categorized into fields, and the number of responses indicates the total number of times that a particular topic was mentioned in all survey responses)

\begin{tabular}{|c|c|c|c|c|c|}
\hline \multicolumn{2}{|l|}{ Useful } & \multicolumn{2}{|l|}{ Not useful } & \multicolumn{2}{|c|}{ Other comments } \\
\hline $\begin{array}{l}\text { Sub- } \\
\text { categories }\end{array}$ & $\begin{array}{l}\text { \# of } \\
\text { responses }\end{array}$ & $\begin{array}{l}\text { Sub- } \\
\text { categories }\end{array}$ & $\begin{array}{l}\text { \# of } \\
\text { responses }\end{array}$ & $\begin{array}{l}\text { Sub- } \\
\text { categories }\end{array}$ & $\begin{array}{l}\text { \# of } \\
\text { responses }\end{array}$ \\
\hline $\begin{array}{l}\text { Variety of } \\
\text { content } \\
\text { delivery } \\
\text { media }\end{array}$ & 1 & $\begin{array}{l}\text { Point grading } \\
\text { (grade on } \\
\text { completion } \\
\text { only) }\end{array}$ & 1 & $\begin{array}{l}\text { Too early in } \\
\text { course to } \\
\text { comment }\end{array}$ & 1 \\
\hline $\begin{array}{l}\text { Orientation } \\
\text { checklist 1-4 }\end{array}$ & 1 & & & & \\
\hline $\begin{array}{l}\text { SoftChalk: } \\
\text { Instructional } \\
\text { design basics }\end{array}$ & 2 & $\begin{array}{l}\text { SoftChalk: } \\
\text { Instructional } \\
\text { design basics }\end{array}$ & 1 & $\begin{array}{l}\text { Lack of } \\
\text { clarity for } \\
\text { orientation } \\
\text { checklist 1-4 }\end{array}$ & 2 \\
\hline $\begin{array}{l}\text { Scavenger } \\
\text { hunt }\end{array}$ & 1 & $\begin{array}{l}\text { Hard to find } \\
\text { assignment } \\
1-1\end{array}$ & 1 & & \\
\hline $\begin{array}{l}\text { Technical } \\
\text { skills } \\
\text { checklist }\end{array}$ & 1 & & & & \\
\hline Everything & 2 & & & & \\
\hline $\begin{array}{l}\text { Online } \\
\text { assessment } \\
\text { submission }\end{array}$ & 1 & & & & \\
\hline $\begin{array}{l}\text { Keeping a } \\
\text { portfolio of } \\
\text { completed } \\
\text { worksheets }\end{array}$ & 1 & & & & \\
\hline
\end{tabular}

Instructor's perspective.

The course was facilitated by a faculty member who had extensive experience teaching online, both at the undergraduate and graduate level. The pilot course instructor was part of the COAT course design team, so she was familiar with the course design and the rationale behind design decisions. Despite her involvement in the design of the course, the instructor acknowledged that 
as an instructor who taught both online and in the face-to-face format for many years, I found myself holding back the desire to tweak the look and feel of various course pages or alter its content even in the slightest degree. The urge to make changes in the course was stemming from not having experienced teaching a class where the learning materials were the result of a group effort. Rather, like many other community college instructors, I was used to crafting my own content.

Instead of implementing changes to the course design as she taught, the instructor kept a personal journal where she noted her thoughts regarding the possible revisions for the following iterations of the course, as well as ideas for how various assignments or topics could be changed, added, or deleted. For example, since Google docs were used for the group project, the instructor suggested in her feedback to the project team that students could use wikis, which could be better assessed.

The instructor reported that with robust and logically organized content, the teaching of the course became a daily enjoyment, also coupled by participants' enthusiasm and interest. Moreover, the exchange of perspectives on education and ideas coming from a diverse group of instructors provided a learning experience for all participants. She noted that the most remarkable fact, however, was the degree to which her own understanding of the distinction between the role of course design and the online teacher's roles play in students' satisfaction and success. As one previously involved in the Quality Matters program, the instructor was aware of these distinct, yet overlapping components. Nevertheless, it was only after she taught the COAT course that the roles of the instructor were crystallized. For one, she realized once more that the most important roles of the online instructor were to set out the tone for communicating online and to serve as a guide. She embraced both roles and noticed participants' positive response to prompt and encouraging feedback.

At the beginning of the course, the instructor conducted a synchronous orientation session in the form of a webinar for interested participants. From the 20 adjunct faculty who were selected for the course, 8 took part in the web-conferencing orientation session, which covered topics such as course expectations and navigating the learning management system. The need for a second synchronous session appeared when participants requested a demonstration of how to add audio content to their courses. Both webinars were very well received by participants who attended.

\section{Conclusions and Recommendations}

The COAT pilot course evaluations indicated that, at the end of the course, the majority of participants found that the course (a) met their needs to prepare them to teach online, (b) modeled good course design and teaching practices, and (c) presented content in a way that met their preferred learning style. However, most participants reported that although the amount of content covered each week was reasonable, it was still challenging to keep up with the workload. The qualitative data painted a rich picture of individuals' experiences in the course but was not cohesive enough to use for major redesign decisions. As a result, the project leadership decided 
that more data needed to be collected before determining if any major changes to the course were needed. However, a few minor changes were recommended for the next iteration of the course:

- including optional synchronous opportunities,

- $\quad$ reducing some of the workload for module 2,

- $\quad$ realigning some of the workload in modules 3 and 4 , and

- making several of the assignments optional or ungraded.

The phase two report was presented to MOL in July 2010, at which time it was recommended that a phase three be implemented in the academic year 2010-2011. Phase three recommendations included a goal of becoming grant-independent (i.e., financially self-sustaining). To accomplish this, there would be a fee for taking the course. The fee was set at $\$ 300$ for adjunct faculty living or teaching in Maryland and $\$ 600$ for all others. These fees were estimated to cover the administrative and instructor costs of running three COAT course sections in 2010-2011.

The primary goal of phase three is to determine if there is sufficient demand for the course at the recommended pricing structure in order for the project to become self-sustaining. To achieve this goal, COAT courses are scheduled for the fall, spring, and summer semesters in 2010-2011. The course will be offered with the same design as the pilot course with the few minor exceptions noted previously: (a) adding optional synchronous session(s), (b) reducing/realigning the workload, and (c) making some assignments optional or ungraded. Participants will again be asked to complete course evaluations. At the end of phase three, the evaluation data for the phase three course offerings will be combined with the phase two data to create a larger sample size. It is hoped that this will provide sufficient data to determine if major design changes are needed. At the end of phase three, the COAT team should also have sufficient data to determine whether the COAT project could be self-sustaining. The COAT team hopes that research conducted in phase three will lead to recommending a phase four of the project in 2011-2012 with the expansion of the number of COAT course offerings and a continuing cycle of evaluation and course improvement. It is anticipated that research in phase four will utilize additional data collection tools in order to address the limitations of this current research study, which focused on the perceptions of a small sample of participants. 


\section{References}

Allen, E. I., \& Seaman, J. (2010). Learning on demand: Online education in the United States, 2009. Needham, MA: Sloan Consortium. Retrieved from http://www.sloanconsortium.org/publications/survey/pdf/learningondemand.pdf

Bandura, A. (1977). Social learning theory. Englewood Cliffs, NJ: Prentice-Hall.

Berge, Z. (1995). Facilitating computer conferencing: Recommendations from the field. Educational Technology, 35(1), 22-30.

Biro, S. C. (2005). Adjunct faculty perceptions about their preparation, support, and value as online instructors. Retrieved from ProQuest Dissertations \& Theses: Full Text. (UMI No. 3255630).

Blodgett, M. (2008). Adjunct faculty perceptions of needs in preparation to teach online. Retrieved from ProQuest Dissertations \& Theses: Full Text. (Publication No. AAT 3311265).

Center for Community College Student Engagement. (2009). Making connections: Dimensions of student engagement (2009 CCSSE findings). Austin, TX: The University of Texas at Austin, Community College Leadership Program. Retrieved from http://www.ccsse.org/publications/national_report_2009/CCSSE09_nationalreport.pdf

COAT Project. (2010a). Acknowledgements for the COAT training project. Retrieved from http://marylandonline.org/coat/acknowledgements.htm

COAT Project. (2010b). COAT course competencies. Retrieved from http://www.marylandonline.org/coat/documents/COAT_Course_Competencies.pdf

$\begin{array}{lllll}\text { COAT } & \text { Project. } & \text { (2010c). } & \text { Syllabus. } & \text { Retrieved }\end{array}$ http://marylandonline.org/coat/documents/COAT syllabus webpage.pdf

Dubins, B. H., \& Graham, M. B. (2009, August). Training instructors to teach online: Research on competencies/best practices. Paper presented at the 25th Annual Conference on Distance Teaching and Learning, Madison, WI. Retrieved from http://www.uwex.edu/disted/conference/Resource_library/proceedings/09_20433.pdf

Garrison, D. R., Anderson, T., \& Archer, W. (2000). Critical inquiry in a text-based environment: Computer conferencing in higher education. The Internet and Higher Education, 2(2-3), 87-105. doi:10.1016/S1096-7516(00)00016-6 
Goodyear, P., Salmon, G., Spector, J. M., Steeples, C., \& Tickner, S. (2001). Competencies for online teaching: A special report. Educational Technology Research and Development, 49(1), 65-72. doi:10.1007/BF02504508

Instructional Design Affinity Group. (2010). IDAG instructional design affinity group. Retrieved from http://www.marylanddla.org/idag/

Instructional Technology Council. (2010). Trends in eLearning: Tracking the impact of eLearning at community colleges. Retrieved from http://www.itcnetwork.org/file.php?file=\%2F1\%2FITCAnnualSurvey2009Results.pdf

Kanuka, H., Jugdev, K., Heller, R., \& West, D. (2008). The rise of the teleworker: False promises and responsive solutions. Higher Education, 56(2), 149-165. doi:10.1007/s10734-0079095-z

Koro-Ljungberg, M., Yendol-Hoppey, D., Smith, J. J., \& Hayes, S. B. (2009). (E)pistemological awareness, instantiation of methods, and uninformed methodological ambiguity in qualitative research projects. Educational Researcher, 38(9), 687-699. doi:10.3102/0013189X09351980

MarylandOnline. (2010). Vision and mission. Retrieved from http://marylandonline.org/about/vision-and-mission

Maryland Higher Education Commission. (n.d.). Colleges and universities. Retrieved from http://www.mhec.state.md.us/higherEd/colleges_universities/index.asp

Morris, L. V., \& Finnegan, C. L. (2008-2009). Best practices in predicting and encouraging student persistence and achievement online. Journal of College Student Retention: Research, Theory and Practice, 10(1), 55-64. doi:10.2190/CS.10.1.e

Morrison, G. R., Ross, S., \& Kemp, J. E. (2007). Designing effective instruction (5th ed.). New York: John Wiley and Sons.

Pagliari, L., Batts, D., \& McFadden, C. (2009). Desired versus actual training for online instructors in community colleges. Online Journal of Distance Learning Administration, 12(4). Retrieved from http://www.westga.edu/ distance/ojdla/

Quality Matters. (2010). FIPSE grant project. Retrieved from http://www.qmprogram.org/research-grants/fipse

Ragan, L. (2009). Defining competencies for online teaching success. Distance Education Report, 13(19), 3-6. Retrieved from http://www.magnapubs.com/distanceeducation/ 
Seaman, J. (2009). Online learning as a strategic asset. Volume II: The paradox of faculty voices. Washington, DC: Association of Public and Land-grant Universities. Retrieved from http://www.sloanconsortium.org/sites/default/files/APLU_online_strategic_asset_vol21.pdf

Smith, T. C. (2005). Fifty-one competencies for online instruction. The Journal of Educators Online, 2(2). Retrieved from http://www.thejeo.com/\%20

Tipple, R. (2010). Effective leadership of online adjunct faculty. Online Journal of Distance Learning Administration, 13(1). Retrieved from http://www.westga.edu/ distance/ojdla/

Varvel, V. E., Jr. (2007). Master online teacher competencies. Online Journal of Distance Learning Administration, 10(1). Retrieved from http://www.westga.edu/ distance/ojdla/

\section{Athabasca University $\mathbf{I}$}




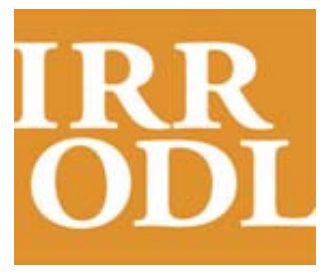

International

Review of

Research in Open

and Distance

Learning

Vol. 12.2

February - 2011

\section{The Isolation of Online Adjunct Faculty and its Impact on their Performance}

\author{
Véra Dolan \\ DePaul University and Ellis University, USA
}

\begin{abstract}
Using a grounded theory qualitative research approach, this article examines the experiences of 28 adjunct faculty members who work at the same university, exploring their views on whether periodically meeting face-to-face with management and peers has the potential to affect their motivation on the job and consequently the quality of education they provide to students. A few management representatives also shared their perspectives on the phenomenon; this enabled the researcher to compare the views of these two populations on whether face-to-face contact among faculty enhances teaching performance. The results of this study suggest a few issues that online schools must address in their efforts to improve adjuncts' sense of affiliation and loyalty to their institution, which in turn will positively affect student retention levels. The main issues of concern to adjunct faculty are (a) inadequate frequency and depth of communication, regardless of the means used, whether online or face-to-face; (b) lack of recognition of instructors' value to the institution; and (c) lack of opportunities for skill development.
\end{abstract}

Keywords: Adjunct faculty; affiliation; isolation; loyalty; organizational commitment; psychological isolation; sense of community; social capital; trust 


\section{Introduction}

A growing number of US workers are telecommuters who perform their jobs remotely most days of the week. Among these millions of virtual workers are many online educators, particularly adjunct instructors who teach for distance education institutions across North America and in other parts of the world.

Academic administrators, increasingly aware of the potential alienation that physical distance can cause, have looked for ways to create a greater sense of community among online adjunct faculty members. The rationale for their efforts is based on the hope that online faculty will exchange best practices, thereby improving both their skills and their motivation; this ideally will enable schools to retain students because superior services are provided by motivated faculty members. However, educational administrators often appear to concentrate solely on the accomplishment of tasks, disregarding the importance of nurturing relational, social, and personal ties with telecommuting staff.

Many administrators who oversee virtual faculty apparently believe that with advanced technology they can create dialogue, knowledge exchange, and collaboration, which in their minds should be sufficient to cultivate loyalty among instructors. However, in order to encourage the best possible performance from remote workers, it is essential for educational institutions to understand that regardless of how sophisticated technology may be in opening communications channels, it cannot create a totally fulfilling work experience (Helms \& Raiszadeh, 2002). The mere existence of a virtual academic community does not necessarily foster faculty loyalty toward management and the institution.

Administrators, for their part, cannot be sure that a technology-based community of practice will provide reliable indicators of mutual trust. In any sector, a significant part of employees' motivation to be strong performers, regardless of the nature of their work, comes from a sense of affiliation with their organization and from the feeling that they are trusted and personally valued by their employers. In higher education, motivated faculty are more likely to strive in their teaching and research if they have a strong sense of belonging to the institution and feel connected to the student body. Fukuyama (1995) defends the idea that reciprocal trust can only emerge within a social context in which virtues such as honesty, reliability, cooperation and a sense of duty to others becomes palpable: "Although there may be some countervailing trends in the newer networking technologies, it remains to be seen whether virtual communities will be an adequate substitute for face-to-face ones” (p. 317). In addition, when people place trust in colleagues and administrators according to "a common set of norms" (p. 27), operational costs decrease. Fouche (2006) asserts that if feelings of isolation are reduced, faculty retention is likely to rise, which means that the university will retain the precious knowledge and skills of good workers. This is important to keep employee turnover rates down and to minimize the need to constantly hire inexperienced instructors, which can entail significant added costs for recruitment, training, and coaching, as well as for additional course materials.

If we accept these added costs as a given, we can conclude that it is critical for the administrators 
of online educational institutions in their ongoing pursuit of higher student retention rates to gain insights into how they can better nurture loyalty and enthusiasm among faculty, particularly in an environment that can easily be perceived as cold and impersonal. Indeed, Roberts, Thomas, McFadden, and Jacobs (2006) point out that a key question to keep in mind with regard to the motivation of adjuncts is how the work of faculty learning communities affects student retention. If instructors do not feel positively connected to their peers and school management, their commitment to the team, including their determination to "not let people down," will be negligible, perhaps even nonexistent. As a result, these faculty members will not put much energy into performing well, which cannot help but affect their students' learning processes significantly. In an online educational environment, it is not uncommon for students to lose momentum due to their lack of proximity with others. If instructors are not willing to be supportive and help such students get back on track, feelings of isolation will put their overall performance at risk, and dropout rates are likely to increase.

Another crucial question, given the difficulty of building strong emotional bridges with virtual staff, is whether periodically gathering remote instructors for face-to-face meetings will encourage stronger relationships and deepen their sense of commitment to the institution. It is just as important to ask whether bringing adjunct faculty together will deliver a better educational experience to students. Finally, in situations where meeting face-to-face on a regular basis is difficult, the challenge for academic managers is to determine how often they should create opportunities for remote faculty to mingle with peers and management in a social context, or, if this is not possible, to decide how they can achieve the same goals from a distance.

\section{Purpose of the Study}

A qualitative study was performed to explore the overall perceptions held by online adjunct instructors regarding the efforts of their academic institution to establish a relationship based on trust, loyalty, sense of affiliation, and commitment to high-quality services. The aim of the study was to explore whether periodically meeting face-to-face would nurture a stronger personal connection between academic management and faculty, a connection in which adjunct instructors' psychological and social needs would be respected, motivating them, in turn, to provide students with the best possible learning experience. Therefore the key question in this proposed study, posed to both management and adjunct faculty, focused on uncovering strategies the institution could use to foster a stronger relationship with adjunct faculty:

Can periodic face-to-face contact create a more significant social and personal bond between management and online adjunct faculty, instilling in instructors a stronger sense of pride and loyalty that will enhance their performance and potentially increase student retention rates? 


\section{Significance of the Study}

This study sought to examine how the sense of isolation from management and peers experienced by instructors teaching remotely might affect their level of motivation and consequently their job performance in the online education environment. It was hoped that the study's findings could help shed light on social desires and needs which if met by the institutions with which these individuals were affiliated would have a significant positive impact on their loyalty, pride, and commitment. At a time when the competition for online students has become fierce, it is vitally important for distance education administrators to extend the best possible treatment to adjunct faculty. Clearly defined and strong incentives for instructors to remain with the organization help build and maintain a positive experience for both current and potential students.

\section{Delimitations}

This study was conducted solely with adjunct instructors and members of the academic administration who were active at the university at the time they were interviewed. Many instructors had direct relationships with the researcher, who had trained and coached them at some point during their contract work with the school. However, other instructors were also invited to participate in the study. The researcher also interviewed management staff in order to gain their perspective on the school's success in nurturing loyalty and commitment among faculty members.

\section{Literature Review}

Although there is growing recognition of the value that part-time and adjunct faculty bring to academic institutions, the drive to create a greater sense of community still faces significant practical obstacles. In 2003 adjunct instructors accounted for 65\% of the workforce in education, according to a US Department of Education report (Abowd, 2008). Brewster points out that these instructors cost less than full-time faculty; moreover, they typically do not receive benefits such as health insurance, sick days, or vacation time (as cited in Gordon, 2003, p. 3). McGuire (1993) rationalizes this practice by saying that hiring adjuncts is an important strategy for saving money and maintaining flexibility. However, it can be difficult, if not impossible, to reconcile the pursuit of cost efficiency with a commitment to being more sensitive to instructors' needs.

Beyond the inequities of compensation, these instructors are often treated as outcasts by the academic mainstream. Adjuncts have been referred to by Smith (as cited in Gordon, 2003, p. 1) as a "sort of migrant underclass in academia." They are accused of degrading "academic quality and integrity of the institution, because their teaching skills are inferior to full-time faculty" (Gordon, 2003, p. 4). Adjunct faculty members are also variously known as academic gypsies, highway fliers, and "roads scholars," among other epithets (Ludlow, 1998, p. 52).

According to Unger (1995), "putting an end to the unethical exploitation of part-time faculty members demands a moral awakening” (p. 61). Academic institutions must understand that, in 
light of the growing number of adjuncts, the integrity and success of many schools will depend on these instructors, which means they must be given the respect they deserve. Not only is this a moral requirement, but it is also a shrewd "business" strategy.

Despite this recognition that attitudes need to change, widespread disenchantment among adjunct instructors remains a problem: "[A] large proportion of universally dissatisfied part-time faculty will likely have a pervasively negative impact on the quality of education throughout higher education” (Gordon, 2003, p. 6). If this statement proves to be true, it is likely that student retention will be negatively affected.

In their quest to deliver quality distance education, many institutions are struggling to define strategies for creating trust and loyalty in their adjuncts. Isolation resulting from physical distance seems to be a huge obstacle for nurturing meaningful, rewarding, and personalized relationships. Feelings of disconnection from issues and policies affecting students, as well as from the overall organizational culture, appear to impede efforts in training and development, along with coaching. The effort required to bridge the gap between management and faculty is considerable, particularly when the bulk of research on this subject has been conducted outside the halls of higher education, which leaves school administrators yearning for more promising insights.

Although more research needs to be conducted in the academic field, it is not unreasonable to assume that many phenomena experienced in the business world could exist in distance education as well. According to Merriman, Schmidt, and Dunlap-Hinkler (2007), "leaders who fail to recognize and adapt to these differences risk alienating a growing segment of the overall virtual workforce” (p. 6). Limited opportunities for personal interaction appear to be detrimental to morale, which leads to poor performance and a lower quality of service delivered to customers. Research has demonstrated a correlation between frequency of communication and interpersonal trust, organizational commitment, and a sense of affiliation with the organization (Marshall, Michaels, \& Mulki, 2007). In order for individuals to see the value of organizational membership, a high level of contact is required between management and employees, as well as between employees and their peers. Quite simply, building a relationship grounded in mutual trust is extremely difficult to accomplish at a distance (Morgan \& Symon, 2002), so much so that some organizations are rethinking telecommuting policies and recalling many employees to traditional offices in the belief that "teamwork improves when people work face-to-face" (Shellenbarger, 2008).

Cummings, Heeks, and Huysman (2008) attempt to explain why organizations believe in providing their teleworkers with sophisticated technology to communicate with peers and management by stating that "[t]he facility to create dialogue, learning and collaboration among these [virtual] groups [...] makes these networks a very attractive proposition” for employers (p. 573). However, the creation of virtual spaces that allow communities of practice to interact does not necessarily translate into social interaction nor does it guarantee the development of emotional ties among members or between members and the sponsoring organization. In a world where many people spend much of their lives working and interacting with bosses, subordinates, and colleagues, it is natural that they also develop a stronger need for friendships based on trust 
and reciprocity in the workplace. Putnam (2000) contends that "many studies have shown that social connections with co-workers are a strong predictor-some would say the strongest single predictor—of job satisfaction” (p. 90).

It is not uncommon to encounter feelings of frustration in the absence of the social cues that occur in a face-to-face environment. This has an impact on motivation, trust, reciprocity, and ultimately job satisfaction with many remote employees citing plans to leave their jobs or at least expressing a lack of interest in organizational outcomes. "With high level of social capital, people are motivated, and are both able to and have the opportunity to share knowledge with each other in a network” (Cummings et al., 2008, p. 582). If face-to-face interaction is limited or nonexistent, trust cannot be developed (Bergum, 2007). And only by gaining trust in workplace relationships, suggest Edwards and Sheperd (2007), will workers be inclined to take part in organizational civic participation and engage in a spirit of volunteerism that promotes actions aimed at the common good.

In light of these findings, while keeping in mind that there has not been much research conducted in the academic sector to better guide administrators, some have argued in favor of gathering virtual instructors together from time to time. Golden (2006) asserts that managers should organize face-to-face activities with their telecommuting workers in order to strengthen socioemotional bonds within the organization. If meeting in person is not possible, management must find ways to create a personalized rapport with each virtual worker and to foster conditions in which social exchanges among remote employees can occur more frequently. Brignall III and Van Valey (2005) stress that computer-mediated communication (CMC) is not the problem per se; the key lies in determining how to make use of this tool in order to bond socially with telecommuters. The importance of creating situations that facilitate casual interactions, friendship, and camaraderie must not be underestimated (Marshall et al., 2007).

\section{Methodology}

This study employed a qualitative inquiry approach in order to understand the cognitive processes of instructors and management as they applied meaning to concepts such as trust, loyalty, and motivation in the workplace. Because the intention was to move from rigorous observation to abstract generalization, the path chosen was a grounded theory inquiry. The researcher developed a systematic set of procedures to inductively derive a theory about the experiences of members of the university community. Using the code system of gathering data, she looked for common themes and patterns of meaning in subjects' responses then developed interpretations that plausibly accounted for the information gathered. The core variable, that is, a sense of isolation on the part of adjunct faculty, was the focal issue, assumed to be alleviated by face-to-face meetings. This, in turn, would potentially lead instructors to feel a deeper sense of loyalty to the institution as well as to students. Using the constant comparative method to contrast the content of all interviews, the researcher tried, as much as possible, not to bring her own biases into the matters being discussed; instead, she compared the opinions expressed by those who were interviewed, without stopping to reflect on whether she agreed or not with what was being said. She then offered hypotheses about the isolation and alienation experienced by adjuncts, along 
with ideas on how to reduce that alienation. Asking open-ended questions and giving respondents time to talk about their experiences was deemed the most effective way to gain a significant amount of information and from there to understand adjuncts' stories and analyze their possible meanings.

Given that a significant number of the instructors were invited to participate in this research, the investigator expected that many would respond and, moreover, that the findings could be representative of what other institutions experience, particularly considering that most of the instructors work for other institutions as well. That said, the analysis of results invited future research. This inquiry, therefore, had two main aims: (1) to understand the needs of virtual instructors and the views of university management using a qualitative methodology, and (2) to authenticate the findings and inspire the school's administrators to introduce effective changes within the university.

Sample size in this grounded theory study was not predetermined. As the study proceeded, the researcher chose to continue gathering samples until no new patterns and codes emerged, that is, until the data achieved a level of theoretical saturation. In practice, this meant that the researcher needed to interview more than 20 individuals (Thomson, n.d; Morse, 2000).

While securing agreements from many instructors to participate in the study, the researcher presented her proposal to university management so she could gain their insights as well, making this a participatory study in which the findings would later be discussed with all of the interested parties.

In order to become a respondent, an instructor had to fulfill two criteria: (1) he or she was a current adjunct faculty member; and (2) he or she was willing to answer an open-ended questionnaire and later talk on the telephone with the researcher. A member of the university's administrative staff provided the researcher with a complete list of current adjunct faculty members in all academic departments. Respondents were chosen at random, their names drawn blindly from a bag.

Participants were asked to respond to an emailed questionnaire. This was followed by a telephone conversation to collect additional details. A questionnaire was also sent to all individuals in management positions with the goal of having as many perspectives from university leaders as possible.

\section{Data Analysis Procedures}

The first step in the data analysis was to look at each completed questionnaire as well as the notes from the telephone interviews in order to obtain a general sense of the messages conveyed in each medium. Categories were defined in terms of significant phenomena that pointed to adjuncts' main concerns: 
1. problems in general, such as worrisome issues with regard to the school's current administrative approach;

2. communication problems, such as flaws in the way the university management keeps adjuncts informed (or their failure to do so);

3. motivators, for example, what keeps instructors enthusiastic about teaching;

4. positive aspects of communication, such as the helpful features of the channels routinely used by the university for the exchange of information;

5. praise, a collection of statements commending the university on different aspects of its management and processes;

6. general suggestions, a compilation of ideas for creating an improved and more motivating work environment;

7. suggestions for face-to-face (F2F) interaction, for example, proposals focused specifically on what adjunct faculty would like to see and do if offered opportunities to meet face-to-face; and lastly,

8. impact, the effect that face-to-face meetings have on adjunct faculty members, particularly with respect to their motivation and loyalty to the institution.

\section{Results}

Many respondents were candid with regard to issues that were a source of frustration for them. Some expressed their dissatisfaction passionately; others welcomed the opportunity to express their views in person (via telephone interview). Although some were more emphatic than others in expressing their unhappiness with aspects of teaching for the university, certain topics were repeated frequently, forming a pattern that led to the creation of subcategories for the category in question.

A number of adjuncts took the opportunity to express their unhappiness regarding their compensation. The practice of offering low pay to adjuncts is not uncommon. Virtual schools can hire instructors from anywhere in the world "without paying the significantly higher cost of an equally qualified full-time faculty” (Gaillard-Kenney, 2006, p.10). Anderson (2002) confirms this when discussing the exploitation of nontraditional faculty by colleges that pay "a fraction of what the same course would cost if taught by a full-time faculty member” (p. 2). When pay is perceived as not enough, many instructors appear to look for other forms of compensation, and a sense of affiliation with the school they work for could be a fundamental factor for their satisfaction at work.

Another constant topic was the sense of disconnection experienced by these adjuncts. This is supported by Schnitzer and Crosby (2003), who observe that “[d]istance learning adjuncts, especially those who are physically removed, are particularly vulnerable to feeling disconnected from the institutional environment" (Orientation and Training section, I 1). Some of the comments from faculty members also illustrate a problem raised by Yu and Young (2008), that "online interaction strips away many of the social cues intrinsic to face-to-face interaction, leading to confusion among group members” (p. 88). If communication is deficient, engagement in cooperative behavior and organizational identification is compromised. 
Many adjuncts reported that they did not feel they belonged to the organization they worked for. A large number did not see themselves as part of a team working with a common vision and goal. According to Nelson (2002), among the obstacles impeding success in virtual organizations, three are of critical importance: “a) people lose interaction with managers and co-workers; b) the ability to participate and contribute to a work team is more difficult; and c) the company culture and sense of bonding around common values of purpose can slowly erode” (p. 1). Therefore, the potential value of frequent and clear communication throughout a virtual academic organization should not be underestimated.

Feeling unvalued and taken for granted was another issue for adjunct instructors. Many expressed unhappiness arising from the perception that the university did not recognize them as a source of valuable knowledge and help. For these participants, there was a perceived failure by management to request instructors' input on matters of academic concern. Moreover, many had the impression that the seniority, academic background, and credentials of adjunct instructors were not valued fairly by the institution. Faculty's individual talents, skills, and history of success in academia seemed to be taken for granted. According to respondents, this issue was related to the fact that no one in management had taken the time to get to know them individually or provide them with customized treatment. The overall perception was that an adjunct instructor was a non-entity within the faculty body and was not well known to management.

There was also a distinct impression among many adjuncts that if someone in management contacted them regarding their performance, usually it was only to discuss a problem and not a situation in which the instructor deserved praise. Ng (2006) acknowledges how challenging it can be to provide performance evaluations for virtual workers. Nevertheless, managers must "provide clear descriptions of performance measures, evaluate and provide feedback regularly" (Issues for the Organization, Remote Management section, \ 2).

Levinson (2005) contends that in order to retain online adjunct faculty, institutions must put significant effort into ample and frequent communication. Often, long periods of time pass without adjuncts having any awareness of events and news regarding the institution they teach for. Keeping workers informed and providing feedback on their performance is critical to reduce feelings of insecurity and to promote self-esteem (Conner, 2003).

Although the results of this research suggests there are many issues leading to adjunct faculty's lack of satisfaction, including apparent shortcomings in leadership beyond the scope of this study, there were also positive comments, particularly about the high-quality technology employed by the university in its learning management systems. Indeed, some instructors expressed the opinion that, despite their dissatisfaction with the way they were treated and their feelings of isolation, the institution's state-of-the-art course platform was reason enough to remain part of the adjunct faculty. Interestingly, the same respondents often offered suggestions for improvement, for instance, the creation of social networking channels through which faculty could exchange all kinds of ideas, including those not necessarily of an academic nature. 
Many interviewees favored creating opportunities to increase knowledge or skills through study, travel, research, seminars, workshops, or courses, as well as social events and other activities aimed at creating a stronger sense of community. All participants appeared to unanimously agree that such events would be helpful for instructors to bond and learn from one another.

Although the desire for more frequent opportunities for socialization with peers and administrators was constant, a great number of adjuncts noted an urgent need for faculty and management to exchange ideas, regardless of how this was achieved (i.e., whether it happened face-to-face or via the Internet). Nevertheless, in advocating strongly for meeting other faculty in person, some instructors talked about the domino effect that this action could have: face-to-face meetings would nurture better communication among faculty and between faculty and management. This in turn would allow instructors to develop their skills more quickly and efficiently, which would benefit their students. And when students enjoyed a successful learning experience, they would tell friends and family, which would enhance the school's reputation and attract more talented students and faculty.

Even so, a number of participants stated that face-to-face meetings for online faculty were not essential for delivering quality services to students. However, they acknowledged that such meetings could yield many benefits, including a heightened sense of affiliation, community, camaraderie, and even motivation on the job.

These findings held the promise of giving this school's management-and presumably administrators at other online institutions as well—solid insights that could improve relationships with faculty members and ultimately benefit students. Administrators and instructors presented similar views regarding the issues raised. However, adjuncts seemed more focused on the current reality in their work situation, whereas management-except in a very few circumstances - spoke about ideal practices for faculty retention and not necessarily about what they saw happening at present. Management's mere understanding of what constitutes best practices does not necessarily translate into an incentive for faculty to remain attached to the institution. As discussed in the review of literature, when educational institutions increasingly make use of adjuncts, they must strive to attract and retain the best instructors in order to perform well against the competition. School administrators must go beyond good intentions, and listening to what adjunct faculty members have to say could help their organizations become employers of choice.

With respect to management's views on the question of gathering faculty members together, once again there was clear agreement that this type of meeting would be of great value for all participants and ultimately for the institution as a whole. However, university administrators were concerned about the costs involved in such an undertaking.

In addition, management seemed to recognize the value of regular communication with and among faculty; however, there is an apparent discrepancy between what managers consider good communication practices and faculty's perception. Some administrators seemed resigned to the idea that the school will never satisfy everyone's needs, given that individual faculty members have various preferences and life/work circumstances. 
However, the discrepancy in perceptions between faculty and administrators was particularly striking when one of the leaders, responding to a question on what could be done to strengthen adjuncts' sense of affiliation with the university, replied, "This question assumes that there is a level of mistrust between the adjuncts and the administration. If there is, I am not aware of it.”

\section{Conclusions and Recommendations}

From the analysis of completed questionnaires and telephone interview recordings, it was obvious that participants placed particular emphasis on the need for constant and clear communication between administrators and faculty members, on the improvement of recognition practices, and on the creation of more opportunities to learn from other members of the university community. Of those adjuncts who took part in the study, most expressed a strong need to become better informed on a range of institutional matters. It is clear that when administrators do not communicate often with adjunct faculty and fail to provide constant updates on the institution's management priorities, a sense of isolation increases among these instructors. Feelings of job insecurity tend to escalate as instructors are not sure whether the school is in a position to continue giving them teaching assignments. This in turn can make faculty members restless and inclined to pursue teaching opportunities elsewhere.

Issues of communication go beyond the perceived lack of feedback adjuncts get from management. In fact, a situation that seems to require even more attention is the absence of events that connect faculty members with one another. In the view of the instructors interviewed, learning from their peers' knowledge and experience would provide inspiration that could make them better teachers.

This investigation also provided insights into the value that these instructors gave to stable and reliable technology, which was their main channel of communication with students. Adjuncts seemed to be primarily interested in serving their students well; they counted on a state-of-the-art course management system to help them do their job effectively. An intuitive and reliable system, such as the one deployed by the university, allowed them to dedicate their time to teaching students instead of having to deal with course navigation and technical issues, a typical drawback of platforms that are not well designed.

All of the suggestions offered by instructors revolved around the need for clear, frequent, and wide-ranging communication. Many suggested that face-to-face gatherings of faculty would allow better interaction. It appears, however, that regardless of the channels people choose for communicating with one another, that is, via technology or face-to-face, management must create opportunities for all stakeholders to share their ideas regarding the ongoing improvement of the institution's services and reputation. This in turn will provide students with a more positive and fulfilling experience.

Although teleworkers in general experience a sense of disconnection from the workplace, there seems to be an underlying reason for adjuncts' frustration that is unique to the academic 
environment. Isolation from the institution and from their peers means that instructors lack a significant opportunity to develop their skills in order to better serve their students. Indeed, the desire to better serve students' needs was an important source of motivation for all interviewees. It appears that the ultimate goal of adjunct faculty who crave more contact with administrators and one another is to become better educators in order to give their students a more fulfilling learning experience. They want to be more informed on institutional issues so they can utilize that awareness to enable successful learning. They want to learn about technology developments so they can optimize their use of the online platform to connect with students. They want feedback on their performance so they can make the necessary improvements in their teaching approach. They want their value recognized so they can share with others their individual insights and contributions to the teaching profession.

In short, improving communication would likely satisfy an intrinsic need among the university's adjunct instructors to make a positive difference in their students' lives. Apparently, a common goal for all study participants was to connect with other faculty members so they could learn from one another's knowledge and firsthand experience. Specifically regarding the main question posed by this study, most adjuncts agreed that having occasional opportunities to meet their peers and administrators face-to-face would allow them to develop their skills in a more effective, efficient, inspiring, and indeed pleasant manner. Many envisioned benefiting from lessons that current technology does not allow them to gain. Connecting directly with colleagues could motivate them to continue discussions through the school's online Centre for Teaching and Learning forum and via email, because many professionals feel more comfortable contacting people they have met in person.

Based on their responses, it appears that adjuncts' primary allegiance is to their students rather than to the institution. The school merely serves as the means for these instructors to satisfy their love of teaching. When asked whether they felt their loyalty to the institution would increase after meeting with colleagues in person, many stated clearly that it would not; their loyalty lay, first and foremost, with their students. Similarly, most respondents expressed the view that their motivation on the job would be unaffected by face-to-face meetings. They remained motivated to give their students thoughtful attention and guidance even if their feelings toward the institution were not positive.

Where adjunct faculty felt face-to-face meetings would have an impact was on their sense of affiliation and collegiality. In their comments, instructors stressed that such gatherings would strengthen their bond with the institution and its stakeholders considerably. By getting to know others in the university community better, adjunct faculty members believed they would gain a greater sense of team spirit, welcoming the guidance and experience of others as they worked to improve their own performance as educators.

The overall conclusion one can draw from this research, therefore, is that the absence of face-toface meetings apparently does not decrease faculty's loyalty and motivation. However, the presence of such events is likely to increase loyalty and motivation for the simple reason that these meetings would allow instructors to enrich their skills and consequently serve their 
students better, which most adjuncts identify as the ultimate object of their commitment. If the school enables faculty to enrich their own academic life and thereby become better teachers by arranging face-to-face meetings, then the sense of loyalty that instructors feel toward their students will presumably extend, by virtue of its intermediary role, to the institution as well. 


\section{References}

Abowd, P. (2008). Part-time professors: Little pay, no pensions, no health care, no seniority, now organizing unions. Truth Out. Retrieved from http://www.truthout.org/issues_06/031008LA.shtml

Anderson, E. L. (2002). The new professorate: Characteristics, contributions, and compensation. Retrieved from ERIC (Education Resources Information Center) Document Reproduction Service, No. ED478300.

Bergum, S. (2007). What has happened to telework? Failure, diffusion or modification? The Journal of E-working, $1 . \quad$ Retrieved from http://64.233.167.104/search?q=cache:n42r138_BcQJ:www.merlien.org/oj/index.php/JO E/article/view/2/2+"What+has+happened+to+telework\%3F"\&hl=en\&ct=clnk\&cd=1\&cli ent=safari

Brignall, T. W. III, \& Van Valey, T. (2005). The impact of Internet communications on social interaction. Sociological Spectrum, 25(3). Retrieved from InformaWorld database.

Conner, D. S. (2003). Social comparison in virtual work environments: An examination of contemporary referent selection. Journal of Occupational and Organizational Psychology, 76, 133-147. Retrieved from ProQuest database.

Cummings, S., Heeks, R., \& Huysman, M. (2008). Knowledge and learning in online networks in development: A social-capital perspective. Development in Practice, 16(6). Retrieved from InformaWorld database.

Edwards, A. P., \& Shepherd, G. J. (2007). An investigation of the relationship between implicit personal theories of communication and community behavior. Communication Studies, 58(4). Retrieved from InformaWorld database.

Fouche, I. (2006). A multi-island situation without the ocean: Tutors' perceptions about working in isolation from colleagues. International Review of Research in Open and Distance Learning, $\quad 7(2)$. Retrieved from http://www.irrodl.org/index.php/irrodl/article/view/295/640

Fukuyama, F. (1995). Trust: The social virtues and the creation of prosperity (1st ed.). New York: Free Press.

Gaillard-Kenney, S. (2006). Adjunct faculty in distance education: What program managers should know. Distance Learning, 3(1). Retrieved from ProQuest Education Journals database. 
Golden, T. D. (2006). The role of relationships in understanding telecommuter satisfaction. Journal of Organizational Behavior, 7(2). Retrieved from http://www.irrodl.org/index.php/irrodl/rt/metadata/299/639

Gordon, M. (2003). Part-time faculty in community colleges: The jury is still out. Retrieved from ERIC Document Reproduction Service, No. ED472020.

Helms, M. M., \& Raiszadeh, F. M. E. (2002). Virtual offices: Understanding and managing what you cannot see. Work Study, 51(5). Retrieved from Ingenta Connect database.

Levinson, D. L., (2005). What do adjunct faculty want? Community College Week 18(5). Retrieved from EBSCOhost database.

Ludlow, J. (1998). Priorities and power: Adjuncts in the academy. Thought \& Action, 2. Retrieved from http://www.nea.org/home/33216.htm

Marshall, G. W., Michaels, C. E., \& Mulki, J. P. (2007). Workplace isolation: Exploring the construct and its measurement. Psychology \& Marketing, 24(3). Retrieved from InterScience Wiley database.

McGuire, J. (1993). Part time faculty: Partners in excellence. Leadership Abstracts, 6(6). Retrieved from ERIC Document Reproduction Service, No. ED367429

Merriman, K. K., Schmidt, S. M., \& Dunlap-Hinkler, D. (2007). Profiling virtual employees: The impact of managing virtually. Journal of Leadership \& Organizational Studies, 14(1). Retrieved from Sage Journals Online database.

Morgan, S. J., \& Symon, G. (2002). Computer-mediated communication and remote management: Integration or isolation? Social Science Computer Review, 20(3). Retrieved from Sage Journals Online database.

Morse, J. M. (2000). Determining sample size. Qualitative Health Research, 10(3). Retrieved from Sage Journals Online database.

Nelson, B. (2002). Managing virtual employees. In Nelson motivation online store. Retrieved from http://nelson-motivation.stores.yahoo.net/maviem.html

Ng, C. F. (2006). Academics telecommuting in open and distance education universities: Issues, challenges, and opportunities. International Review of Research in Open and Distance Learning, $\quad 7(2)$. $\quad$ Retrieved from http://www.irrodl.org/index.php/irrodl/article/view/300/632

Putnam, R. D. (2000). Bowling alone: The collapse and revival of American community (1st ed.). New York: Simon \& Schuster. 
Roberts, C., Thomas, M., McFadden, A. T., \& Jacobs, J. (2006). Leading online learning through collaboration. Journal of Online Learning and Teaching, 2(3). Retrieved from http://jolt.merlot.org/vol2no3/roberts.htm

Schnitzer, M., \& Crosby, L. S. (2003). Recruitment and development of online adjunct instructors. Retrieved from http://www.westga.edu/ distance/ojdla/summer62/crosby_schnitzer62.html

Shellenbarger, S. (2008). Some companies rethink the telecommuting trend. The Wall Street Journal. Retrieved from http://online.wsj.com/article/SB120416669485798807.html

Thomson, B. S. (n.d.). Qualitative research: Grounded theory-sample size and validity. Retrieved from http://www.buseco.monash.edu.au/research/studentdoc s/mgt.pdf.

Unger, D. N. S. (1995). Academic apartheid: The predicament of part-time faculty. The NEA Higher Education-Thought and Action JOURNAL, 61. Retrieved from http://www2.nea.org/he/heta00/f00p61.pdf

Yu, C. \& Young, M. (2008). The virtual group identification process: A virtual educational community case. CyberPsychology \& Behavior, 11(1), 87-90. Retrieved from EBSCOhost database.

\section{Athabasca University $\mathbf{A}$}




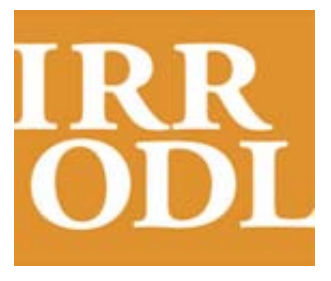

International

Review of

Research in Open

and Distance

Learning

Vol. 12.2

February - 2011

\section{A Pedagogical Framework for Mobile Learning: Categorizing Educational Applications of Mobile Technologies into Four Types}

\author{
Yeonjeong Park \\ Virginia Tech, USA
}

\begin{abstract}
Instructional designers and educators recognize the potential of mobile technologies as a learning tool for students and have incorporated them into the distance learning environment. However, little research has been done to categorize the numerous examples of mobile learning in the context of distance education, and few instructional design guidelines based on a solid theoretical framework for mobile learning exist. In this paper I compare mobile learning (m-learning) with electronic learning (e-learning) and ubiquitous learning (u-learning) and describe the technological attributes and pedagogical affordances of mobile learning presented in previous studies. I modify transactional distance (TD) theory and adopt it as a relevant theoretical framework for mobile learning in distance education. Furthermore, I attempt to position previous studies into four types of mobile learning: 1) high transactional distance socialized m-learning, 2) high transactional distance individualized m-learning, 3) low transactional distance socialized mlearning and 4) low transactional distance individualized m-learning. As a result, this paper can be used by instructional designers of open and distance learning to learn about the concepts of mobile learning and how mobile technologies can be incorporated into their teaching and learning more effectively.
\end{abstract}

Keywords: m-learning; e-learning; u-learning; transactional distance theory; cultural-historical activity theory; distance education; mobile technology 


\section{Introduction}

As mobile devices are becoming increasingly ubiquitous, many researchers and practitioners have incorporated the technology into their teaching and learning environments. As Keegan (2002) anticipated, "mobile learning is a harbinger of the future of learning” (p. 9). The applications of mobile learning range widely, from $\mathrm{K}-12$ to higher education and corporate learning settings, from formal and informal learning to classroom learning, distance learning, and field study. Despite the many forms of and increasing services offered by mobile learning, it is still immature in terms of its technological limitations and pedagogical considerations (Traxler, 2007). And although some researchers offer a framework for theorizing about mobile learning with conversation theory and activity theory (Sharples, Taylor, \& Vavoula, 2005; Uden, 2007; Zurita \& Nussbaum, 2007), instructional designers and teachers need a solid theoretical foundation for mobile learning in the context of distance education and more guidance about how to utilize emerging mobile technologies and integrate them into their teaching more effectively.

The main purpose of this study is to provide a better understanding of the characteristics of mobile learning in the context of distance education, and this is achieved by reaching three smaller goals. First, I compare mobile learning with electronic learning and ubiquitous learning. Based on this understanding of the past and current evolution of mobile learning, I describe its technological attributes and pedagogical affordances. Second, I adopt Moore's transactional distance (TD) theory and modify it by adding another dimension: two distinctive forms of distance learning that I label individualized and socialized. This establishes a total of four types of mobile learning. Third, I classify previous studies done on this topic according to the four types of mobile learning. Finally, I conclude that instructional designers and individual learners will continue to incorporate mobile technologies into their teaching and learning effectively and will pursue their educational purposes in the pedagogical framework of mobile learning.

\section{Mobile Learning}

\section{The Evolution of Mobile Learning}

Mobile learning refers to the use of mobile or wireless devices for the purpose of learning while on the move. Typical examples of the devices used for mobile learning include cell phones, smartphones, palmtops, and handheld computers; tablet PCs, laptops, and personal media players can also fall within this scope (Kukulska-Hulme \& Traxler, 2005). The first generation of truly portable information has been integrated with many functions in small, portable electronic devices (Peters, 2007). Recent innovations in program applications and social software using Web 2.0 technologies (e.g., blogs, wikis, Twitter, YouTube) or social networking sites (such as Facebook and MySpace) have made mobile devices more dynamic and pervasive and also promise more educational potential.

However, it has been widely recognized that mobile learning is not just about the use of portable devices but also about learning across contexts (Walker, 2006). Winter (2006) reconceptualized 
the nature of mobile learning and addressed "mediated learning through mobile technology" (p. 9). Pea and Maldonado (2006) used the term wireless interactive learning devices or WILD, an acronym created at SRI International's Center for Technology in Learning, to define technology that made it possible for learners to work at unique activities in ways that were previously impossible.

Peters (2007) viewed mobile learning as a useful component of the flexible learning model. In 2003, Brown summarized several definitions and terms and identified mobile learning as "an extension of e-learning” (Brown, 2005, p. 299). Peters (2007) also stated that it was a subset of elearning, a step toward making the educational process "just in time, just enough and just for me" (Peters, 2007, p. 15). Finally, Pea and Maldonado (2006) stated that mobile learning incorporates “transformative innovations for learning futures” (p. 437).

\section{The Evolution to Ubiquitous Learning}

As Weiser (1991) stated, "the most profound technologies are those that disappear" (p. 94). He was the first scholar to define ubiquitous computing as an environment where the computer is integral but embedded into the background of daily life. Applying this concept to the education field, ubiquitous learning (u-learning) involves learning in an environment where "all students have access to a variety of digital devices and services, including computers connected to the Internet and mobile computing devices, whenever and wherever they need them" (van’t Hooft, Swan, Cook, \& Lin, 2007, p. 6).

In the education field, "ubiquitous computing allows us to envision a classroom in which the teacher remains focused on his or her field of expertise (e.g., math or social studies) while still utilizing technology to enhance student learning” (Crowe, 2007, p. 129). Although technological tools used for ubiquitous learning can be numerous, Crowe (2007) identified handheld computers as a key component of ubiquitous learning. Many researchers whose investigations involve handheld and mobile devices are referring to their research as ubiquitous learning (Roschelle \& Pea, 2002). As the similar terms "pervasive computing” or “context-aware computing” (Moran \& Dourish, 2001) emphasize,

smaller and lighter laptops free us from the confines of the single desk . . . the distinction between communication and computation is blurring . . . on a different scale, wall-sized displays allow us to get and interact with information in an inherently social manner.” (p. 87)

Figure 1 illustrates these conceptual shifts from e-learning to m-learning then to u-learning. 


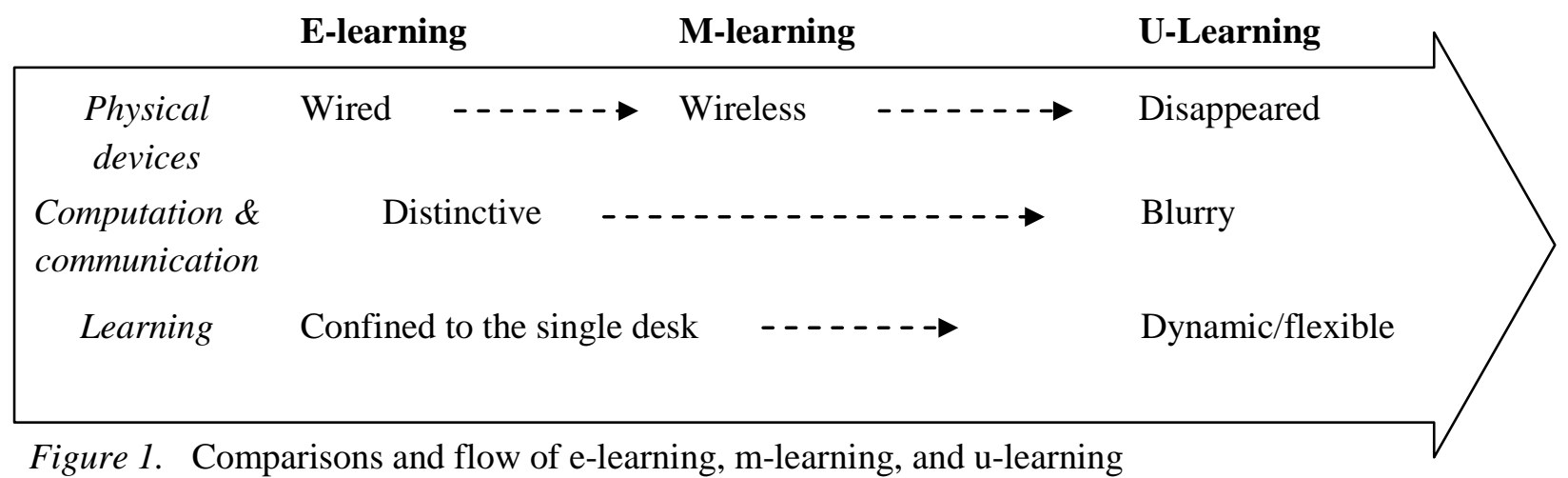

\section{Technological Attributes and Pedagogical Affordances}

Mobile learning has unique technological attributes which provide positive pedagogical affordances. Pea and Maldonado (2006) summarized seven features of handheld device use within schools and beyond: "portability, small screen size, computing power (immediate startingup), diverse communication networks, a broad range of applications, data synchronization across computers, and stylus input device” (p. 428). As Klopfer and Squire (2008) summarized, "portability, social interactivity, context, and individuality" (p. 95) are frequently cited affordances of mobile learning. Specifically, portability is the most distinctive feature which distinguishes handheld devices from other emerging technologies, and this factor makes other technological attributes such as individuality and interactivity possible.

Above all, this mobility enables ubiquitous learning in formal and informal settings by decreasing "the dependence on fixed locations for work and study, and consequently change the way we work and learn” (Peters, 2007). Gay, Rieger, and Bennington (2002) developed the "mobility hierarchy," including four levels of objectives that encourage the use of mobile computers in education settings. This hierarchy presents the contrasting attributes of mobile devices (see Figure 2). The focus of "productivity" (level 1) is content-intensive, whereas the focus of collaboration and communication (level 4) is communication-intensive. Level 1 aims at individual learning, and level 4 aims at collaborative learning by multiple users. Levels 2 and 3 fall into the "middle-range applications, such as personal tour guides, computer-aided instruction, database activity, mobile libraries, and electronic mail” (pp. 512-513).

As this hierarchy indicates, mobile technology has two comparable attributes. Scheduling and calendar applications are useful to increase an individual's organizational skills and selfregulative (or self-directed) learning ability; whereas, real-time chat and data sharing applications support communication, collaboration, and knowledge construction. This shows that students can consume and create information both “collectively and individually” (Koole, 2009, p. 26). 


\begin{tabular}{|c|c|c|c|c|}
\hline \multicolumn{2}{|c|}{ Mobility Hierarchy } & Sample Applications & & $\begin{array}{c}\text { Technological } \\
\text { Affordances }\end{array}$ \\
\hline $\begin{array}{c}\text { Level } \\
4\end{array}$ & $\begin{array}{l}\text { Communication \& } \\
\text { Collaboration }\end{array}$ & $\begin{array}{l}\text { - Real-time chat } \\
\text { - Annotations } \\
\text { - SMS (Simple Message System) } \\
\text { - Wireless email }\end{array}$ & $\begin{array}{r}-1 \\
1 \\
1 \\
1\end{array}$ & $\begin{array}{l}\text { Communication } \\
\text { intensive } \\
\text { Group work }\end{array}$ \\
\hline $\begin{array}{c}\text { Level } \\
3\end{array}$ & $\begin{array}{l}\text { Capturing \& } \\
\text { Integrating Data }\end{array}$ & $\begin{array}{ll}1 & \text { Network database } \\
1 & \text { - Data collection/synthesis } \\
1 & \text { - Mobile library } \\
1 & \end{array}$ & $\begin{array}{l}1 \\
1 \\
1 \\
1 \\
1 \\
1\end{array}$ & Synchronous \\
\hline $\begin{array}{c}\text { Level } \\
2\end{array}$ & $\begin{array}{l}\text { Flexible Physical } \\
\text { Access }\end{array}$ & $\begin{array}{l}\text { - Local database } \\
\text { - Interactive prompting } \\
\text { - Just-in-time Instruction }\end{array}$ & $\begin{array}{l}1 \\
1 \\
1\end{array}$ & $\begin{array}{c}\downarrow \\
\text { Asynchronous }\end{array}$ \\
\hline $\begin{array}{c}\text { Level } \\
1\end{array}$ & Productivity & $\begin{array}{ll}\text { - Calendars } \\
\text { - Schedule } \\
\text { - Contact Information } \\
\text { - Grading }\end{array}$ & $\begin{array}{l}1 \\
1 \\
1 \\
1 \\
\text { i }\end{array}$ & $\begin{array}{l}\text { Individual work } \\
\text { Content } \\
\text { intensive }\end{array}$ \\
\hline
\end{tabular}

Figure 2. Mobility hierarchy, sample applications, and technological affordances. Note: Adopted from Gay, Rieger, and Bennington (2002).

Another unique attribute that mobile technology has is its ability to support effective face-to-face communication when students use the devices in the classroom. In contrast to using a desktop computer with several students, with mobile devices students do not need to crowd around one computer (Crowe, 2007; Pea \& Maldonado, 2006; Roschelle \& Pea, 2002). In many empirical research studies and pilot tests, participants owned the handheld devices (even though it was temporary), and such ownership involved them more in the learning process. Above all, researchers and practitioners alike have pointed out the advantages of the lower cost of these devices (Crowe, 2007; Pea \& Maldonado, 2006; Roschelle \& Pea, 2002; Shin, Norris, \& Soloway, 2007).

\section{Limitations and Considerations}

Every technology has some limitations and weaknesses, and mobile devices are no exception. They have shown some usability problems. Kukulska-Hulme (2007) summarized these problems as follows:

1) physical attributes of mobile devices, such as small screen size, heavy weight, inadequate memory, and short battery life; (2) content and software application limitations, including a lack of built-in functions, the difficulty of adding applications, challenges in learning how to work with a mobile device, and differences between applications and circumstances of use; (3) network speed and reliability; and (4) physical environment issues such as problems with using the device outdoors, 
excessive screen brightness, concerns about personal security, possible radiation exposure from devices using radio frequencies, the need for rain covers in rainy or humid conditions, and so on.

It is important to consider these issues when using mobile devices and designing the learning environment.

However, looking at how rapidly new mobile products are improving, with advanced functions and numerous applications and accessories available these days, the technical limitations of mobile devices may be a temporary concern. Also, the use of mobile technologies in education is moving from small-scale and short-term trials or pilots into sustained and blended development projects (Traxler, 2007).

The most serious issue faced by mobile learning is the lack of a solid theoretical framework which can guide effective instructional design and evaluate the quality of programs that rely significantly on mobile technologies. As Traxler (2007) pointed out, evaluation of mobile learning is problematic because of its "noise" characteristic with "personal, contextual, and situated" attributes (p. 10). Several attempts to conceptualize mobile learning have been made since the emergence of mobile and wireless technologies. Traxler (2007) provided six categories by reviewing existing trials and pilot case studies in the public domain: 1) technology-driven mobile learning, 2) miniature but portable e-learning, 3) connected classroom learning, 4) informal, personalized, situated mobile learning, 5) mobile training/performance support, and 6) remote/rural/development mobile learning.

Koole (2009) developed a framework for the rational analysis of mobile education (FRAME) model which presents three aspects of mobile learning: the device, the learner, and the social environment. This model also highlights the intersections of each aspect (device usability, social technology, and interaction learning) and the primary intersection of the three aspects (mobile learning process) in a Venn diagram. What makes this FRAME model useful are the criteria and examples of each aspect and interaction and the checklist that might help educators plan and design mobile learning environments.

The definitions, technological attributes, and existing frameworks of mobile learning introduced above can help readers gain an understanding of mobile learning and how it is relevant to the future of teaching and learning with mobile technologies. However, previous studies and efforts suffer from the lack of a pedagogical framework. A number of the applications of mobile technologies in learning have shown a few links to established pedagogical theory. There is a need for the many different directions and unique applications to be logically categorized within the context of distance education. In order to better understand the current status of mobile learning and come up with comprehensive design guidelines for its future use, it is necessary to categorize educational applications with mobile technologies and position them in a logical framework. The transactional distance theory provides a useful framework based on sound 
theoretical and pedagogical foundations that can define the role of mobile learning in the context of distance education.

\section{Transactional Distance Theory}

Transactional distance theory is an educational theory that defines the critical concepts of distance learning. It presents a definition of distance education which implies the separation of teachers and learners (Moore, 2007). Since its first appearance in publications (Moore, 1972, 1973), this theory has influenced numerous researchers and practices. Many scholars praise it as a classical and all-encompassing theory of distance learning (Gokool-Ramdoo, 2008; Saba, 2005) and view it as a major contribution to the field of distance education.

Transactional distance theory is defined by the fact that distance is considered not only as geographic separation but also (and more importantly) as a pedagogical concept (Moore, 1997). As a result, the theory enables the inclusion of both types of education, that is, "a program in which the sole or principal form of communication is through technology" and where "technology-mediated communication is ancillary to the classroom" (Moore 2007, p. 91). This is especially important for mobile learning because mobile devices sometimes enter the school setting (Tatar, Roschelle, Vabey, \& Pennuel, September, 2003) as an ancillary element but mostly they extend beyond the classroom to non-traditional, informal, and non-institutional settings. The inclusive nature of transactional distance theory and its applicability and flexibility illustrates its important contribution to the framework for mobile learning.

This theory was derived from the concept of "trans-action," which is considered by many scholars to be the most evolved level of inquiry, compared to self-action and inter-action (Dewey \& Bentley, 1946), and "the interplay among the environment, the individuals and the patterns of behaviors in a situation” (Boyd \& Apps, 1980, p. 5). Thus transactional distance is defined as the "interplay of teachers and learners in environments that have the special characteristics of their being spatially separate from one another” (Moore 2007, p. 91). In short, transactional distance is the extent of psychological separation between the learner and the instructor (Moore, 2007; Shearer, 2007).

The transactional distance is controlled and managed by three interrelated factors: (1) the program's structure; (2) the dialogue that the teacher and learners exchange; and (3) the learners' autonomy. Moore (2007) explained that these three factors were derived from the analysis of (1) curricula of the distance learning program; (2) communication between teachers and learners; and (3) the role of learners in deciding what, how, and how much to learn. Table 1 summarizes the three elements along with the unit of analysis, focus, related questions, constructs, and degrees or ranges. However, the most appealing component of Moore's transactional distance theory is the inverse relationship between structure and dialogue. That is, as structure increases, transactional distance increases. However, as dialogue increases, transactional distance decreases. This hypothesis has been verified in several studies (Saba, 1988; Saba \& Shearer, 1994). The theory becomes more complex by adding the third variable, learner autonomy, because it is unclear whether this represents the learner's personal autonomy or the autonomy associated with learning 
materials. However, the theory explains that as transactional distance increases, so does learner autonomy.

Moore (1997) illustrated four types based on the presence or absence of dialogue (D) and structure (S), ranging from $-\mathrm{D}-\mathrm{S},-\mathrm{D}+\mathrm{S}$, $+\mathrm{D}+\mathrm{S}$, to $+\mathrm{D}-\mathrm{S}$. Considering the combinations of variables that are relative and continuous rather than absolute or dichotomous, there could well be infinite types of learning and teaching. Further, for each type, learner autonomy can vary widely from complete autonomy (AAA) to no freedom (NNN), even though the right balance is necessary for successful results.

Table 1

The Three Elements of Original Transactional Distance Theory

\begin{tabular}{|c|c|c|c|}
\hline & Structure & Dialogue & Learner autonomy \\
\hline $\begin{array}{l}\text { Unit of } \\
\text { analysis }\end{array}$ & $\begin{array}{l}\text { Curricula of distance } \\
\text { learning program. }{ }^{1}\end{array}$ & $\begin{array}{l}\text { Communication between } \\
\text { instructor and learner. }{ }^{1}\end{array}$ & Learner's role. $^{1}$ \\
\hline Definition & $\begin{array}{l}\text { A measure of an } \\
\text { educational program’s } \\
\text { responsiveness to } \\
\text { learners' individual } \\
\text { needs or preferences. }{ }^{3}\end{array}$ & $\begin{array}{l}\text { Exchanges of words and other } \\
\text { symbols between instructor and } \\
\text { learner occurred after a course } \\
\text { is designed, for improved } \\
\text { understanding and knowledge } \\
\text { construction. } 1,3\end{array}$ & $\begin{array}{l}\text { Learners' degree of freedom } \\
\text { and self-management ability in } \\
\text { regard to determination of } \\
\text { learning goal, process, and } \\
\text { evaluation. }{ }^{1}\end{array}$ \\
\hline Focus & $\begin{array}{l}\text { Rigidity and flexibility } \\
\text { of structure. }{ }^{1}\end{array}$ & Extent and nature of dialogue. $^{1}$ & $\begin{array}{l}\text { Dimensions and ranges of } \\
\text { autonomy. }{ }^{1}\end{array}$ \\
\hline $\begin{array}{l}\text { Related } \\
\text { question }\end{array}$ & $\begin{array}{l}\text { How rigid or flexible is } \\
\text { the distance learning } \\
\text { program? }\end{array}$ & $\begin{array}{l}\text { How many types and what } \\
\text { quality of communication do } \\
\text { the instructor and students } \\
\text { generate? }\end{array}$ & $\begin{array}{l}\text { How much and what kind of } \\
\text { autonomy does the program } \\
\text { give to learners? }\end{array}$ \\
\hline Constructs & $\begin{array}{l}\text { Sequence, contents, } \\
\text { theme, objectives, } \\
\text { outcomes, teaching and } \\
\text { assessment strategy }^{2}\end{array}$ & $\begin{array}{l}\text { Direct, indirect, active, and } \\
\text { passive speech }^{3} \\
\text { Academic, collaborative, and } \\
\text { interpersonal interaction }^{5}\end{array}$ & $\begin{array}{l}\text { Goals, execution, and } \\
\text { evaluation }\end{array}$ \\
\hline \multirow[t]{2}{*}{$\begin{array}{l}\text { Degrees or } \\
\text { ranges }\end{array}$} & $\begin{array}{l}\text { Sequence: } \\
\text { from tightly controlled } \\
\text { to loosely controlled } \\
\text { Contents: } \\
\text { from predetermined to } \\
\text { postdetermined } \\
\text { Strategy: } \\
\text { from rigidly set to } \\
\text { flexibly changeable }\end{array}$ & $\begin{array}{l}\text { Quantity: } \\
\text { from frequent communication } \\
\text { to rare communication between } \\
\text { instructor and learner } \\
\text { Quality: } \\
\text { · from deep to superficial } \\
\text { interaction } \\
\text { - from factual (information } \\
\text { share) to reflective dialogue } \\
\text { (knowledge share) }^{6}\end{array}$ & \multirow[t]{2}{*}{$\begin{array}{l}\text { From AAA to NNN } \mathrm{N}^{1,2} \\
\text { AAA: full autonomy } \\
A A N \text { : autonomy in setting goals } \\
\text { and execution (external } \\
\text { certification program) } \\
\text { ANA: autonomy in setting goals } \\
\text { and evaluation } \\
\text { (programmed learning) } \\
\text { ANN: autonomy only in setting } \\
\text { goals (uncommon) } \\
N A A \text { : autonomy in execution }\end{array}$} \\
\hline & \multicolumn{2}{|c|}{ From high transactional distance to low transactional } & \\
\hline
\end{tabular}




\begin{tabular}{|c|c|c|c|}
\hline & Structure & Dialogue & Learner autonomy \\
\hline & \multicolumn{2}{|c|}{$\begin{array}{l}\text { distance }^{2} \text { (Examples) } \\
\text { - D-S: low dialogue and low structure (e.g., textbook) } \\
\text {-D+S or +S-D: low dialogue and high structure (e.g., } \\
\quad \text { radio program, programmed text) } \\
+\mathrm{D}+\mathrm{S} \text { or +D+S: high dialogue and high structure (e.g., } \\
\quad \text { correspondence, computer-assisted instruction) } \\
\text { +D-S: high dialogue and low structure (e.g., tutorial, } \\
\text { teleconference) }\end{array}$} & $\begin{array}{l}\text { and evaluation } \\
\text { (uncommon) } \\
\text { NNA: autonomy only in } \\
\text { evaluation (most rare) } \\
\text { NAN: autonomy only in } \\
\text { execution (the most } \\
\text { common situation) } \\
N N N \text { : no autonomy }\end{array}$ \\
\hline $\begin{array}{l}\text { Relation } \\
\text { with TD }\end{array}$ & $\begin{array}{l}\text { As structure increases, } \\
\text { transactional distance } \\
\text { increases. }{ }^{1}\end{array}$ & $\begin{array}{l}\text { As dialogue increases, } \\
\text { transactional distance } \\
\text { decreases. }^{1}\end{array}$ & $\begin{array}{l}\text { As transactional distance } \\
\text { increases, learner autonomy } \\
\text { increases. }{ }^{1}\end{array}$ \\
\hline
\end{tabular}

Notes: ${ }^{1}$ Moore (2007), ${ }^{2}$ Moore (1997), ${ }^{3}$ Saba and Shearer (1994), ${ }^{4}$ Shearer (2007), ${ }^{5}$ Jung (2001),

${ }^{6}$ Sahin (2008).

Another interesting aspect of this theory is the influence of communication media on transactional distance. Using Moore's examples (2007), a recorded television or radio program is considered to have a high degree of structure because the program would not be changed to meet individual learners' needs, resulting in relatively high transactional distance; whereas an audio or video teleconference between an instructor and a single student would involve a high degree of dialogue because the instructor can change the program's structure based on individual learners' responses, resulting in relatively low transactional distance. Considering the attributes of today's advanced mobile technologies that support both individualized application and networked communication, synchronous and asynchronous communication, and text-based communication and videoconferencing, the transactional distance is influenced not only by a single communication medium but also by diverse learning contexts, including multiple communication methods and channels.

Benson and Samarawickrema (2009) positioned those different e-learning contexts in a two-bytwo matrix of dialogue and structure and demonstrated the relative levels of dialogue, structure, and autonomy. They introduced several cases, including 1) on-campus, classroom-enhanced (-DS-A); 2) on-campus, blended (-D+S-A); 3) workplace-based, blended (+D-S+A); 4) on-campus, multiple campuses, wholly online $(+\mathrm{D}-\mathrm{S}+\mathrm{A})$; 5$)$ off-campus, transactional, wholly online $(+\mathrm{D}+\mathrm{S}-$ A); and 6) off-campus, transactional, partially online $(+\mathrm{D}+\mathrm{S}+\mathrm{A})$. Although the cases were derived from two university situations, the matrix presents the categorized types of current e-learning contexts. This study points out that "transactional distance is likely to be high for students who are less familiar with learning in Web 2.0 environments” (Benson \& Samarawickrema, 2009, p. 17). As a result, "teachers need to design for high levels of dialogue and structure surrounding the Web 2.0 environment in order to support students.” (p. 17). This study concludes that the understanding of transactional distance theory is still useful and important for analyzing and designing such diverse contexts of e-learning.

Kang and Gyorke (2008) also state that the recent developments of social software and communication technologies require a more "seamlessly synchronized" theory (p. 203). They 
compare transactional distance (TD) theory with cultural-historical activity theory (CHAT), which provides important insights about the social aspects of human activity. They point out that both theories identify "mediation" but each explains it differently. In TD theory, the physical device mediates communication to overcome the separation of teacher and student. In CHAT, artifacts including language, technology, tools, and signs mediate all of the social aspects of human activity. As a result, "in contrast to CHAT's view of communal individual, TD isolates learners from their multi-society contexts” (p. 212). This study concludes that the major variables in TD theory are "contradictory and complementary" (Kang \& Gyorke, 2008, p. 211). Such a perspective is consistent with previous critiques: the variables' tautology is such that "as understanding increases, misunderstanding decreases” (Gorsky \& Caspi, 2005, p. 8), but inconsistent use of terms and ambiguous relations among variables allow different people to interpret the theory differently (Garrison, 2000).

The majority of interpretations of and previous studies about transactional distance theory commonly indicate its usefulness in understanding distance learning and evaluate its usefulness as a pedagogical and philosophical framework. However, several issues raised from previous studies include 1) problems with terminology, 2) divergent views about relations between variables, and 3) an inability to explain the individual's social characteristics; thus several researchers have addressed the need for a more refined theory that addresses these issues.

\section{A Pedagogical Framework of Mobile Learning}

In this paper I do not propose a newer version of the theory but attempt to adapt it in order to review a variety of educational applications of mobile technologies and categorize them into several types to gain a better understanding of current mobile learning. While this paper follows the original concepts, I wish to make my own perspective of this theory clear and consistent.

Many researchers have interpreted TD theory in different ways and the various interpretations and operational definitions have influenced its evolution. Garrison (2000) pointed out earlier that "understanding transactional distance very much depends upon whether we are discussing a twoby-two matrix, a single continuum, or distinct clusters” (p. 9). For this paper, I choose to regard transactional distance as a single continuum from high transactional distance to low transactional distance because viewing it as a two-by-two matrix or distinct clusters makes the model more confusing due to the complex interrelations of variables. Three variables (structure, dialogue, and autonomy) control transactional distance (Moore, 1997, 2007), but as other scholars (Garrison, 2000; Gorsky \& Caspi, 2005; Saba \& Shearer, 1994) have pointed out, the interrelationships are inverse or orthogonal between structure and dialogue and overlapping or hierarchical between structure and autonomy (Gorsky \& Caspi, 2005).

Such viewpoints about variable interrelationships in TD theory might be valid. However, in this case complex variables and their relationships with each other determine transactional distance. What we need to determine is how to define transactional distance as a single continuum. For the purpose of this paper, I adhere to the original and official definition of the theory: "a 
psychological and communications space to be crossed, a space of potential misunderstanding between the inputs of instructor and those of the learner” (Moore, 1997, p. 22).

Nevertheless, when the transactional distance is defined as a psychological gap between instructor and learner, it still contradicts definitions of structure and dialogue. Due to the recent developments of emerging communication technologies, structures of learning are built not only by the instructor or instructional designer but also by collective learners; and dialogue is also formed not only between the instructor and learners, but also among the learners themselves. Working in wikis is an example of how learners build structure through dialogue (Benson \& Samarawickrema, 2009). Regarding dual types of dialogue, Moore (1997) already mentioned that a new form of dialogue called "inter-learner dialogue" can make knowledge creation possible for distance learners. Structure and dialogue, previously defined as being under the instructor's control, have evolved into something that learners can also form. Because of this, every definition regarding transactional distance must now include the interaction among learners, which contradicts the original definition of transactional distance as a communicational gap between instructor and learner. To resolve this contradiction, it is necessary to define the dialogue and structure that influence transactional distance as only the interactions that take place between the instructor and learners and to exclude the interactions among learners. Any kind of dialogue and structure built by learners alone should be discussed in a different dimension. Such a dimension is discussed below.

This new dimension connotes "individual versus collective (or social)" activities by considering the importance of the social aspects of learning as well as newer forms of social technologies. This idea was formed by the influence of cultural-historical activity theory that Kang and Gyorke (2008) compared with transactional distance theory. However, I move beyond comparing each theory and synthesize them to understand some phenomena more effectively. A number of researchers (Frohberg, Goth, \& Schwabe, 2009; Sharples, Taylor, \& Vavoula, 2007; Taylor, Sharples, O'Malley, Vavoula, \& Waycott, 2006; Uden, 2007; Zurita \& Nussbaum, 2007) have utilized activity theory as a theoretical framework for mobile learning.

Some researchers recognize activity theory as a powerful framework for designing constructivist learning environments and student-centered learning environments (Jonassen, 2000; Jonassen \& Rohrer-Murphy, 1999). However, certain limitations and unsolved problems in activity theory have been raised. Barab, Evans, and Baek (1996) pointed out that "life tends not to compartmentalize itself or act in ways that are always wholly consistent with our theoretical assumptions” (p. 209). They suggested researchers move from isolated to complementary theoretical perspectives. Although I do not describe the details of activity theory in this paper (Engeström, 1987; Leont'ev, 1978; Vygotsky, 1978), I do use several elements of it to modify transactional distance theory, adding a dimension and creating a pedagogical framework for mobile learning that is illustrated in Figure 3. 


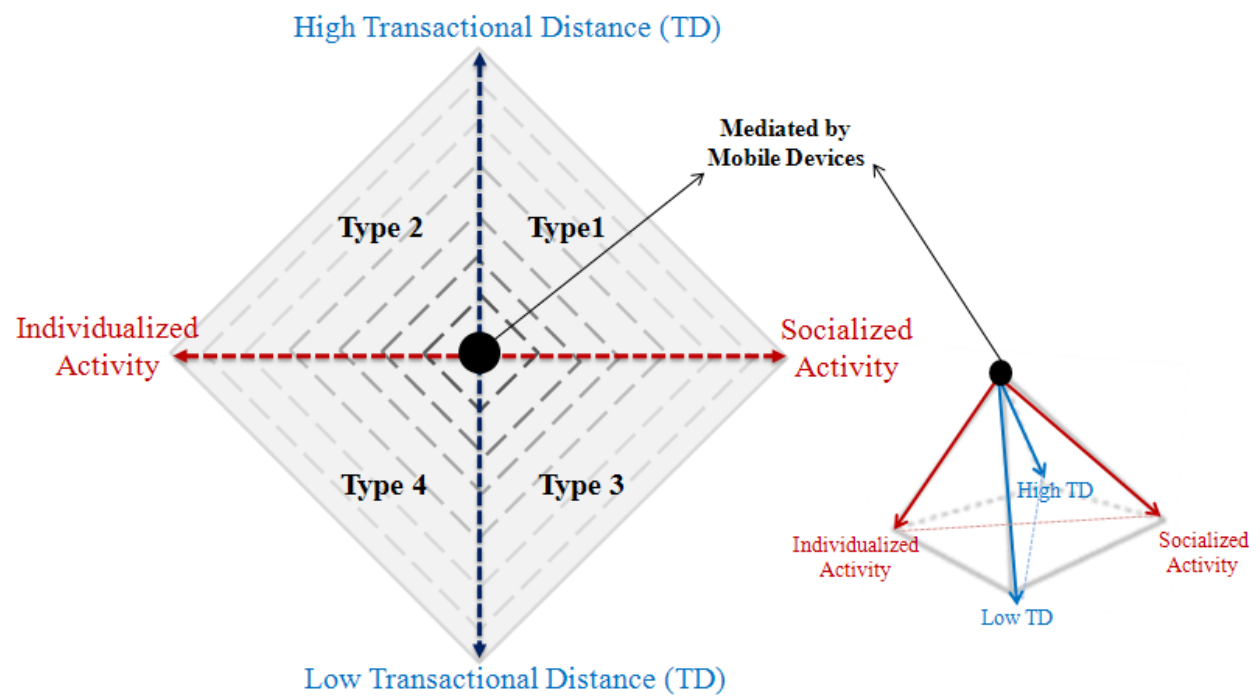

Figure 3. Four types of mobile learning: A pedagogical framework.

First, activity is conceived as a unit of analysis. Since transactional distance theory considers a course or program to include several lessons (Moore, 2007), this made it difficult to decide the transactional distance for the course as a whole. For example, the presentation of information is likely highly structured, while questions for discussion require high dialogue process, but both of these activities are typically course components. As a result, a course including several activities with different degrees of transactional distance cannot simply be categorized as either high or low transactional distance. Thus, by confining the unit of analysis to "activity," it is easier to determine to what extent transactional distance can exist because the activity is a "minimal meaningful context for individual actions” (Kuutti, 1996, p. 26).

Second, individualized and socialized activities are mediated by communication technology which is one kind of cultural-historical artifact in activity theory. As Kang and Gyorke (2008) point out, both transactional distance theory and activity theory consider mediation to be important. Thus, with "mediation" at the center of the framework, individualized activity at one extreme indicates a form where a learner is isolated from communicating with other students, and socialized activity at the other extreme indicates a form where students work together, share their ideas, and construct knowledge. At the same time, activities are mediated by the rule which can be either highly structured with fewer dialogic negotiations (high transactional distance) or loosely structured with more free dialogic negotiations (low transactional distance). As mentioned above, mobile learning is "mediated learning by mobile technologies" (Winters, 2006) and the mobile technologies uniquely support students' learning both collectively and individually (Koole, 2009). In placing high or low transactional distance on the $y$ axis and individualized or socialized activity on the $x$ axis, the framework generates four types of mobile learning activities.

Third, the dualism of individual versus collective (or social) is a dichotomy, but it is also something to be connected and balanced. Activity theory has attempted to transcend the issue of dualism in such pairs as individual-society, subjectivity-objectivity, agency-structure, psychological-social (Roth \& Lee, 2007; Watson \& Coulter, 2008). However, according to 
Garrison (2001), Leont'ev's activity theory (1978) drew close to Dewey's theory of transactional coordination, but Dewey pushed his functionalism beyond describing “inter-actions” to a theory of "trans-actions." There are similarities and differences between the approach of activity theory and the approach of transactional distance theory derived from Dewey's work. Activity theory is an analytic framework for understanding an individual's (subject) actions on learning material (objects) mediated through artifacts, interacting with a community, moderated by a set of rules, and distributed by a division of labor (Engeström, 1991). It forms a part of the basis for transactional distance theory, which is a framework for understanding the relations of key variables (structure, dialogue, and autonomy) in the context of distance learning. Although a number of important concepts from activity theory are simplified in Figure 3, a dimension indicating the range of individualized to socialized activity can be a useful lens for reviewing diverse mobile learning activities. Above all, the distinction between individual and socialized activity is a generally understood and accepted categorization; for example, Keegan (2002) stated that distance learning has two forms, individual and group learning.

\section{Educational Applications of Mobile Technologies}

The major purpose of this study is to review and classify a variety of educational applications with mobile technologies. For this purpose, a conceptual and pedagogical framework was generated based on high versus low transactional distance and individualized versus socialized activity. As shown in Figure 3, the four types of mobile learning generated in the context of distance education include (1) high transactional distance socialized m-learning, (2) high transactional distance individualized m-learning, (3) low transactional distance socialized mlearning, and (4) low transactional distance individualized m-learning.

\section{Type 1: High Transactional Distance and Socialized Mobile Learning Activity (HS)}

A mobile learning activity is classified as this type when 1) the learners have more psychological and communication space with their instructor or institutional support; 2) the learners are involved in group learning or projects where they communicate, negotiate, and collaborate with each other; 3) learning materials or the rules of activity are delivered from the predetermined program through mobile devices; and 4) transactions mainly occur among learners, and the instructor or teacher has minimal involvement in facilitating the group activity. This type might replace the traditional technology-mediated classroom group activity where students in a group or pair conduct given tasks or assignments.

NetCalc (Vahey, Roschelle, \& Tatar, 2007; Vahey, Tatar, \& Roschelle, 2004), for instance, is a handheld version of SimCalc, an application designed to help middle school students learn mathematics of change and variation. Three innovations were considered during the development of the SimCalc project, "restructuring the subject matter, grounding mathematical experience in students' existing understanding, and providing dynamic representations” (Vahey, et al., 2004, p. 554). NetCalc allowed students to play games in pairs and practice very specific mathematical 
concepts. For example, in the game Match-My-Graph "one student (the grapher) creates a function that is hidden from the other (the matcher). . . . The matcher makes and beams an initial guess of the function, and receives a verbal clue from the grapher” (Vahey, et al., 2004, p. 555). While this game involves learning the characteristics of position graphs and velocity graphs and how to translate between each kind, the mobile activity supported both "communication capabilities and representational infrastructures of handheld computers” (p. 553).

The MCSCL system (Cortez, Nussbaum, Santelices, Rodriguez, \& Zurita, 2004) is another example of this type. This system was developed to teach high school students in a physics classroom. It was designed and implemented for students in groups to answer a set of multiplechoice questions transmitted through mobile devices. In this activity, students have to debate how to answer the questions and must come to an agreement on the choices that the group selects. In this process, they modify their existing knowledge schemes and construct new knowledge by collaborating with other students. The teacher helps to set up and transmit the questions to students prior to the collaborative activity and collects the students’ work afterwards.

The Math MCSCL project (Zurita \& Nussbaum, 2007) utilizes activity theory as a conceptual framework; an activity was developed to enable Grade 2 students to practice addition, subtraction, and multiplication in a group. In this activity, students with a certain number of objects (such as bananas, apples, and oranges) on their mobile device have to reach the target quantity for each object by exchanging them with other students. Individual students keep track of the quantities of each object by performing arithmetic operations and search for other students who can exchange objects with them. They have to talk, negotiate, and collaborate to achieve the goal of the game.

The examples introduced above were selected as high transactional distance because these activities all require a highly structured program. Questions for activities or the rules of the game are determined prior to the activity. Although the content area in the above examples was science or mathematics, these activities nonetheless required and aimed to build social interaction, negotiation, and collaboration skills among group members. In developing this type of activity, instructors and instructional designers may need to give special attention and effort to 1) the design of the mobile application and 2) the setup of social interaction, such as defining the rules of the game and the roles of players. Considerations on both the computational (software) aspect and the functionality (hardware) aspect of mobile devices might be critical to successful implementation of the activity.

\section{Type 2: High Transactional Distance and Individualized Mobile Learning Activity (HI)}

Mobile learning activities are classified as type 2 when 1) the individual learners have more psychological and communication space with the instructor or instructional support; 2) the individual learners receive tightly structured and well organized content and resources (e.g., recorded lectures, readings) through mobile devices; 3 ) the individual learners receive the content and control their learning process in order to master it; and 4) the interactions mainly occur 
between the individual learner and the content. This type demonstrates an extension of e-learning which allows greater flexibility and portability. Individual learners fit this flexible learning into their mobile lifestyle. This type is mostly influenced by the context regarding when and where to learn. It also includes mobile learning that makes access to the educational system possible for students in rural areas.

The off-campus postgraduate development program of the Australian National University (Beckmann, 2010), is an example of this type, implemented both online and on mobile modes of distance learning. For the MAAPD (Master of Applied Anthropology and Participatory Development) program, students who are enrolled in distance learning are offered downloadable resources (e.g., readings, audio or video lectures, presentation slideshows, etc.) and opportunities to interact with others in online discussion. The major role of lecturers is to establish the online discussion and upload podcasts and vodcasts to the learning management system (LMS). Authoring tools such as Camtasia studio or Wimba Create were utilized to build these media-rich resources. Although learning activities and tasks based on a constructivist perspective were implemented and demonstrated, comments on this project describe the benefits of mobility. The responses of participants included these statements: "the ability to download lectures onto my iPod while I was travelling was really useful” (p. 166), and "I downloaded lectures (audio version) . . . played them over my stereo via my laptop while I cooked dinner at home . . this was invaluable as I had a very demanding job” (Beckmann, 2010, p. 169). This feedback shows that mobile devices are utilized to make it possible for individual workers with busy schedules to learn at their preferred places and times.

Mobile learning for students in remote sites or underserved areas is another typical example of this type. Vyas, Albright, Walker, Zachariah, and Lee (2010) applied mobile technology to clinical training at remote secondary hospital sites in India. Synergy was achieved with the use of the TUSK knowledge database through the partnership of the Christian Medical College (CMC) in India and Tufts University School of Medicine in the US. This is a mobile learning system that is part of campus-based e-learning supports in CMC. It is designed to enable students to access a knowledge repository through their own mobile phones and to fulfill their learning needs using other mobile applications.

As another example, Kim (2009) shared action research to design a mobile learning project for underserved migrant indigenous children in Latin America. In this project, mobile learning was utilized to develop the literacy of migrant children who live in villages far away from the centers of towns, where a formal education is not easily accessible. Through early prototypes of mobile devices, an Alfabeto lesson is delivered to children. The lesson displays alphabet letters and sample words starting with each letter, delivers a voice recording of letters and words, and provides short stories with sequenced animations and corresponding texts. This project shows how the portability and multimedia features of mobile technology as well as its low cost can help disadvantaged populations, including illiterate children and their families who live far away from public services such as education or health care. 
Mobile assisted language learning (MALL) is a notable example of type 2. MALL is distinguished from computer assisted language learning (CALL) because it focuses on the "continuity or spontaneity of access and interaction across different contexts of use” (KukulskaHulme, 2009, p. 162). As an example of such a function of “context-awareness” Chen and Li (2010) applied a wireless positioning technique to a program for teaching English vocabulary. Individual learners discover and learn new vocabulary by logging in to a personalized contextaware ubiquitous learning system (PCULS). The system retrieves learners' personal portfolios, including their leisure time and English level, automatically senses their location, and appropriate vocabulary material is suggested from the database based on the learner's portfolio and location context. In spite of technical problems (e.g., access difficulties), there is a relatively high success rate in detecting the learner's location and facilitating enhanced learning performance. Learner satisfaction in the experiment holds promise for a future seamless ubiquitous English learning environment.

Although it was not possible to find a case in the scholarly literature in which the learners simply accessed open resources (e.g., YouTube) or online tutorials through mobile devices, such a case could also fall into this type because individual learners engage in self-directed learning as they search for information and gain knowledge without the intervention of a teacher or instructor. The examples introduced above represent relatively high TD because the instructor or teacher played a minimal role in helping individual learners take control of the learning process. Individual learners in this type decided where and when to learn and personalized their learning environments. In developing this type of mobile learning activity, instructional designers or institutional distance learning support staff should pay special attention to the creation and management of a knowledge database, including well-organized learning materials such as lecture (audio or video) files, reading materials, and vocabulary databases. The most important considerations might be accessibility and technical connection problems. The studies introduced above commonly indicated such technical issues caused by different learner environments.

\section{Type 3: Low Transactional Distance and Socialized Mobile Learning Activity (LS)}

In this type, individual learners interact both with the instructor and other learners as they use mobile devices. They have 1) less psychological and communication space with the instructor; and 2) loosely structured instruction; but (3) work together in a group as they solve the given problem and try to achieve a common goal; and (4) engage in social interaction, negotiation, and frequent communication naturally. This type demonstrates the most advanced forms in terms of the versatility of mobile devices and learners' social interactions.

Klopfer, Squire, and Jenkins (2002) developed and Klopfer and Squire (2008) examined Environmental Detectives, a simulation platform designed as a game for mobile devices. Students play the role of environmental engineers and are given a scenario in which the spread of a toxin is simulated on a location-aware Pocket PC equipped with a GPS (geographical positioning system). The Pocket PC allowed students to investigate a toxic spill by collecting samples to test for chemicals in the groundwater and required them to respond to different 
variables programmed by the teacher. Many students indicated that these types of collaborative activities helped them evaluate diverse choices, motivated them, and transformed their perceptions of learning.

An audio-based learning forum project (Chang, 2010) enabled learners to participate in an asynchronous learning forum on mobile devices, which replaced the text-based discussion online forum. Since multimedia message services (MMS), an evolved form of short message services (SMS), can send not only text but also graphics, video, and audio clips, this project utilized audiobased input to post discussion articles in an audio file format. Learners can download audio files recorded by their peer learners and listen while on the move. Although there are some disadvantages, such as background noise, the inability to search through a message, and difficulty in reviewing the recorded audio files, hands-free operation and the flexibility of learning are great advantages. In order to increase the participation in discussion and collaborative learning, a team game tournament (TGT) was integrated into this activity. Heterogeneous groups consisting of three members were initially formed then regrouped for the tournament based on their performance in the first round.

Relatively few studies of this type exist. A common characteristic in both examples is that concrete contents or a specific learning outcome are not defined prior to starting the activity. Also, mobile devices are utilized for multiple functions as an investigation tool, a communication tool, and a simulation and game tool. When developing this type of learning, instructional designers and instructors should promote active participation and allow students to have many social experiences. The most important consideration is to develop a meaningful collaborative task or a complex situation so that higher order thinking, negotiation, evaluation, reflection, debate, competition, and scaffolding can naturally occur.

\section{Type 4: Low Transactional Distance and Individualized Mobile Learning Activity (LI)}

This last type of mobile activity refers to 1) less psychological and communication space between instructor and learner and 2) loosely structured and undefined learning content. On this basis, 3) individual learners can interact directly with the instructor, and 4) the instructor leads and controls the learning in an effort to meet individual learners' needs while maintaining their independence. This type shows characteristics unique to mobile learning that support blended or hybrid learning.

A large blended classroom project in China (Shen, Wang, Gao, Novak, \& Tang, 2009; Wang, Shen, Novak, \& Pan, 2009) is a similar approach to type 2 as it pursues anytime, anywhere learning. However, this project aims to increase Chinese students' class interactivity using technical intervention. In the upper-level English class, a mobile phone broadcasting system, classroom management system, and a networking system are all established for distance learners not only to download course materials but also to connect with the class in real time, while the instructor provides lectures using a computer, a projector, whiteboards and other tools for instruction. Since this type of learning is a kind of large-scale lecture, frequent dialogue between 
instructor and students is difficult (that is why it is not categorized as type 2, high transactional distance). However, students can send messages and ask questions of the instructor using their mobile phones, and the instructor can respond to them with an oral explanation in real time. This function, enabled by mobile technology, supports a reduction of transactional distance.

Mobile butterfly-watching and bird-watching learning system (BWL) projects (Y.-S. Chen, Kao, \& Sheu, 2003; Y.-S. Chen, Kao, Yu, \& Sheu, 2004) support outdoor mobile learning activities. In these projects, mobile devices were used by independent learners to access a bird or butterfly knowledge database to match the butterfly or bird that they observe and photograph. In this system, mobile devices make field trips for science learning much simpler because learners do not need to carry a notebook for observation and can find the necessary information more easily and quickly. They take pictures with the digital camera that is built into the mobile device, store their notes in it, and send them to the server using a wireless internet connection. While the teacher encourages students to observe diverse objects and assigns questions to make sure they are learning, students engage mostly in self-directed and independent learning, and the mobile devices support the learning process through scaffolding.

Because a teacher mainly controls and leads the activities in this type, and learning contents and processes are structured as individual students reach the end of the activity and the class, these examples are considered low transactional distance. Also the flexibility and portability afforded by the mobile devices supports individualized learning. To prepare for this type of learning, instructional designers and teachers should pay attention to the student environment from a distance both in the classroom and on field trips and should provide appropriate supports as students ask questions and complete the given tasks or assignments.

\section{Conclusion}

In this paper I introduced a definition of mobile learning, outlined its characteristics, and compared it with e-learning. Despite the great potential mobile learning has and the innovative development of mobile technologies, a theoretical framework in which to review diverse mobile learning projects in the context of distance learning has been lacking. The framework for this analysis was adopted from transactional distance theory and modified by adding a new dimension to reflect the characteristics of mobile technologies that support both individual and social aspects of learning. Previous studies dealing with mobile learning were reviewed and categorized into four types based on transactional distance and individualized versus socialized learning.

The literature reviewed in this study was limited to a few examples from the rapidly growing body of research on mobile learning. Although a small number of case studies have been introduced here, there are several other exemplary projects which can be classified within the four types of mobile learning activities. I developed this classification scheme hoping to help instructional designers and instructors to design and implement mobile learning more effectively. Reviewing mobile projects within the framework of the four types also confirmed that mobile devices uniquely support seamless movement and switch (Looi et al., 2008; Vahey, et al., 2007) 
A Pedagogical Framework for Mobile Learning: Categorizing Educational Applications of Mobile Technologies into Four Types Park

between individualized (personalized) and socialized learning and between high transactional distance and low transactional distance. 


\section{References}

Barab, S. A., Evans, M. A., \& Baek, E.-O. (1996). Activity theory as a lens for characterizing the participatory unit. In D. H. Jonaassen (Ed.), Handbook of research for educational communication and technology (2nd ed., pp. 199-211). New York: Simon \& Schuster Macmillan.

Beckmann, E. A. (2010). Learners on the move: Mobile modalities in development studies. Distance Education, 31(2), 159-173.

Benson, R., \& Samarawickrema, G. (2009). Addressing the context of e-learnimg: using transactional distance theory to inform design. Distance Education, 30(1), 5-21.

Boyd, R. D., \& Apps, J. W. (1980). Redefining the discipline of adult education. San Francisco: Jessey-Bass.

Brown, T. H. (2005). Towards a model for m-learning in Africa. International Journal of ELearning, 4(3), 299-315.

Chang, C.-K. (2010). Acceptability of an asynchronous learning forum on mobile devices. Behaviour and Information Technology, 29(1), 23-33.

Chen, C.-M., \& Li, Y.-L. (2010). Personalised context-aware ubiquitous learning system for supporting effective English vocabulary learning. Interactive Learning Environments, 18(4), 341-364.

Chen, Y.-S., Kao, T.-C., \& Sheu, J.-P. (2003). A mobile learning system for scaffolding bird watching learning. Journal of Computer Assisted Learning, 19, 347-359.

Chen, Y.-S., Kao, T.-C., Yu, G.-J., \& Sheu, J.-P. (2004). A mobile butterfly-watching learning system for supporting independent learning. Paper presented at the The 2nd IEEE International Workshop on Wireless and Mobile Technologies in Education, JungLi,Taiwan.

Cortez, C., Nussbaum, M., Santelices, P., Rodriguez, P., \& Zurita, G. (2004). Teaching science with mobile computer supported collaborative learning (MCSCL). Paper presented at the The 2nd IEEE International Workshop on Wireless and Mobile Technologies in Education.

Crowe, A. R. (2007). Learning to teach with mobile technology: A teacher educator's journey. In M. van't Hooft \& K. Swan (Eds.), Ubiquitous computing in education (pp. 127-144). Mahwah, New Jersey: Lawrence Erlbaum Associates. 
Dewey, J., \& Bentley, A. F. (1946). Interaction and transaction. The Journal of Philosophy, 43(19), 505-517.

Engeström, Y. (1987). Learning by expanding. Helsinki: Orienta-Konsultit.

Engeström, Y. (1991). Activity theory and individual and social transformation. Multidisciplinary Newsletter for Activity Theory, 7(8), 14-15.

Frohberg, D., Goth, C., \& Schwabe, G. (2009). Mobile learning projects: a critical analysis of the state of the art. Journal of Computer Assisted Learning, 25, 307-331.

Garrison, R. (2000). Theoretical challenges for distance education in the 21st century: A shift from structural to transactional issues. International Review of Research in Open and Distance Learning, 1(1), 1-17.

Gay, G., Rieger, R., \& Bennington, T. (2002). Using mobile computing to enhance field study. In T. Koschmann, R. Hall \& N. Miyake (Eds.), CSCL2: Carrying forward the conversation (pp. 507-528). Mahwah, NJ: Lawrence Erlbaum Associates.

Gokool-Ramdoo, S. (2008). Beyond the theoretical impasse: Extending the applications of transactional distance theory. The International Review of Research in Open and Distance Learning, 9(3), 1-17.

Gorsky, P., \& Caspi, A. (2005). A critical analysis of transactional distance theory. The Quartely Review of Distance Education, 6(1), 1-11.

Jonassen, D. (2000). Revisiting activity theory as a framework for designing student-centered learning environments. In D. H. Jonassen \& S. M. Land (Eds.), Theoretical foundations of learning environments (pp. 89-121). Mahwah, NJ: Lawrence Erlbaum Associates, Publishers.

Jonassen, D., \& Rohrer-Murphy, L. (1999). Activity theory as a framework for designing constructivist learning environments. Educational Technology Research and Development, 47(1), 61-79.

Jung, I. (2001). Building a theoretical framework of web-based instruction in the context of distance education. British Journal of Educational Technology, 32(5), 535-534.

Kang, H., \& Gyorke, A. S. (2008). Rethinking distance learning activities: a comparison of transactional distance theory and activity theory. Open Learning, 23(3), 203-214.

Keegan, D. (2002). The future of learning: From eLearning to mLearning, ZIFF papiere 119. Retrieved from ERIC ED472435 database. Available from http://www.fernunihagen.de/ZIFF 
Kim, P. H. (2009). Action research approach on mobile learning design for the underserved. Educational Technology Research and Development, 57, 415-435.

Klopfer, E., Squire, J., \& Jenkins, H. (2002). Environmental detectives: PDAs as a window into a virtual simulated world. Paper presented at the IEEE international Workshop on Wireless and Mobile Technologies in Education (WMTE'02), Los Alamitos, CA.

Klopfer, E., \& Squire, K. (2008). Environmental Detectives: the development of an augmented reality platform for environmental simulations. Educational Technology Research and Development, 56(2), 203-228.

Koole, M. L. (2009). A model for framing mobile learning. In M. Ally (Ed.), Mobile learning: Transforming the delivery of education and training (pp. 25-47). Edmonton, AB: AU Press, Athabasca University.

Kukulska-Hulme, A. (2007). Mobile usability in educational context: What have we learnt? International Review of Research in Open and Distance Learning, 8(2), 1-16.

Kukulska-Hulme, A. (2009). Will mobile learning change language learning? ReCALL, 21(2), 157-165.

Kukulska-Hulme, A., \& Traxler, J. (2005). Mobile learning: A handbook for educators and trainers. London: Routledge.

Kuutti, K. (1996). Activity theory as a potential framework for human-computer interaction research. In B. A. Nardi (Ed.), Context and consciousness: Activity theory and humancomputer interaction (pp. 17-44). Cambridge, MA: The MIT Press.

Leont'ev, A. N. (1978). Activity, consciousness, and personality (M. J. Hall, Trans.). Englewood Cliffs, NJ: Prentice-Hall, Inc.

Looi, C.-K., Seow, P., Zhang, B., So, H.-J., Chen, W., \& Wong, L.-H. (2008). Leveraging mobile technology for sustainable seamless learning: a research agenda. British Journal of Educational Technology, 41(2), 154-169.

Moore, M. G. (1972). Learner autonomy: The second dimension of independent learning. Convergence, 5(2), 76-88.

Moore, M. G. (1973). Toward a theory of independent learning and teaching. The Journal of Higher Education, 44(9), 661-679. 
Moore, M. G. (1997). Theroy of transactional distance. In D. Keegan (Ed.), Theoretical principles of distance education (pp. 22-38). NY: Routlege Studies in Distance Education.

Moore, M. G. (2007). The theory of transactional distance. In M. G. Moore (Ed.), Handbook of distance education (pp. 89-105). Mahwah, NJ: Lawrence Erlbaum Associates.

Moran, T. P., \& Dourish, P. (2001). Introduction to this special issue on context aware computing. Human-Computer Interation, 16(2), 87-95.

Pea, R., \& Maldonado, H. (2006). WILD for learning: Interacting through new computing devices anytime, anywhere. In R. K. Sawyer (Ed.), The Cambridge handbook of the learning sciences (pp. 427-441). Cambridge: Cambridge University Press.

Peters, K. (2007). m-Learning: Positioning educators for a mobile, connected future. International Journal Of Research in Open and Distance Learning, 8(2), 1-17.

Roschelle, J., \& Pea, R. (2002). A walk on the WILD side: How wireless handheld may change computer-supported collaborative learning. International Journal of Cognition and Technology, 1(1), 145-168.

Roth, W.-M., \& Lee, Y.-J. (2007). "Vygotsky's Neglected Legacy": Cultural-historical activity theory. Review of Educational Research, 77(2), 186-232.

Saba, F. (1988). Integrated telecommunications systems and instructional transaction. The American Jounal of Distance Education, 2(3), 17-24.

Saba, F. (2005). Is distance educationl losing its identity? or what shoud we call or field these days? Paper presented at the 21st Annual Conference on Distance Teaching and Learning, University of Wisconsin-Madison.

Saba, F., \& Shearer, R. L. (1994). Verifying key theoreitcal concepts in a dynamic model of distance education. The American Jounal of Distance Education, 8(1), 36-59.

Sahin, S. (2008). The relationship between student characteristics including learning styles, and their perceptions and satisfaction in web-based courses in higher education. Turkish Online Journal of Distance Education, 9(1), 123-138.

Sharples, M., Taylor, J., \& Vavoula, G. (2005). Towards a theory of mobile learning. Retrieved from http://www.lsri.nottingham.ac.uk/msh/Papers/Theory\%20of\%20Mobile\%20Learning.pdf 
Sharples, M., Taylor, J., \& Vavoula, G. (2007). A theory of learning for the mobile age. In R. Andrews \& C. Haythornthwaite (Eds.), The Sage handbook of e-learning research (pp. 221-247). Sage: London.

Shearer, R. (2007). Instructional design and the technologies: An overview. In M. G. Moore (Ed.), Handbook of distance education (pp. 219-232). Mahwah, NJ: Lawrence Erlbaum Associates.

Shen, R., Wang, M., Gao, W., Novak, D., \& Tang, L. (2009). Mobile learning in a large blended computer science classroom: system function, pedagogies, and their impact on learning. IEEE Transactions on Education, 52(4), 538-546.

Shin, N., Norris, C., \& Soloway, E. (2007). Findings from early research on one-to-one handheld use in K-12 education. In M. van't Hooft \& K. Swan (Eds.), Ubiquitous computing in education (pp. 19-39). Mahwah, New Jersey: Lawrence Erlbaum Associates.

Tatar, D., Roschelle, J., Vabey, P., \& Pennuel, W. R. (September, 2003). Handhelds go to school: Lessons learned. The IEEE Computer Soceity, 30-37.

Taylor, J., Sharples, M., O'Malley, C., Vavoula, G., \& Waycott, J. (2006). Towards a task model for mobile learning: a dialectical approach. International Journal of Learning Technology, 2, 138-158.

Traxler, J. (2007). Defining, discussing, and evaluating mobile learning: The moving finger writes and having write... International Review of Research in Open and Distance Learning, 8(2), 1-12.

Uden, L. (2007). Activity theory for designing mobile learning. International Journal of Mobile Learning and Organization, 1(1), 81-102.

Vahey, P., Roschelle, J., \& Tatar, D. (2007). Using handhelds to link private cognition and public interaction. Educational Technology, 47(3), 13-16.

Vahey, P., Tatar, D., \& Roschelle, J. (2004). Leveraging handhels to increase student learning: Engaging middle school students with the mathematics of change. Proceedings of the Sixth International Conference of the Learning Sciences (pp. 553-560). Hilsdale NJ: Lawrence Erlbaum Associates.

van't Hooft, M., Swan, K., Cook, D., \& Lin, Y. (2007). What is ubiquitous computing? In M. van't Hooft \& K. Swan (Eds.), Ubiquitous computing in education. Mahwah, New Jersey: Lawrence Erlbaum Associates. 
Vyas, R., Albright, S., Walker, D., Zachariah, A., \& Lee, M. Y. (2010). Clinical training at remote sites using mobile technologies: An India-USA partnership. Distance Education, 31(2), 211-226.

Vygotsky, L. S. (1978). Mind in society: The development of higher psychological processes. London: Harvard University Press.

Walker, K. (2006). Introduction: Mapping the landscape of mobile learning. In M. Sharples (Ed.), Big issues in mobile learning: Report of a workshop by the kaleidoscope network of excellence mobile learning initiative. University of Nottingham.

Wang, M., Shen, R., Novak, D., \& Pan, X. (2009). The impact of mobile learning on students' learning behaviours and performance: Report from a large blended classroom. British Journal of Educational Technology, 40(4), 673-695.

Watson, R., \& Coulter, J. (2008). The debate over cognitivism. Theory, Culture, and Society, 25(2), 1-17.

Weiser, M. (1991). The computer for the 21st century. Scientific American, 265(3), 94-104.

Winters, N. (2006). What is mobile learning? In M. Sharples (Ed.), Big issues in mobile learning: Report of a workshop by the kaleidoscope network of excellence mobile learning initiative. University of Nottingham.

Zurita, G., \& Nussbaum, M. (2007). A conceptual framework based on activity theory for mobile CSCL. British Journal of Educational Technology, 38(2), 211-235.

\section{Athabasca University $\mathbf{a}$}




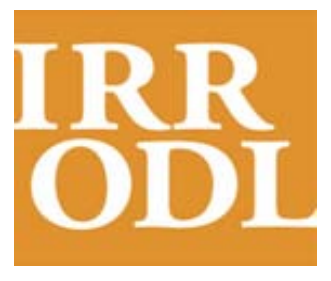

International

Review of

Research in Open

and Distance

Learning

Vol. 12.2

February - 2011

\section{Delimiting the Prospect of Openness: An Examination of Initial Student Approaches to E-Learning}

\author{
Christopher Naughton and Juliette Smeed \\ New Zealand Tertiary College
}

John Roder

University of Auckland

\begin{abstract}
When converting from a paper-based distance mode to an online mode of teaching, certain expectations arise that students may engage not only in the development of extended research activity but that the quality of discussion and thinking will change. With access to open-ended discussion within the online forum the opportunity is afforded to students to share ideas and in turn develop their shared knowledge, a facility denied to them when in the paper distance mode. However, in a recent study conducted in New Zealand, it was shown that despite having access to online forums students moving to an online platform refrained from participation in this social exchange. A possible explanation for this indifference was thought to be the students realising that the online exchange made no impact on their assessment. Hence, the collaborative rhetoric of Web 2.0 made little impact when the summative evaluation remained unchanged from previous paper-based assessment. This paper reports on the introduction of online learning at a private tertiary college in New Zealand and describes the response of students who found difficulty in reconciling a community of learners and openness within what was perceived as an evaluation that remained individualistic and competitive in nature.
\end{abstract}

Keywords: Online learning; strategic learner; dialogue; discussion forum; Web 2.0; affordance 


\section{Introduction}

This paper arose from a two-year longitudinal study of staff and students as they changed from a correspondence, paper-based course to an online provision. Prior to full implementation, two pilot studies were undertaken with sample groups of students who volunteered to complete their programme in the online environment. This paper reports on the second of the two studies undertaken in 2008-2009. The students were based in New Zealand and were all early childhood student teachers taking a six-month degree upgrade. The object of this study was to examine the student teachers' reactions to the new learning environment and their ability to make use of the discussion forum allocated to them for the duration of the course. Among many diverse findings, the student interviews revealed a significant number who appeared to be strategic in their approach to learning. The term strategic, in this paper, is similar to the term used by Marton and Säljö (1976), Entwhistle (1981), and Biggs (1993), for whom a strategic learner is seen as impersonal and working at a surface level. In this paper strategic learners are also characterised as looking for the most expedient way to complete coursework and showing deference to what was said or written by the college tutor and accepting whatever advice was said or written by the tutor; whereas learning that implies sharing, not being recognised as merely "getting the job done,” is regarded in this paper as the most important aspect of studying.

This strategic approach, where knowledge is seen as there to be appropriated or consumed, appears to have little in common with the current Web 2.0 concept of learning. The fundamental of Web 2.0 (see O’Reilley, 2009) is that knowledge is created and validated through shared dialogue (Dysthe, 2007). Learning in Web 2.0 is also seen as emergent as ideas are developed through acts of shared thinking (Lave \& Wenger, 1991). Shared ownership of learning in turn becomes the antithesis of the "strategic" worldview, wherein sharing is seen as non-productive and learning is regarded as the appropriation of knowledge as private property. Knowledge in this sense becomes a commodity, an entity which is static and unchanging, acquired through individual enterprise. Once gained, knowledge has to be protected and removed, so others don't gain access. This view of learning seems to typify aspects of the strategic learner in Biggs (1993), for whom knowledge remains impersonal and at a surface level. In relation to this study, the irony of the strategic approach was that the students whose daily work in early childhood education was characterised by sociocultural principles of learning, similar to those of Web 2.0, did not develop themselves in a similar manner while studying at their own level. Even though the opportunity was there for students to engage in a form of social learning in the discussion forum, a fundamental in Web 2.0, they chose not to engage and not to recognise the learning space, or discussion forum, as a potential community.

An attempt to bridge this divide between assessment and appointed tasks that are more open and democratic in nature has been proposed by Biggs and Tang (2007). The emphasis on the intended learning outcome is mitigated in their study by the inclusion of teaching learning activities that align with the assessment tasks. The concept is highlighted by providing students the freedom to select activities that are open in nature with the opportunity to reflect on the ideas presented in the coursework and a choice in how to develop an overall educational focus for activity rooted in practice. The students were, in the study reported on by Biggs and Tang (2007), asked for 
complete journals that could be read and discussed to see how, or if, they could provoke changes in practice. With increased response and better marks being achieved, this would indicate that the approach was a success. Named constructive alignment, this approach seemed to hold promise for online learners. Although the reconfiguration of a hierarchy still remained in assessing students' work, this approach seemed to go forward in aligning tasks and observing constructivism as a basis for learning at tertiary level. It was this openness in approach to learning and sharing ideas that was sought in the project being reported.

This paper begins with an acknowledgement of several leading figures in the world of Web 2.0, and outlines their thinking, in relation to the shifts in learning patterns brought about through the development of Web 2.0 technologies. The practice of refining attitudes towards learning is further considered before reference is made to the project environment under discussion. This project was titled the Web-Enhanced Digital Learning or WEDL project. The study had no preconceived idea as to the outcome, and the strategic learner was a discovery that was made through the grounded approach to the data gained through interviews and analysis of the discussion forums with staff and students.

\section{Learning in the Age of Web 2.0}

With access to the Internet becoming more freely available, new challenges have arisen for teachers and students (Roder \& Hunt, 2009). The ease with which information can be obtained and online dialogue engaged raises many questions as to how this influences teaching and learning. Can tertiary institutions continue to provide courses and teaching structures as they did prior to the advent of online learning, or must they adapt to the new learning environment? Instead of being primarily purveyors of knowledge, should institutions become places for the exchange of ideas as in Web 2.0 philosophy (Siemens, 2008)? With information so freely available, does open access learning, which includes discussion, need to offer more than information supplied in neat parcels such as study guides? Should knowledge and knowledge acquisition be reconceptualised in the new online learning environment?

Commentators have suggested that owing to Internet accessibility there have already been changes in the nature of our relationship to information and society (Castells, 2000: Fisher, Higgins, \& Loveless, 2006: Lankshear 2003: Roder \& Hunt, 2009: Siemens, 2008). The argument is made that there has arisen a shift away from controlled teaching to a greater sense of governance being exerted by the learner. This implies students making decisions over the content and their level of interaction with other learners no longer being confined by the classroom or the knowledge boundaries set up by the institution (Siemens, 2008). For some, the impact of the communications revolution implies that knowledge can no longer remain unquestioned. Knowledge is instead seen as in a state of flux (Kress \& Pachler, 2007), where ownership is produced through interaction between authors. Aldrich (2009) adds that online learning is an opportunity to "unschool" students and create a meaningful, wider sense of ownership. This wider ownership would allow students to develop a sense of shared knowledge to replace existing ideas of scholarship as fixed and immutable (LaPointe \& Gunawardena, 2004). The development, in other words, of a "Web 2.0 mindset" may be more important than being in possession of 
prescribed facts. This debate about information and learning, which can be traced back to Illich's notion of deschooling (Illich, 1971, 2000), implies students being critical, discursive, acquisitive, position taking, and open to new ideas (McWilliam, 2005). For students in a critical thinking community, the interactive experience becomes a recognised part of what Bauman describes as the unlearning process (Bauman, 1993). This broad definition of learning is seen to have a significant impact on students sharing ideas and gathering knowledge in a more informal context (Gulati, 2004). These characteristics of the learner as open, engaging, and willing to discuss and develop new thinking was the hope of the WEDL research team.

The five stages of initiating students into the online environment advocated by Salmon (2000) provide a support through which students can be initiated into the new environment. As the students grow in technical accomplishment and confidence in the use of online provision, together with support from the moderator, Salmon suggests that at stage five students can achieve wholehearted engagement, becoming fully responsible for their learning using their personal experience in developing their exploration of a topic or area being studied. It is at this point that Salmon suggests the moderator leave the discussion. However, despite Salmon's and others' models for learning online, the potential for radical change in the learning is often undermined by summative assessments, designed to meet learning outcomes rather than focus on the processual and discursive aspects of learning such as the discussion and development of ideas. The resulting prioritization of assessment reduces the scope of learning online. Openness challenges the institution and threatens the privileged status of the textbook or study guide. However it is the concern of the Web 2.0 educator to achieve learning with reference to potential learning outcomes (Davis \& Sumara, 2006). For Siemens, learning within a Web 2.0 environment is one that permits learning to become the "creation and navigation of networks" (Siemens, 2008, p. 8). Students who are able to self-regulate develop their learning in a fashion of their own making, which reflects their ability to manage networks that they have constructed. In this way the role of the online provider is one of extended teaching, embracing the network, and enabling connectionforming relationships (Driscoll, 2000; Downes, 2010). The role of the provider as a space for research is considerably advanced in this instance as an active connector to faculty becomes another aspect of networking. Structured modules such as study guides are not, therefore, to be removed, but less structured ways of working are provided, letting students take advantage of the new learning environment while still observing practical competence in any vocational field. Education is thus concerned with learning how to share information, and seeing oneself as a learner within a human endeavour of seeking change, in advancing the needs of ethical living (Lave \& Wenger, 1991). While these aspirations were held in relation to the ambition of Web 2.0 implementation, the project had less ambitious goals and was intended to open to the students an opportunity to work online with tools provided as in Web 2.0 platforms but without a specific grounding in Web 2.0 as a philosophy of learning.

\section{Background to the WEDL Research Project}

The students selected for the WEDL project were 21 early childhood student teachers who had completed a Diploma in Teaching at a private tertiary college prior to undertaking the six-month upgrade to a degree. The upgrade programme became the basis for this research project. The 
student teachers, who were all working in early childhood centres, ranged in age from early twenties to early sixties. The students came from all over New Zealand. Only a few had met any of the college staff on a face-to-face basis. Some had completed their diploma as class-based students, while most had completed their diploma in a paper-based distance-learning mode, and others had experienced a combination of both field (evening class-based) and distance learning.

The research method involved students and staff in a constructivist grounded research approach (Charmaz, 2005). In practice this study involved individual interviews with students on two occasions as well as two focus groups and two individual interviews with the staff. The students were interviewed by phone for half an hour after five weeks in the online programme and again at the end of the six-month programme. The premise was that the first interviews would generate themes for analysis and coding that could, additionally, inform the approach for the second interviews. Students were prepared for online study through a series of tasks that together constituted a non-assessed orientation course. In preparation for the online discussion forum students were shown how to make an entry and how to follow discussions on the forum pages. The nature of the student preparation was to ensure that the learning platform that they were to use was well understood and that they had some experience of exchanging information about themselves in the forum prior to the course commencing. This warm-up period, similar to the first two stages in Salmon's model (2000), lasted for three weeks, with online and telephone support being offered to the students as well as a designated member of staff acting as course moderator. The discussion forums lasted for the duration of each course, which was up to a month. The exception was the research course, which lasted for the whole of the six months. The expectation was that students would make at least two postings for each course, and while many did far more, some were unable to keep up with even two postings towards the end of the course. The staff attended a pre-commencement series of workshops, which were video-recorded and reported on as part of the study. These workshops once again focused on gaining a good understanding of the tools provided. These included how staff could gain access to the students' online discussion forum, add anything to that forum, and access online assignments, mark, and return those assignments online.

Each interview was audio-recorded digitally, including phone interviews with students and staff focus groups. The recordings were sent to an external transcription service, where they were transcribed. The recordings and transcriptions were then returned as electronic typescripts of each interview. The interview data was coded and analysed using Weft free domain software.

\section{The First Round of Student Interviews}

The student interviews were semi-structured to allow the interviewers - three researchers based at the private tertiary college - to ask supplementary questions if there appeared to be more information forthcoming from the student interviewees. The questions included reference to students' past experience of working online, the expectations students felt that the college had of them, the value of the discussion forum, and how they felt about the forum. It was only after the first set of interviews had been completed that themes for coding the data were identified. It was at this point that strategic approaches to the course started to become evident. 


\section{The Forum}

Before reporting on the interviews it is valuable to consider for a moment the role and nature of the exchange in the discussion forums that the students engaged in. Throughout many of the online forums, each separate course having a four-week forum, the exchange was characterised with a great deal of well-wishing and support. This sense of camaraderie was encouraging for the early stages of the project. However, after a period of time and at the request of the research team, "ethical dilemmas," after Dysthe (2007), were posted for the students to consider. These proved popular, the hope being that students would engage with the text and that they would develop their ideas. A critical engagement was not anticipated as follow-up readings to the ethical dilemmas were not provided and the availability of posting web links was not considered or provided for. There was, however, in the research forum a sense of opening up and discussing ideas. The discussions were mostly on the choice of topic for the research paper and the difficulties that were being encountered in undertaking a research project. (It should be added that the students had to undertake a 3,500-word research project, of their own choice of topic, as part of the coursework.)

\section{Getting the Job Done}

At the outset what marked the strategic students was their preoccupation with isolating only what "had to be done." This was exemplified at the start of the orientation course, where the tutor was constantly asked about what counted and what did not count towards their marks. Some of the students expressed a need to know exactly what was being assessed during the orientation even before the course had begun:

Student: Are we meant to do all of those little things?

Researcher: I think it's good. I can't say no.

S: We don't get them marked do we?

R: Not that first course, no.

$\mathrm{S}$ : But the other ones?

This exchange exemplified the attitude of needing to know the strategic value of any contribution. First encounters with the discussion forum also saw students asking if they had to answer all the posts by other students. While the query can be partly explained by the novelty of the online mode, using the tutor to clarify what gets marked in an orientation course suggests a strategic preoccupation.

After five weeks the students were asked in the first interview what value they saw in the online discussion forum. Some of the students answered by saying that time was a big factor in being able to discuss their work with other students in the forum:

I know I want to be an active part of it. I know what I have to do; it's finding the time to be completely involved in it at the 
moment. I might flick in during the day and read the discussions but you know, as people keep telling me, I've got a lot on my plate so my main focus is to get the assignments done and in. (Student, 2009)

Since many of the students were working full-time, it is understandable that prioritising how they spent their time was an important influence on their participation in online discussions. Another student experiencing similar difficulties with time and priorities clarified her attitude with additional comments:

Yes it depends what mood I'm in. I think it's great, you know, people ask you for readings and that but sometimes it's like I haven't got the time. I'm so busy trying to get everything done that I've got to do instead of trying to help someone out, or trying to go through all my readings, but then I know - that's what we're supposed to be doing. (Student, 2009)

Both students appear to want to be a part of the discussion forum, but multiple demands on their time cause them to approach it strategically by distancing themselves. The second student clearly viewed participation in the discussion forum as a duty to the college and a service to other students, rather than as a contribution to her learning. However, she also acknowledges that "... it's great . . . people ask you for readings," which is a recognition of her valuing being seen as part of the group, an interesting admission and one that will be revisited later in this paper.

\section{Valuing the Tutor}

A tendency to revere the contribution of the tutor often appeared in the interviews. One student reported,

Whenever I go on the discussion forum I always search down and look for a lecturer's name so I go for lecturers more than the students. I mean I do read it all when I expand the text but I look for their notes. I know that's sort of like gospel. It's the right one. They know what they're talking about. (Student, 2009)

For this student, the discussion forum did not in any way disrupt traditional concepts of a tutor's authority; it merely necessitated the development of new practical strategies for locating that voice. This attitude may well have inhibited the discussion as the strategic students often emailed the tutors directly. When tutors responded to a one-to-one e-message, students were again in effect acting strategically by avoiding the discussion. When the tutor's ideas are considered the most important, there is a danger that student contributions to the discussion will remain at the level of requests for clarification or confirmation of "rightness." 
Another student's response as to the experience of the discussion forum showed her to be in a stage of adaptation to the new facility:

Researcher: How has it helped you?

Student: Sometimes I try and get ideas for things, like everyone says pretty much different things so they all help you to think what you want to do, like the resources page everyone is giving different ideas.

R: How are you finding that, how are you finding the discussion forums?

S: It's quite good. Sometimes I think there's so much to read on there whereas maybe I should spend that 20 minutes getting into my reading. Then of course there are the six messages, you've got to read-you want to know what they say. To start with there was quite a lot on.

Here we find a student weighing up the benefits and potential distractions of the new mode. Curiosity about the various contributions of the other students and recognition that there is valuable information there appear to compete for the time allocated to traditional learning tasks. From a Web 2.0 learning perspective it is interesting to see the student talking about "different things" on the resources page, where readings and reflections were left by the students for each other. Could this be seeing learning in a broader light than the supply of the right answer to a specific question?

Another student saw the discussion forum as a way to clarify her previous work rather than to share or develop anything:

Usually I will read a lot and finish the entire study guide and the readings and I take some notes and then I start doing my assignment. Only when I have a question will I ask people for help and join the discussion forum. I probably do it all myself. (Student, 2009)

The approach of using the discussion forum to get help and collect information was a common feature of the student interviews and could be seen as strategic. Another response to this approach to the forums was,

Yeah you take on board what you want and you leave out what you want to leave out. I found it really helpful when the tutors clarified points or if people put up the questions for the discussion and others started giving their answers. Sometimes people were getting way off track and the tutor would come in and just clarify more clearly what they want actually answered. I found that helpful. (Student, 2009) 
Having information or questions come in from various contributors provides one recognised benefit for this student's learning, but the greater benefit is having that information subsequently controlled and valued by the tutor. This seems to be a missed opportunity, where student's dialogue could have been fostered only for the tutor to make a ruling. A more widespread tendency for students to view participation in the forum exclusively in terms of giving or taking is also evident in this quote. For the student quoted below, the discussion forum served little or no purpose, although she could see the benefit it provided for others:

For me they didn't seem useful because I participated because I had to, not because I needed to. I can see how for other people it could be very helpful and I did see other people posting things and questions and bouncing ideas off of each other which obviously was a good idea and it assisted their learning. (Student, 2009)

There is something quite wistful in this response, a sense, perhaps, of what has been lost through this adopted strategic approach to her learning. It is interesting how again the interaction is recognised as positive learning but seen as something that "others" do. It is interesting to look at the language of learning. She states that she had to participate so she did, but that the students in their own space were bouncing ideas off each other. One is very didactic, seeing learning as having to, whereas the student-to-student activity was bouncing off, a much more light-hearted description and something that they do. It is almost a vision of sitting indoors while watching others play outside as her self-imposed vision of learning activity is one of being removed from a community of learning.

\section{The Second Round of Student Interviews}

When the second interviews were held at the end of the six-month course, it was plain that many of the students still held unchanged attitudes towards the discussion forum. Participation at a minimum level was still the accepted approach for the strategic students:

Basically at the end of the day you're going to do what you're required to do to get through as much as it is a requirement to enter into it, they would do the bare minimum and then that's it. (Student, 2009)

Again the strategic student switches from the first-person I statements to the third-person they. By omitting themselves from the answer a way is found to justify a position. It is not "just" the person speaking who does this, so it is okay! Another student remarked, "Just getting it done, and in on time ... you know, studying for me was more about getting the essays done” (2009). This represents a more typical strategic perspective. 
When students were asked how helpful the course study guides had been, the responses to the Research Study Guide were particularly mixed. This course relied heavily on the students' ability to devise their own project and was the least prescriptive of the study guides. The strategic response was very clear:

The only Study Guide that I didn't find helped me was the investigation (Research). I think it was hard because they couldn't write a Study Guide on every single area; you had to choose your own area. So that was the one that I didn't find useful. (Student, 2009)

This student's attitude can be linked to that of another student, explaining why the study guides suited her:

I suppose it does depend on the person. For me I think they were quite good-to just be given things. Otherwise if I chose things, I might you know choose stuff that I maybe already knew about already. Otherwise I might choose something completely different that I think that I should know about but at least if I got given something that I have to actually do, that specific thing makes it easier. (Student, 2009)

The last response is interesting as the student readily admits she could seize the opportunity and write about something she may have already written about. The next statement sees the student considering making a different choice about "something completely different that I think I should know about." This might be a genuine interest and shows a readiness to try something new. However, this thinking is then dispelled as she sees the easier option being to do something that is a given, as in following the study guide. Again, as in the first series of interviews, students spoke of being overseen by tutors in the discussion forums as a good thing: "I think he [the lecturer] is doing wonderful. What he put on there last night actually made me stop and think! His comments were really good” (Student, 2009). Perhaps what was needed was less tutor input and more emphasis on the student potential so that they might validate their writing and their voice and pay less heed to the tutor. 


\section{Getting the Job Done}

A development in the strategic approach saw one student considering participation in discussion forums as compulsory:

I think it would be a good thing. I think it's all very easy (as it's not part of the assessment) not to do it. To sit back, and take all that other people have said and think, "Yes I'll use that," and not actually put your input into it. I think if it was part of the assessment that you would then look at it in a different light and think, "Well actually I need to contribute, this is part of my assessment, and I need to think about what I'm going to help the others with.” (Student, 2009)

The statement above might indicate confusion on the part of the student as to the role of the discussion forum in her learning and whether participation is a matter of giving or taking, helping others, or developing her own thinking. Once again the third person is evident as the student describes contributions to the discussion forum being something "you would look at in a different light."

Some students expressed anxiety that others poached more than contributed ideas. This brought up issues of knowledge acquisition versus knowledge sharing, as one student explained:

There was one discussion that I put on something about transition to school. I said too much, because a few people later said, "That's a great idea I might do the same as you." I'm thinking, "That's not what it's about." I got a little bit peeved with that so, I've changed my topic. I thought people took it a bit too far, I mean too much information can be shared. (Student, 2009)

Another student was less circumspect: “I'm very cautious about what I write on there. I just don't want people to steal my ideas” (Student, 2009).

Neither student demonstrates an understanding of the value that may be gained from sharing and exploring ideas together. Additionally, the accusatory way of speaking about other students in the same cohort suggests a very strategic approach to knowledge. This lack of knowing and sense that sharing is copying suggests a lack of trust in how students are working with each other. A discussion of this approach may have been useful as a topic early on in the forums to challenge these ideas. 


\section{A Summary of the Student Interviews}

The interviews revealed much about how students felt about their study. Above all, it was clear that an exploration of ideas beforehand, concentrating on the rationale behind the discussion, was required. Undertaking an exchange on knowledge as property to be acquired or knowledge as something that was developed through dialogue might have helped in alleviating student anxiety that they had to "protect" knowledge once gained. While some of the students recognised the learning potential of online discussion forums, other students were not clear about the concepts of sharing in a learning community. How the exchange of knowledge worked in the online discussion also appeared to be poorly understood. Knowing what to do in an online environment will be discussed in more detail in the section following a review of the staff response to strategic approaches adopted by the students. The role of the tutor was another topic that might have been valuable to discuss. Where once knowledge was to be parcelled out, discussing the role of a tutor in an age where knowledge is far more accessible would have been enlightening for the students and a useful opportunity for them to have expressed their own opinions.

\section{Interviews with Staff}

Three full-time members of staff were interviewed in focus sessions and individual interviews at the start and end of the project. Questions were again set within a semi-structured framework to allow the interviewer to ask supplementary questions if required. The interviews were again coded and interpreted within a constructivist grounded framework (Charmaz, 2005). The use of the grounded approach implied that the information gathered in the first interviews was subsequently thematised and provided the focus for the second round of interviews. In addition to developing a set of themes, the answers given by the students and staff in the first interviews were, in line with the disclosed themes, used to generate questions in relation to their first response.

The three staff members who acted as online tutors were provided with extensive preparation for online teaching experience, including technical support and mock discussion forums that they had to supervise. Interviews conducted at the end of the professional development phase revealed that tutors considered the discussion forum useful for a variety of reasons, including developing open discussion, clarifying assignments, having opportunities to ask more in depth questions, and creating a sense of trust. The tutors felt that students had to undertake background reading on a subject in order to be able to discuss it in the forum; therefore, it was important to encourage students to undertake the course readings first. The student experience was seen as getting through a crisis of confidence after the reading stage. As to the discussion forum, this was envisaged as a space where the students could clarify their ideas after having read on the subject. Ideally, staff wanted students to develop the ability to comprehend readings online so that tutors could "get them to think how the readings relate to the assignment" (Tutor, 2009). The online discussion was seen as having little or no consequence if the readings hadn't been assimilated. One tutor suggested, 
The whole point of being here is to express your point of view, but also being open to persuasion by someone else's point of view or by someone else's perception-I suppose that's where the dialogue comes in. (Tutor, 2009)

In relation to the discussion forum, staff clearly saw the need to direct students: "If you go into a lesson without a clear objective and without a clear plan of where you want to be and how you're going to get there, you won't end up anywhere” (Tutor, 2009). When further questioned whether there was a link between theory and practice, the tutors appeared to hold a view of theory as unquestionable and unchanging, and therefore a reliable guide for students. Hence understanding and developing a familiarity with readings was integral to any learning process. Study guides and learning objectives were seen as valuable ways to organise the course, especially for English as a second language (ESOL) students. Frequent references to the classroom also suggested the carryover of traditional teaching and learning beliefs, such as learning having a predetermined direction that was contained within a discrete structure (Siemens, 2008). When asked, at the start of the research project, how to advise students embarking on their first online learning experience, one tutor stated:

My advice would be think of it as a classroom, like they were walking into a classroom, yes it can be scary but if they go in there willing to try something new and learn different things and interact with these people in different ways then I think anyone could do well. (Tutor, 2009)

\section{Staff-Student Experience and Web 2.0}

Reflecting on the tutors' responses, the principle of an open learning experience, where students are seen as experts in their own right, co-constructing meaning, seems at odds with the approach of the strategic learner (Kress \& Pachler, 2007). However, use of the schoolroom metaphor (see Siemens, 2008) to exemplify an online forum indicates a lack of awareness by staff of the extent to which past structures influence their work with students in the online environment. Staff also felt that the study guide lent coherence and strength to the learning process, especially for the ESOL students. What is not recognised is that student ownership of the process (Dysthe, 2007) is advanced when less reliance is placed on prescribed texts. The principle underlying Web 2.0 is that students should question fixed knowledge, creating in the process a sense of shared ownership of learning (see O'Reilley, 2009). The sense of seeing others as doing the sharing, reported on above, may reflect the dislocation felt by students who did not engage in the discussions.

On the topic of the development of ability within an online learning community, the staff asserted that students should read set texts prior to engagement with others. However, this response belied a sense of distrust in the learning community's ability to create meaningful dialogue without institutionally sanctioned terms of reference. In addition, requiring students to immediately become efficient in assimilating set texts and discussing them online seems to be an unrealistic 
basis for developing dialogue. Emphasis on set texts reduces the possibility that students might be empowered during the process of studying online through the development of their sense of identity and self-efficacy. The potential for the community to develop ideas in the "rhizomatic" sense (see Cormier, 2008) through a dialogical exchange is thus undermined. According to Gulati (2004), it is within the informal/formal aspect of exchange that students can develop their own means for gathering ideas from each other (Gulati, 2004). Emergent learning is inhibited by the privileging of other, authoritative voices and student opinions that are informed by them. The centrality of the tutor in much of the discussion by students was made apparent with reference to their words being seen as "gospel" (Student, 2009). The dependence of students on the tutors for guidance might be an indication of "too little attention being paid to the learner's voice in the process of learning” (Gulati, 2004, p. 3). Gulati claims it is time for the tutor to adapt to the learner: "This includes the adaptation by the teacher, of the learner's world, through feedback on [the] learners' work and discussion” (Gulati, 2004, p. 3).

\section{The Value of Preparation in an Online Environment}

It is always easier to look in hindsight and make suggestions on how to improve the effectiveness of such a big undertaking as switching from class-based and correspondence distance learning to an online learning mode. Many more factors come into play beyond the logistics of making a new system work. Students in an online mode can have access to a far wider learning experience, particularly those who previously studied by traditional correspondence learning. The ease of communications and the combined knowledge about learning through peer group interaction has meant that the concept of what it is to learn and develop your own knowledge base has changed dramatically.

The students in this study who have been designated as strategic learners might have been strategic because they were unaware of any other approach to learning. The students' concept of learning in the programme may not have altered because previously held views that learning is individualistic, even competitive, were not addressed prior to the online experience. By not being familiar with "networked learning" the students failed to recognise the potential benefits of learning through interaction with others (Goodyear \& Yang, 2008). Is it then the role of institutions to introduce the implications for learning in a digital environment to staff and students? However, institutions cannot, or may not wish to, alter the assessment procedures integral to any award-bearing course. If institutions retain a summative approach to assessment no matter how much emphasis is laid on developing knowledge through a community of learners, ultimately this leaves the strategic learner unchallenged. This in turn would vindicate an individualistic attitude, given that the assessment remains individualistic and in turn competitive in nature.

If the online exchange was seen as an aspect of the learning outcomes, for example through processual evaluation of how the student is engaged within the learning episode, then there might be value in developing a more overt acceptance of online discussion. As there was no change in the assessment practices to match the change of mode, in this study there was little incentive for a significant number of students to move beyond a strategic approach. Marking that looks only at 
the end product and the students' ability to produce a final product runs counter to valuing engagement. The educational view of Web 2.0, the concept of emergent learning, is thus disregarded. In some ways, following the logic of this argument, the strategic learners are quite correct in their estimation of the learning task, that it is the product that is most important, not the learning process.

\section{Conclusion}

The development of Web 2.0 and open-ended learning presents tertiary education with many challenges. The scope for developing dialogue and student autonomy has important implications for institutions when shifting from a paper-based correspondence mode to an online mode. The affordance of new learning through dialogue and the scope for students to empower their own ideas and sense of ownership of their learning challenge many aspects of the learning process.

As reported in this paper, students can see learning as a chore with the best approach being to get the job done as quickly as possible. It would be a great concern if these early childhood teachers transmitted this same attitude to learning in their workplaces, and this might be a subject for subsequent study. Approaches to the discussion forum also illustrate how strategically minded students appeared to have little concept of a learning community. As a result their engagement remained tangential as references to the suitability of the forum for "others" would suggest. Again this would be a useful area to look at in more detail.

The role of the tutor was out of proportion with engagement at stage three of a degree-level course, and this might have been challenged if there had been more preparation beforehand to assuage students' fears and reduce the number of calls on the tutors for help. The very principle of the "right" answer is one that has now been overcome in most quarters of the social sciences. However, the tutors in this study did not appear to have a well-developed understanding as to how students learn through dialogue in stages. The assumption being made was that students can effectively discuss a text within a forum as a first level of engagement. This appeared to be not only unrealistic but to practically ensure that an overseer is required who can provide a clear sense of direction to the reading and learning experience. Again, this counters the sense of shared learning in the Web 2.0 context. A greater sense, therefore, of what was implied by working in the online environment may have opened up to the tutors other possibilities for how they might interact with the students and change their role when working online.

The information presented at the start of a course can effectively drive the way in which students and staff respond to the online experience. If the emphasis is on participation and giving, as opposed to individual narrowing of scope and prescribing, opportunities are afforded for lecturers and students to wholeheartedly engage in a meaningful, lasting, and at times profound exchange. Knowing what the new environment offers can lead to new realms of learning for each party (Dysthe, 2007). If the staff and students are not clear about the nature of the learning that they are engaged in, it is unlikely that a rich learning experience will eventuate. 
Despite the potential richness of the learning environment and the educational opportunities that online discussion can provide, the difficulty remains of assessment practices not being in alignment with the online context. The logic of the strategic learner defeats sharing and engagement practices when the assessment scheme is summative in nature. If the assessment were processual and the learning outcomes valued the process of learning, then further engagement by the strategic learner would be validated. The current alignment between learning tasks, experience, conditions, and assessment criteria that are summative removes participation in a learning community to the periphery of the learning process, reinforcing a strategic approach for both tutor and student. 


\section{References}

Aldrich, C. (2009). Learning online with games, simulations, and virtual worlds: Strategies for online instruction. San Francisco, CA: Jossey-Bass.

Bauman, Z. (1993). Postmodern ethics. London: Blackwell.

Biggs, J. (1993). What do inventories of students' learning process really measure? A theoretical review and clarification. British Journal of Educational Psychology, 83, 3-19.

Biggs, J., \& Tang, C. (2007). Teaching for quality learning at university. Maidenhead, UK: Society for Research into Higher Education and Open University Press.

Castells, M. (2000). The rise of the network society (2nd ed., Vol. 1). Oxford, UK: Blackwell Publishers.

Charmaz, K. (2005). Grounded theory in the 21st century: Applications for advancing social justice studies. In N. K. Denzin \& Y. S. Lincoln (Eds.), The Sage handbook of qualitative research (pp. 507-535). Thousand Oaks, CA: Sage Publications.

Cormier, D. (2008). Rhizomatic education: Community as curriculum. Retrieved from http://davecormier.com/edblog/2008/06/03/rhizomatic-education-community-ascurriculum/

Davis, B., \& Sumara, D. J. (2006). Complexity and education: Inquiries into learning, teaching and research. Mahwah, NJ: Lawrence Erlbaum Associates.

Downes, S. (2010). Stephen's Web: A series of questions. Retrieved from http://www.downes.ca/cgi-bin/page.cgi?post=52701

Driscoll, M. (2000). Psychology of learning for instruction. Needham Heights, MA: Allyn \& Bacon.

Dysthe, O. (2007). Dialogic postgraduate supervision - characteristics, constraints and affordances. University of Bergen, Norway. Retrieved from http://cc.msnscache.com/cache.aspx?q=dysthe+2007+dialogic +postgr aduate $\& d=75921804192776 \& m k t=e n-N Z \&$ setlang=en-NZ\&w=83001cbd,c5d12701

Entwhistle, N. (1981). Styles of learning and teaching: An integrated outline of educational psychology for students, teachers and lecturers. Chichester UK: John Wiley.

Fisher, T., Higgins, C., \& Loveless, A. (2006). Teachers learning with digital technologies: A review of research and projects. Bristol, UK: FutureLab. 
Goodyear, P., \& Yang, D. (2008). Patterns and pattern languages in educational design. In L. Lockyer, S. Bennett, S. Agostinho, \& B. Harper (Eds.), Handbook of research on learning design and learning objects: Issues, applications and technologies (pp. 167187). Hershey PA: Information Science Reference.

Gulati, S. (2004, April). Constructivism and emerging online learning pedagogy: A discussion for formal to acknowledge and promote the informal. Paper presented at the Annual Conference of the Universities Association of Continuing Education, University of Glamorgan.

Illich, I. (1971/2000). Deschooling society. St. Paul MN: Marion Boyars.

Kress, G., \& Pachler, N. (2007, October). Thinking about the ' $m$ ' in mobile learning. mlearn 2007, Melbourne. Retrieved from http://www.mlearn2007.org/

Lankshear, C. (2003). Wide open spaces: Wikis, ready or not. Educause Review, 39, 36-48. Retrieved from http://www.educause.edu/ir/library/pdf.erm0452.pdf

LaPointe, D. K., \& Gunawardena, C. N. (2004). Developing, testing and refining of a model to understand the relationship between peer interaction and learning outcomes in computer mediated conferencing. Distance Education, 25(1), 83-106.

Lave, J., \& Wenger, E. (1991). Situated learning: Legitimate peripheral participation. Cambridge: Cambridge University Press.

Marton, F., \& Säljö, T. (1976). On qualitative differences in learning: Outcome as a function of the learner's conception of the task. British Journal of Educational Psychology, 46, 115-127.

McWilliam, E. (2005). Unlearning pedagogy. Journal of Learning Design, 1(1), 1-11.

O’Reilley, T. (2009). What is Web 2.0? Retrieved from http://elearnspace.org/Articles/systemic_impact.htm

Roder, J., \& Hunt, T. (2009). Web 2.0 in the curriculum of the future: Exploring the educational potential of new developments in Web-based digital tools. In C. M. RubieDavies \& C. Rawlinson (Eds.), Challenging thinking about teaching and learning. New York: Nova Science Publications.

Salmon, G. (2000). E-moderating: The key to teaching and learning online. London: Kogan Page.

Siemens, G. (2008). New structures and spaces of learning: The systemic impact of connective knowledge, connectivism, and networked learning. Retrieved from http://elearnspace.org/Articles/systemic_impact.htm 
Weft Qualitative Analysis Software: http://www.pressure.to/qda/

\section{Athabasca University $\mathbf{Z}$}

(c) 


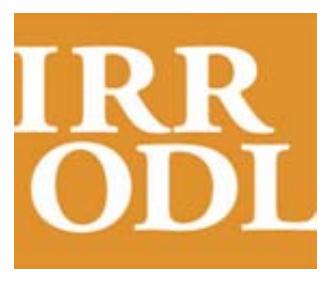

International

Review of

Research in Open

and Distance

Learning

Vol. 12.2

February - 2011

\section{Mobile Learning via SMS at Open University Malaysia: Equitable, Effective, and Sustainable}

Tina Lim, Mansor Fadzil, and Norziati Mansor

Open University Malaysia, Malaysia

\begin{abstract}
This article describes Open University Malaysia's efforts at enhancing the blended learning approach for undergraduate distance learners with the successful implementation of the Mobile Learning via SMS initiative. The pilot project was implemented in the May 2009 semester, and this coming January 2011 semester will be in its sixth consecutive semester. Aspects such as the conceptual model, the process flow of group messaging, and challenges faced, as well as effectiveness of the initiative, are discussed.
\end{abstract}

Keywords: Distance education; mobile learning; SMS; text messaging; enhanced blended learning 


\section{Introduction}

True to the university's vision of being the leader in flexible learning, Open University Malaysia (OUM), Malaysia's first open and distance learning institution of higher education, embarked on a Mobile Learning via SMS initiative in an effort to support distance learners, who are mostly working adults, and to make learning more flexible and ubiquitous for them. The initiative may be considered the first and only one of its kind that has successfully been implemented on a large scale (to date involving an approximate total of 13,200 learners) by a Malaysian higher education institution. The general objectives of mobile learning are

1. to enhance the blend of learning modes at OUM;

2. to increase the flexibility of learning offered to OUM learners; and

3. to encourage and support ubiquitous learning (just in time, anytime, anywhere) via mobile technologies.

Open University Malaysia's mission is to widen access to quality education and to provide lifelong learning opportunities by leveraging technology, by adopting flexible modes of learning, and by providing a conducive and engaging learning environment at a competitive and affordable cost. With that in mind and in line with the motto "University for All," text messaging was chosen over other mobile technology applications because it is the lowest common denominator of all mobile technologies: It can be used on all types of mobile phones and students are familiar with receiving SMSes. This is consistent with the university's philosophy of democratizing education, which means making education available to all, regardless of time, place, age, and social economic background. Further, with the high penetration rate of mobile phone subscriptions of 106.2 per 100 people in Malaysia (Malaysian Communications and Multimedia Commission, 2009), it appeared this was the way to go in making inroads into the use of mobile devices for learning among Malaysian distance learners. A "saturation of technology in the target audience" would lend a hand in bringing to scale a successful application for m-learning as advocated by Vitelli (2000), as cited in Caudill (2007).

Since its inception, the university has adopted a blended learning approach, an approach commonly used by open and distance learning higher education institutions and which, according to Melton, Graf, and Chopak-Foss (2009), has been found to be helpful in increasing retention rates. However, as indicated by OUM's cumulative attrition rate of $42.3 \%$ from the years 2001 to 2008 (Abdol Latif, Sumalee, \& Bahroom, 2009), much more needs to be done to help sustain the distance learners who are likely to feel isolated and alienated because of a lack of interaction and communication with fellow learners, tutors, and the university as compared to those in traditional universities (Hara \& Kling, 2001; Flowers, 2001; Zirkle, 2002; Dzakiria, 2005). In trying to bridge the transactional distances faced by the learners, it was noted that the university needed to provide a higher level of support to the learners more regularly and unobtrusively and to engage them psychologically by motivating and reminding them to keep pace with course schedules and requirements, as well as to help them develop self-regulation skills (Tyler-Smith, 2006; Crawford, 2008). 
Available literature records that in the last ten years, there have been numerous successful attempts by higher education institutions worldwide in using text messages to support distance learners. From Africa, these include the University of Pretoria, South Africa, and Makerere University, Uganda. From the Asia-Pacific region are the Allama Iqbal Open University of Pakistan, the Sheffield Hallam University branch in India, the Srinakharinwirot University of Thailand, the Chinese University of Hong Kong, and Box Hill Institute of TAFE, Victoria, Australia. Elsewhere, in the United Kingdom, universities that have also implemented mobile learning via SMS include Kingston University and the University of Ulster.

The universities recorded success in the following areas of support to their learners:

1. administrative support - reminding learners of contact session dates and registration deadlines, particularly those who have been missing face-to-face sessions (Ericsson Global, n.d.; Viljoen, du Preez, \& Cook, 2005; Kajumbula, 2006; Yousof, 2007; Keegan, Kismihok, Mileva, \& Rekkedal, 2009);

2. academic purposes - sending SMSes that contain important course content, which is chunked in small sizes (Uday Bhaskar \& Govindarajulu, 2008);

3. e-Counselling services (Commonwealth of Australia, 2006);

4. learner development support - helping learners to self-manage their studies better (Stone, 2001);

5. learner assessment - sending interactive quizzes for learner self-assessment (Sukaphat, 2007; Clarke, Keing, Lam, \& McNaught, 2008).

OUM's Mobile Learning via SMS was initiated in 2009 after a study that was conducted to determine the percentage of OUM learners possessing a mobile phone and the extent to which learners perceived themselves to be ready for such a project indicated that $98 \%$ of OUM learners have at least one mobile phone and approximately $82 \%$ perceived themselves to be ready for mobile learning (Abas, Chn'g, \& Mansor, 2009). Five dimensions of support were identified, namely administrative support, academic support, learner motivation enhancement, learner selfmanagement development, and learning activities co-ordination.

\section{Conceptual Model}

Under the university's blended approach to learning, undergraduate students learn via a blend of three modes: 10 hours of face-to-face tutorials per semester, self-managed learning using modules, and online learning via asynchronous forum discussions in the university's learning management system, as well as online resources such as digital learning objects. (Refer to Figure 1.) With the incorporation of mobile learning, the blended learning environment is enhanced in that the text messages (a.k.a. SMSes) give timely important information about the course, help learners to better manage their studies, motivate them, and encourage as well as remind them to tap into the three existing modes. 


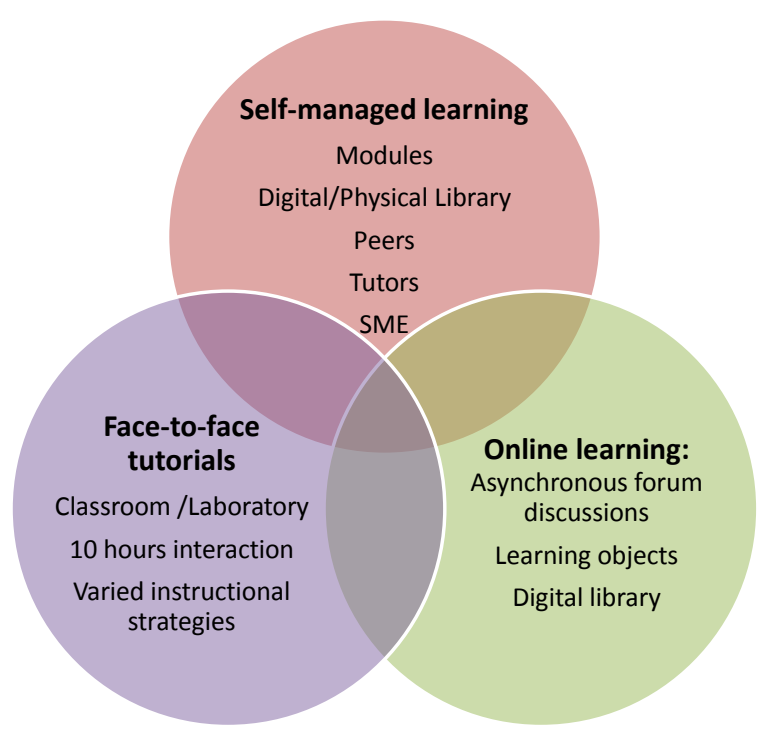

Figure 1. Blended learning approach at OUM.

Based on the recorded advantages afforded by mobile learning found in a review of related literature, five categories of SMS were identified: 1) content, 2) forum/Facebook, 3) tips, 4) motivation, and 5) course management. The five categories of text messages, their purpose, and examples are as shown in Table 1. 
Table 1

SMS Categories, Purpose, and Examples

\begin{tabular}{|c|c|c|}
\hline Category & Purpose & Example \\
\hline Content & $\begin{array}{l}\text { To help learners locate/remember } \\
\text { important course facts easily }\end{array}$ & $\begin{array}{l}\text { There are } 4 \text { pairs of learning styles: } \\
\text { Active/Reflective; Sensing/Intuitive; } \\
\text { Visual/Verbal; Sequential/Global. Which is } \\
\text { yours? See Appendix 1.1. }\end{array}$ \\
\hline Forum/Facebook & $\begin{array}{l}\text { To remind and motivate learners to } \\
\text { participate in discussion forums }\end{array}$ & $\begin{array}{l}\text { Would you consider Tony Fernandez a } \\
\text { successful entrepreneur? Why do you say so? } \\
\text { Post your views in LMS forum. }\end{array}$ \\
\hline Tips & $\begin{array}{l}\text { To provide hints/strategies on how } \\
\text { to do well in their studies }\end{array}$ & $\begin{array}{l}\text { Revise focus assessment for renal patients and } \\
\text { effective nurse-client communication in } \\
\text { preparation for OSCE. }\end{array}$ \\
\hline Motivation & $\begin{array}{l}\text { To motivate learners to persevere in } \\
\text { the learning process }\end{array}$ & $\begin{array}{l}\text { To succeed, we must first believe that we can. } \\
\text { By Michael Korda. Always believe in yourself } \\
\text { :-). }\end{array}$ \\
\hline $\begin{array}{l}\text { Course } \\
\text { management }\end{array}$ & $\begin{array}{l}\text { To provide timely } \\
\text { announcements/reminders related to } \\
\text { tutorials/assessments }\end{array}$ & $\begin{array}{l}\text { Your assignment is due next week. Remember } \\
\text { to submit by T4. Best wishes! }\end{array}$ \\
\hline
\end{tabular}

In the May 2010 semester, interactive SMS applications were developed so that learners could respond to the SMSes received. Two types of interactive SMS application used are as shown in Table 2. 
Table 2

Interactive SMS Applications

\begin{tabular}{|c|c|c|}
\hline & Sequence of events & Example \\
\hline 1. & \multicolumn{2}{|c|}{ Survey Question and Response } \\
\hline a. & $\begin{array}{l}\text { OUM sends a survey } \\
\text { item }\end{array}$ & $\begin{array}{l}\text { Dear OUM learner, if you do NOT wish to receive anymore } \\
\text { Mobile Learning SMS for OUMH1103, please key in OUM } \\
\text { OUMH1103 STOP and send to } 32255 \text {. }\end{array}$ \\
\hline b. & Student responds & \\
\hline c. & OUM replies & $\begin{array}{l}\text { Thank you for your SMS. You will discontinue receiving the } \\
\text { Mobile Learning SMSes within a week. Best wishes from OUM. }\end{array}$ \\
\hline 2. & \multicolumn{2}{|c|}{ Multiple Choice Questioning, Response, \& Feedback } \\
\hline a. & $\begin{array}{l}\text { OUM sends a } \\
\text { multiple choice } \\
\text { question with } 4 \\
\text { answer options }\end{array}$ & $\begin{array}{l}\text { What TQM area of focus refers to employee authority to make } \\
\text { decisions? } \\
\text { A. Training } \\
\text { B. Empowerment } \\
\text { C. Involvement } \\
\text { D. Recognition }\end{array}$ \\
\hline b. & $\begin{array}{l}\text { Instruction on how to } \\
\text { respond }\end{array}$ & $\begin{array}{l}\text { To check your answer, key in OUM OUMM2103 A, B, C or D } \\
\text { and send to } 32255 \text {. }\end{array}$ \\
\hline c. & Student responds & \\
\hline d. & OUM sends feedback & $\begin{array}{l}\text { A : Sorry, your answer is incorrect. The correct answer is B. } \\
\text { Empowerment is the authority to take control and make decisions. } \\
\text { B : That is correct! Empowerment is the authority to take control } \\
\text { and make decisions. Congratulations! } \\
\text { C : Sorry, your answer is incorrect. The correct answer is B. } \\
\text { Empowerment is the authority to take control and make decisions. } \\
\text { D : Sorry, your answer is incorrect. The correct answer is B. } \\
\text { Empowerment is the authority to take control and make decisions. }\end{array}$ \\
\hline
\end{tabular}




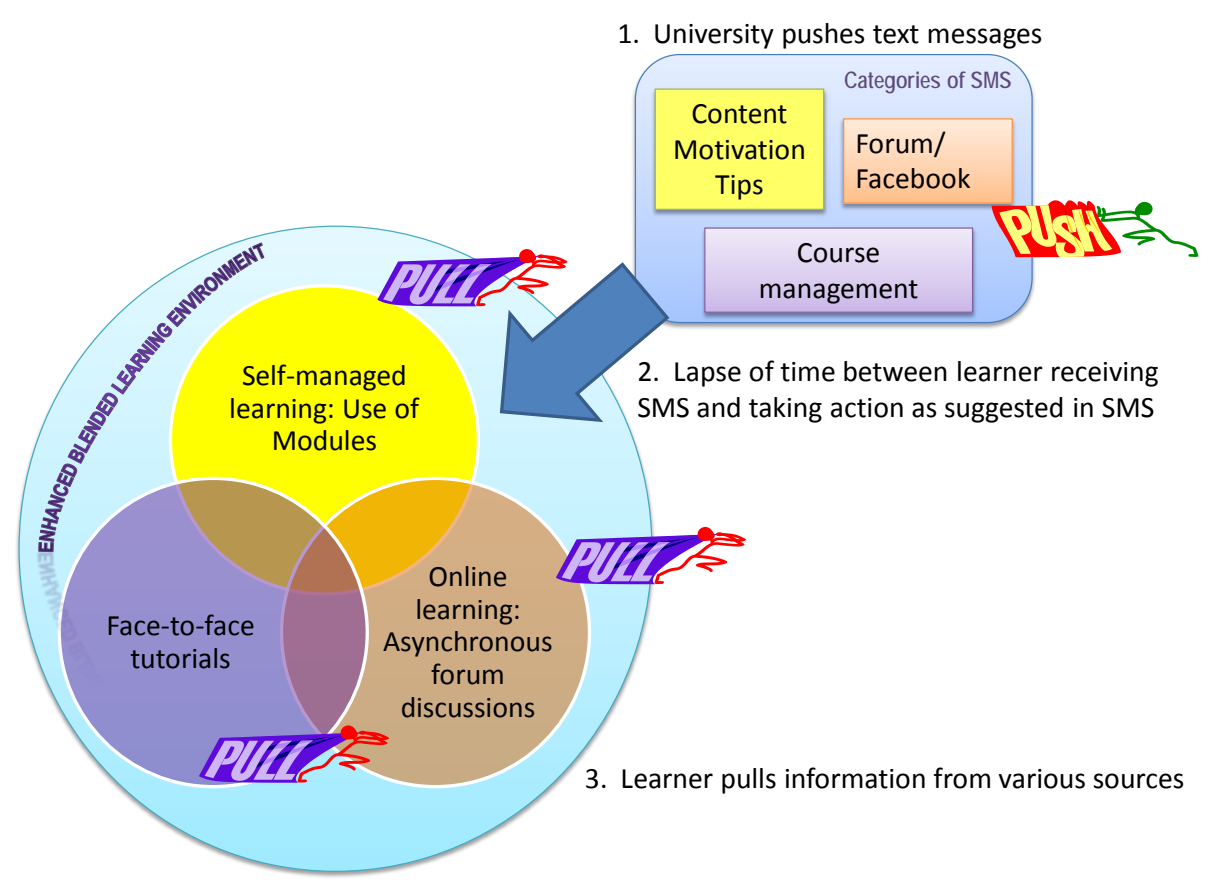

Figure 2. Enhanced blended learning environment.

In essence, when the university sends the text messages to learners, unsolicited information is pushed to learners outside normal interaction hours and communication spaces. Upon receiving the SMS, learners may choose to respond by 'pulling' information immediately, or if they are busy with work or family commitments, they may opt to do that at a later time when they are free. The type of action that learners engage in depends on the category of SMS received. If a contentrelated SMS is received, they may 'pull' information from their modules, or if they are not clear on course concepts, they can seek further clarification/explanation from their tutors during faceto-face tutorials. However, if they receive a text message encouraging them to discuss in online forums/Facebook, learners may log onto the asynchronous forums to interact with their peers or tutors. Besides extending learning space, the other advantage afforded by mobile learning is that it facilitates "just-in-time” learning and lends more flexibility to the whole learning process.

\section{Courses Involved}

The courses for which Mobile Learning were offered are as shown in Table 3. 
Table 3

Details of Mobile Learning Courses

\begin{tabular}{|c|c|c|c|}
\hline Semester & $\begin{array}{l}\text { Course Code } \\
\text { Course }\end{array}$ & $\begin{array}{l}\text { No. of learners } \\
\text { involved }\end{array}$ & $\begin{array}{l}\text { No. of } \\
\text { SMSes } \\
\text { sent per } \\
\text { course }\end{array}$ \\
\hline MAY 2009 & $\begin{array}{l}\text { OUMH } 1103 \\
\text { Learning Skills for ODL }\end{array}$ & 1863 & 31 \\
\hline \multirow[t]{3}{*}{ SEPT 2009} & $\begin{array}{l}\text { OUMH } 1103 \\
\text { Learning Skills for ODL }\end{array}$ & 1173 & 25 \\
\hline & $\begin{array}{l}\text { BBUS } 2103 \\
\text { Company Law }\end{array}$ & 243 & 31 \\
\hline & $\begin{array}{l}\text { NBNS } 3504 \\
\text { Renal Nursing }\end{array}$ & 318 & 30 \\
\hline \multirow[t]{6}{*}{ JAN 2010} & $\begin{array}{l}\text { OUMH } 1103 \\
\text { Learning Skills for ODL }\end{array}$ & 1942 & 29 \\
\hline & $\begin{array}{l}\text { BBMA } 3103 \\
\text { Management Accounting } 1\end{array}$ & 93 & 26 \\
\hline & $\begin{array}{l}\text { CBCP } 2103 \\
\text { Computer Programming }\end{array}$ & 149 & 28 \\
\hline & $\begin{array}{l}\text { HBCA } 2103 \\
\text { Principles of Advertising }\end{array}$ & 27 & 22 \\
\hline & $\begin{array}{l}\text { NBNS } 2804 \\
\text { Mental Health Nursing }\end{array}$ & 89 & 32 \\
\hline & $\begin{array}{l}\text { SBBI } 4203 \\
\text { General Genetics }\end{array}$ & 346 & 21 \\
\hline \multirow[t]{3}{*}{ MAY 2010} & $\begin{array}{l}\text { OUMH } 1103 \\
\text { Learning Skills for ODL }\end{array}$ & 1477 & 25 \\
\hline & $\begin{array}{l}\text { OUMH } 1203 \\
\text { English for Written Communication }\end{array}$ & 2961 & 25 \\
\hline & $\begin{array}{l}\text { OUMM } 2103 \\
\text { Entrepreneurship }\end{array}$ & 1857 & 29 \\
\hline $\begin{array}{l}\text { SEPT } \\
2010\end{array}$ & $\begin{array}{l}\text { MPW1133/2133 } \\
\text { Malaysian Studies } \\
\text { (fully online) }\end{array}$ & 196 & 20 \\
\hline
\end{tabular}

\section{Learner Support}

To take advantage of popular Web 2.0 technologies, Facebook and Twitter were used to support this initiative; Facebook provided an alternative platform to the normal asynchronous online 
forums in the university's learning management system for learners to discuss related content, while Twitter was used to archive the SMSes sent. Throughout the initiative, learner support was

provided in the form of telephone and email helplines. Guidelines in OUM's learning management system covered reporting non-receipt of SMSes, accessing and interacting in Facebook, and updating mobile phone numbers. Approximately midway through the semester, learners were given the option to stop receiving the SMSes. Thus far, less than $5 \%$ of the learners have chosen to do so in any one semester.

\section{Process Flow}

The process flow for group messaging is as shown in Figure 3. Prior to the start of each semester, the Mobile Learning via SMS team together with the subject matter experts develop the SMS schedule and content (see sample in Figure 4.) Mobile phone numbers of learners are also obtained from the Registry database and .txt files are prepared using Notepad for incorporation in the university's group messaging application known as OUM Workmate (see Figure 5.) During the academic semester, individual text messages are copied and pasted into Workmate and set to be sent at a predetermined delayed date and time. In addition, delivery of the SMSes is monitored and technical problems that arise such as non-delivery or late delivery of SMSes are noted, and the frequency of such occurrences are analysed. Finally, at the end of each semester, the effectiveness of the initiative in supporting our distance learners is evaluated. 
OUM SMS

Application

Bulk SMS

Gateway

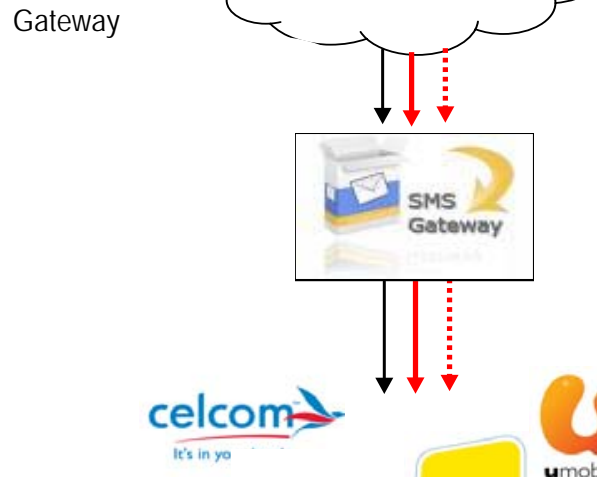

Local TelCo

operators
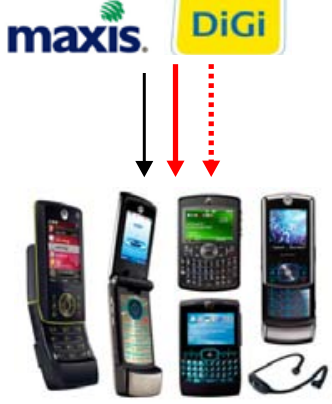

Obtain learners' mobile phone number from Registry database

Prepare .txt file

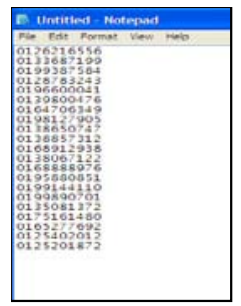

Key in SMS, set delivery date and time

Process flow of interactive SMS

Process flow of interactive SMS when learners respond

Figure 3. Process flow diagram. 


\begin{tabular}{|c|c|c|c|}
\hline DAYS & $\begin{array}{c}\text { Week } 1 \text { (21 - } 27 \text { Sept 2009) } \\
\text { (Before T1) }\end{array}$ & $\begin{array}{c}\text { Week } 2 \text { (28 Sept - } 4 \text { Oct 2009) } \\
\text { (Topic 1- Introduction to Company } \\
\text { Law) }\end{array}$ & $\begin{array}{c}\text { Week } 3(5-11 \text { Oct 2009) } \\
\text { (Topic 1- Introduction to Company } \\
\text { Law) }\end{array}$ \\
\hline MONDAY & HARI RAYA PUASA & $\begin{array}{l}\text { There are } 4 \text { types of business structure in } \\
\text { Malaysia. Discuss the advantages and } \\
\text { disadvantages of each type in the forum. } \\
\text { Refer to } 1.2 \text { and } 1.3\end{array}$ & $\begin{array}{l}\text { Is the company liable for all contracts } \\
\text { entered into by promoter before } \\
\text { incorporation of the company? Refer to } \\
\text { 1.8.4 }\end{array}$ \\
\hline TUESDAY & $\begin{array}{l}\text { HARI RAYA PUASA } \\
\text { Welcome back to OUM! You will be } \\
\text { receiving a series of SMSes for Company } \\
\text { Law as part of our value added service. } \\
\text { It is free. Enjoy! }\end{array}$ & 29 & 6 \\
\hline WEDNESDAY & $\begin{array}{l}\text { Do you know that learning is an active } \\
\text { process? We learn by doing. Only } \\
\text { knowledge that is used sticks in your } \\
\text { mind. Dale Carnegie }\end{array}$ & $\begin{array}{l}\text { What are the effects of incorporation to } \\
\text { a company according to the Companies } \\
\text { Act 1965? Refer to 1.4.5 }\end{array}$ & $\begin{array}{l}\text { Why is partnership business structure } \\
\text { very popular among entrepreneurs in ? } \\
\text { Discuss in myLMS forum. Refer to } 1.3 .2\end{array}$ \\
\hline THURSDAY & $\begin{array}{l}\text { Your tutor is very keen to meet you } \\
\text { during tutorials. Welcome you all and be } \\
\text { on time. See you! }\end{array}$ & $\begin{array}{l}\mathrm{Hi} \text {, try to read your module regularly and } \\
\text { participate actively in the forum. This } \\
\text { will help you do well in your studies. :-) }\end{array}$ & 8 \\
\hline $\begin{array}{l}\text { FRIDAYISATI } \\
\text { SUNDAY }\end{array}$ & $\begin{array}{c}\text { TUTORIAL } 1 \\
\text { (25-27 Sept 2009) }\end{array}$ & 2 & $\begin{array}{c}\text { TUTORIAL } 2 \\
(9-11 \text { Sept 2009) }\end{array}$ \\
\hline
\end{tabular}

Figure 4. Sample SMS Content and Schedule.

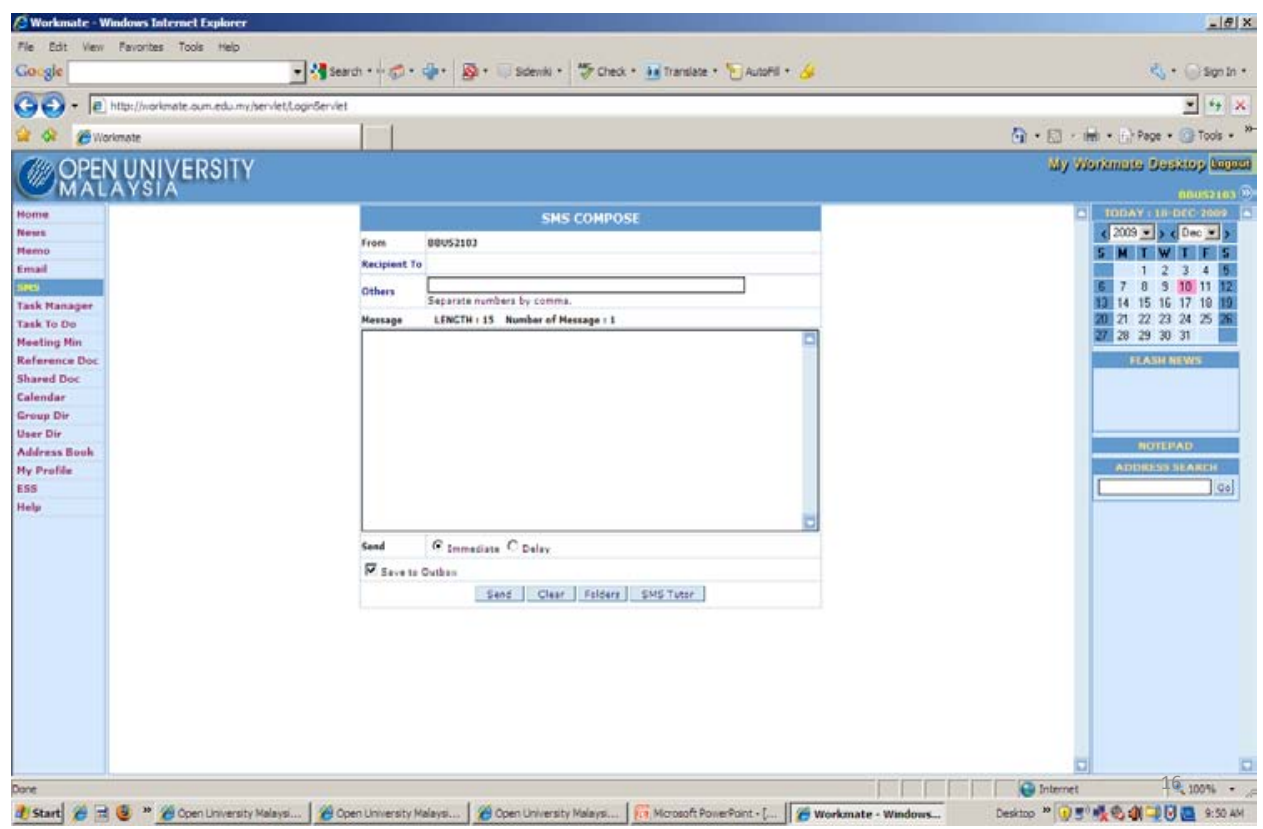

Figure 5. Screen capture of OUM’s Workmate (Group messaging application). 


\section{Challenges}

When developing the text messages, the number of characters available is currently only 134 (145 prior to the September 2010 semester, i.e., before the standard change in short code which requires RM0.00 to be shown if the cost of the SMS sent is borne by the sender). This is markedly less than that available in normal SMSes because when using group messaging via the bulk SMS gateway, several characters are taken up in showing the short code involved (e.g., RM0.00 OUM OUMH1103). Thus, when developing the SMS content, much care has to be taken in ensuring the message is meaningful yet concise and the language used is simple. In order to discourage learners from thinking that short forms are acceptable in written documents, abbreviations like 'tq' are not used unless absolutely necessary, that is, when the number of characters for a particular message already exceeds the limit.

Further, some technical issues that have surfaced during implementation of the initiative include non-delivery or late delivery of SMSes either due to problems at the bulk SMS gateway provider or because of service glitches at certain telecommunication providers. When a message is not received at the targeted time, the Mobile Learning team generally waits until the following day to see if it is a permanent failure. In such cases, the same message will be reset for the following day and the subsequent SMS is also rescheduled if it was scheduled for the day after the failed SMS.

\section{Effectiveness of the Initiative}

Findings from summative evaluations of the initiative have consistently shown that learners appreciated the text messages and felt that the SMSes had helped them to stay focused and engaged in their studies. The messages were also useful in providing important information related to the course. Additionally, in general, the learners agreed that the messages had allowed them to learn anytime and anywhere and had helped them manage their studies better (Abas, Lim, \& Woo, 2009; Abas, Lim, Singh, \& Wei, 2009; Singh, 2010; Abas, Lim, \& Ramly, in press). Every semester over 95\% of the learners involved expressed their wish that Mobile Learning via SMS be extended to other courses as well.

In monetary terms, the cost of sending one SMS is 20 sen. Thus, for an average of 25 SMSes to a single learner for one course per semester, the cost borne by the university is RM5.00. If one were to compare that to the benefits of possible successful retention and progress of a learner in his/her studies, one might safely say it is a great investment in terms of ensuring learner success and satisfaction. While it is noted that a proper cost-effectiveness study on the use of SMS in retaining students and recouping costs would be able to shed light on how viable the initiative is, it ought to be also emphasized that not all things valued may be measured in monetary terms. Helping even a single learner to enjoy and succeed in learning is what counts for a responsible distance education provider. 


\section{Conclusion}

Mobile learning via SMS helps reduce the transactional distance of psychological and communication space often faced by distance learners who are separated in terms of geographical distance and time (Moore, 1997). It also enables the university to reach out to learners outside of conventional communication spaces, and it helps to keep learners connected to the university, their peers, and their tutors.

As the project has been found to be sustainable in terms of costs, efforts, and resources, the university plans to further extend the service to other courses, in particular those that will be conducted fully online.

\section{Acknowledgement}

The authors wish to acknowledge all members of Open University Malaysia's Mobile Learning team for their esteemed collaborative efforts, enthusiasm, and commitment throughout the planning and implementation stages of this initiative since its inception. 


\section{References}

Abas, Z. W., Chng, L. P., \& Mansor, N. (2009). A study on learner readiness for mobile learning at Open University Malaysia. In Proceedings of IADIS International Conference Mobile Learning (pp. 151-157).

Abas, Z. W., Lim, T., \& Woo, T. K. (2009). Mobile learning initiative through SMS: A formative evaluation. ASEAN Journal of Open and Distance Learning, 1 (1), 49-58. Retrieved from http://ajodl.oum.edu.my/fajodl/201007/15070126Article_6.pdf.

Abas, Z. W., Lim, T., Singh, H. K. D., \& Wei, W. S. (2009). The design and implementation of mobile learning at Open University Malaysia. In Proceedings of the South-east Asia Association for Institutional Research Conference 2009, Penang. 13-15 October 2009.

Abas, Z. W., Lim, T., \& Ramly, R. (in press). Unleashing the potential of mobile learning through SMS text for open and distance learners. In A. Kitchenham (Ed.), Models for interdisciplinary mobile learning: Delivering information to students. Hershey, PA: IGI Global.

Abdol Latif, L., Sumalee, S., \& Bahroom, R. (2009). Managing retention in ODL institutions: A case study on Open University Malaysia and Sukothai Thammathirat Open University. ASEAN Journal of Open and Distance Learning, 1(1), 1-10. Retrieved from http://ajodl.oum.edu.my/fajodl/201007/15072338Article_1.pdf .

Caudill, J. G. (2007). The growth of m-learning and the growth of mobile computing: Parallel developments. International Review of Research in Open and Distance Learning, 8(2). Retrieved from http://www.irrodl.org/index.php/irrodl/article/view/348/873

Clarke, P., Keing, C., Lam, P., \& McNaught, C. (2008). Using SMSs to engage students in language learning. In E. R. Weipp \& J. Luca (Eds.), ED-MEDIA 2008 (pp. 6132-6141). Proceedings of the 20th annual World Conference on Educational Multimedia, Hypermedia \& Telecommunications, Vienna, Austria, 30 June-4 July. Chesapeake VA: Association for the Advancement of Computers in Education.

Commonwealth of Australia. (2006). Australian Flexible Learning Framework. Retrieved from http://pre2009.flexiblelearning.net.au/flx/webdav/site/flxsite/shared/Inclusive\%20Elearning/Box_Hill_case_study_06.pdf

Crawford, C. M. (2008). Belonging and identity: Creating and sustaining communities of learning within distance learning environments, while focusing upon making connections, creating communities of learning, and maintaining personal and professional identities. Paper presented at the Fourth International Conference on Environmental, Cultural, Economic \& Social Sustainability. 4-7 January 2008. Universiti Malaysia Terengganu. 
Dzakiria, H. (2005). The role of learning support in open and distance learning: Learners' experiences and perspectives. Turkish Online Journal of Distance Education (TOJDE). Retrieved from http://tojde.anadolu.edu.tr/tojde18/articles/article4.htm

Ericsson Global. (n.d.). Achievements of mobile learning today. Retrieved from http://www.ericsson.com/ericsson/corpinfo/programs/the_role_of_mobile_learning_in_eu ropean_education/products/workpackage2.shtml

Flowers, J. (2001). Online learning needs in technology education. Journal of Technology Education, 13(1), 17-30.

Hara, N., \& Kling, R. (2001). Student distress in web-based distance education. Educause Quarterly, 3, 68-69.

Kajumbula, R. (2006). The effectiveness of mobile short messaging service (SMS) technologies in the support of selected distance education students of Makerere University, Uganda. Paper presented at PCF4, the Fourth Pan-Commonwealth Forum on Open Learning, Jamaica, 30 October-3 November 2006. Retrieved from http://pcf4.dec.uwi.edu/viewpaper.php?id=98\&print=1 .

Keegan, D., Kismihok, G., Mileva, N., \& Rekkedal, T. (2009). The role of mobile learning in European education. Retrieved from http://www.ericsson.com/ericsson/corpinfo/programs/the_role_of_mobile_learning_in_eu ropean_education/products/workpackage4.shtml

Malaysian Communications and Multimedia Commission. (2009). Penetration rates at a glance. Retrieved from http://register.skmm.gov.my/facts_figures/stats/ViewStatistic.asp?cc=36702694\&srid=50 $\underline{919742}$

Melton, B., Graf, H., \& Chopak-Foss, J. (2009). Achievement and satisfaction in blended learning versus traditional general health course designs. International Journal for the Scholarship of Teaching and Learning, 3(1). Retrieved from http://academics.georgiasouthern.edu/ijsotl/v3n1/articles/_MeltonGrafChopakFoss/index.htm

Moore, M. (1997). Theory of transactional distance. In D. Keegan (Ed.), Theoretical principles of distance education (pp. 22-38). New York: Routledge.

Singh, H. K. D. (2010, June). Effectiveness of 5-category pedagogical model using SMS technology. Paper presented at the International Conference on Communication and Media, Melaka, Malaysia. 
Stone, A. (2001). Mobile scaffolding: An experiment in using SMS text messaging to support first year university students. Proceedings from the Fourth IEEE International Conference on Advanced Learning Technologies (ICALT'04), 30 August-1 September 2004 (pp. 405-409).

Sukaphat, S. (2007). Applying of bulk SMS system to enhance educational communications. Proceedings of the 13th Asia Pacific Management Conference, Melbourne, Australia, 2007 (pp. 582-586). Retrieved from http://mlearning.danysto.info/library/files/a267.pdf

Tyler-Smith, K. (2006). Early attrition among first time e-learners: A review of factors that contribute to drop-out, withdrawal and non-completion rates of adult learners undertaking e-learning programmes. Journal of Online Learning and Teaching, 2(2). Retrieved from http://jolt.merlot.org/Vol2_No2_TylerSmith.htm

Uday Bhaskar, N., \& Govindarajulu, P. (2008). Implications of mobile technology usage on learners in a learning process. International Journal of Computer Science and Network Security, 8(5), 251-259.

Viljoen, J., du Preez, C., \& Cook, A. (2005). The case for using SMS technologies to support distance education students in South Africa: Conversations. Perspectives in Education, 23(4), 115-122.

Yousof, (2007). Effectiveness of mobile learning in distance education. Turkish Online Journal of Distance Education, 8(4). Retrieved from http://tojde.anadolu.edu.tr/tojde28/articles/article_9.htm

Zirkle, C. (2002). Identification of distance education barriers for trade and industrial teacher education. Journal of Industrial Teacher Education, 40(1), 20-44.

\section{Athabasca University $\mathbf{a}$}




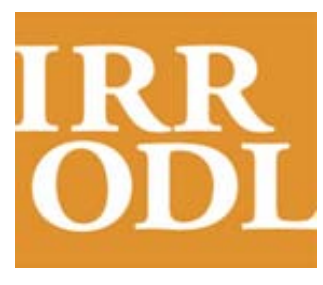

International

Review of

Research in Open

and Distance

Learning

Vol. 12.2

February - 2011

\section{Book Review}

\section{Economics of Distance and Online Learning: Theory, Practice and Research}

Editors: Bramble, W. J. \& Panda, S. Economics of Distance and Online Learning: Theory, Practice and Research (2008). London: Routledge. 312 pages. ISBN-13: 978-0415963893

Reviewer: Wolfram Laaser, FernUniversität in Hagen, Germany

The book edited by Bramble and Panda provides a comprehensive overview of the organizational models of distance and online learning from an international perspective and from the point of view of planning, costing, management, and decision making. Chapters are written by different experts working in the field. For those not familiar with costing and distance education it provides a valuable introduction to the different facets of handling the economic aspects of distance education and online learning. Experienced scholars will find some interesting viewpoints and methodologies to inspire further discussion and research.

\section{Chapter 1: Organizational and Cost Structures for Distance and Online Learning}

The chapter written by the editors themselves introduces the term distance education and highlights the generations of distance education according to Taylor. It then goes on to list models of delivery following Peters. Finally general factors are listed that influence costs, such as country characteristics, system design, organizational type, and curriculum focus. The chapter ends with a listing of cost categories and types of cost analysis. (The definition given of cost effectiveness is not shared by the reviewer. "A cost effective system is one that minimizes cost and maximizes effectiveness of outcomes." In my view cost can only be minimized for given output; minimization and maximization are not achievable at the same time.) 


\section{Chapter 2: Changing Distance Education and Changing Organizational Issues}

Written by Canadian authors Garrison and Kanuka, the chapter describes the changes that are related to the spread of online learning to both distance education and campus-based education. "Blended learning is a disruptive technology in that it has the potential to overcome the resistance to change of any large educational institution” (p.20). In this respect, bottom-up and top-down strategies are mentioned to motivate administrative staff to adapt to changes. The authors furthermore state that the diversity of institutional and pedagogical settings will increase and the distinction between the two educational models will become blurred.

\section{Chapter 3: Online Learning and the University}

Curran extends and deepens the topics raised in the previous chapter. He gives an overview on growth of online learning both in the US and Europe and tries to identify the different effects of online learning on the role and model of the traditional university. Due to constraints of context, cost, and culture, he concludes that radical or revolutionary changes in universities are an unlikely prospect.

\section{Chapter 4: Virtual Schooling and Basic Education}

Clark extends the perspective of the university to the school level with special reference to the US context. Types of virtual schools and their different funding policies are explained. The author doubts that online distance education via virtual schools will catch on outside North America.

\section{Chapter 5: Historical Perspectives on Distance Learning in the United States}

This chapter written by Edelson and Pittman brings us back to the US context. The authors cite a study that predicts online courses will eventually account for $31 \%$ of all course enrolments at the postsecondary level. The authors claim that developing online courses is more costly than conventional print-based independent study. Cost savings are however expected from cooperation with professional publishers. The authors expect nevertheless a rise of online courses of up to $50 \%$ of all enrolments. The US government is supposed to lower some funding restrictions and thereby increase support for students learning at a distance.

\section{Chapter 6: Funding of Distance and Online Learning in the United States}

From an historical perspective, Smith and Bramble explain why, unlike in Europe, in the United States dual-mode institutions, rather than single-mode institutions, are the prevailing educational model. With respect to higher education, US federal government influence has been exerted 
through accreditation, land and financial grants, and financial aid to students. State influence has been achieved through direct budget contributions. Due to economic constraints, however, state funding has lost some of its importance. The authors complain that the greater need for distance and online learning is for recurrent, rather than project-based, funding that tends not to fit the funding priorities established for traditional institutions.

Many institutions have adopted a business-like model to operate distance education as a separate business operation or profit centre. Often profits generated are then absorbed into the general budget. The authors conclude that rather than a pioneering national effort to meet a national need to educate the masses, distance education in the United States is most often a supplement to traditional campus-oriented education.

\section{Chapter 7: Funding Distance Education - A Regional Perspective}

This chapter by Panda and Gaba describes funding policies with special reference to the situation of India. The authors report that funding for Indira Gandhi National Open University, one of the mega universities, has decreased over time. Today open universities have to finance themselves mainly by student fees.

\section{Chapter 8: Costs and Quality of Online Learning}

Inglis starts with the following observation that the belief on the part of senior managers that moving to online education offers a way to reduce cost was misplaced; they now realize that the relation between cost and quality is more complicated than they had thought previously. After presenting the difficult definition of online learning, she proceeds to state the fact that compared to printed modules, more interactivity and multimedia components increase costs. Efforts to lower cost by joining consortia for course development and distribution have not been overly successful. For the moment, the same holds true with respect to cost savings via use and reuse of learning objects.

\section{Chapter 9: Costing Virtual University Education}

Jung again deals with factors that determine the cost of virtual university education. Her statement that virtual university education is characterized by high fixed costs and low variable costs, compared to conventional universities is difficult to accept without exact specification of system characteristics. Other authors of this book suggest for example that the development cost of classroom lectures is not very different from developing online courses.

\section{Chapter 10: Cost-Benefit of Student Retention Policies and Practices}

Simpson elaborates on the influence of reducing dropout rates and of respective retention policies. He shows that reduction of dropout rates is an important strategy to increase return on investment. This is especially important as high dropout rates were associated with traditional 
distance learning environments. However, while increased interactivity or tutoring services may reduce the rate of dropout, they may also increase the cost of the system.

\section{Chapter 11: Costing Virtual University Education}

Berge and Donaldson discuss the use of return on investment (ROI) to assess profitability of training measures. They cite an example of cost calculations, comparing classroom and online learning. E-learning is said to take $25-60 \%$ less time to convey the same amount of information as in a traditional classroom setting. Less likely to be generalized and also difficult to demonstrate with concrete figures is their notion of differences in opportunity costs.

\section{Chapter 12: Transforming Workplace Learning}

To train the workforce, the authors Strattner and Oblinger favour the concept of embedded learning, (i.e., insertion of learning activities into job tasks). Online embedded learning seems to lead to flexibility, time savings, and skill enhancement.

\section{Chapter 13: Open Basic Education}

In this chapter, Edisingha compares open basic education programmes with respect to audiences, curricula, and media. He comes to the conclusion that compared to regular programs open basic education programs have certain cost advantages and can achieve financial sustainability. (However, due to different definitions of statistical concepts, comparative data can be difficult to obtain.)

\section{Chapter 14: From Baobap to Bonsai}

In this chapter, Hülsmann reviews the history of costing distance learning and explains in detail the famous cost calculations of Wagner in assessing the cost of the British OU compared to conventional universities. He reports some historical calculations to cost different educational media. From a methodological point of view more than because of the credibility of the results, this part is interesting. A bit disappointing is the uncritical notion of Daniels' "triangle" based on simplistic reasoning that is quite difficult for an educated economist to accept.

The exciting part is Hülsmann's elaboration of the cost of distributed e-learning. According to Jewett, unbundling of teaching tasks shifts cost of content development and instructional design from variable to fixed costs and frees teachers for student-related workload. (However, the cost of familiarizing teachers with online teaching is neglected.) 


\section{Chapter 15: Implications for Planning and Management of Distance and Online Learning}

Like the introduction, the final chapter is written by the editors themselves. They end with some general conclusions.

\section{Evaluation}

First of all, as literature about costing of distance learning and of online learning is relatively seldom treated, we can congratulate the editors for choosing this subject. However, at first sight I expected to learn more about the economics of distance learning in the sense of modelling economic decisions of stakeholders rather than about the historical development and organizational changes of distance learning. From the various statements, I learned that while online education might be more expensive than conventional education and probably also more expensive that the so-called "Fordist Model" of distance education, cooperation and modular production may reduce the potential gaps. However, in light of these statements, the rapid diffusion of e-learning technologies lacks explanation. Or is it that educational institutions wrongly believed in the promises of the software vendors?

In my view the book suffers a bit from the rapid application of technology to the field. Much of the literature cited in the book is from five to ten years ago. Today, although nearly every educational institution in industrialized countries uses learning platforms, in such varied contexts it is difficult to provide common definitions of the terms distance learning or online learning. Cost analysis is impossible without specifying the particular institutional and pedagogical environment and clearly identifying the stakeholders referred to. Copying and pasting and the comfort of actual platforms ease considerably the production of content. For detailed assessment of costs, online cost calculators are available today. The entire way of producing content and organizing communication has changed today; it is therefore not comparable to prior ways of doing so. Learning effects are another important issue to be considered here.

However, all in all, the different perspectives and expertise of the authors who come from different cultural contexts enriched the reader's perception of the problems involved to determine the costs and benefits of educational offerings today.

\section{Athabasca University $\mathbf{I}$}




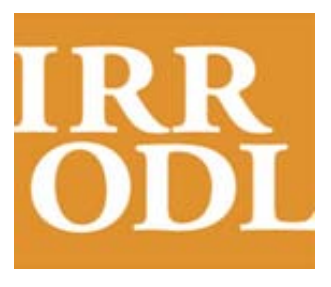

International

Review of

Research in Open

and Distance

Learning

Vol. 12.2

February - 2011

\section{Universal Instructional Design Principles for Mobile Learning}

\section{Tanya Elias}

Athabasca University, Canada

\begin{abstract}
The report extends a previous analysis of universal instructional design principles in distance education, by applying them to the design of mobile learning. Eight principles with particular relevance for distance education are selected, and their recommendations are discussed in relation to the design of educational materials for a range of mobile devices. The problems and opportunities of mobile learning are discussed, and the need for educators to focus on its content design issues rather than on searching for the next new technology.
\end{abstract}

Keywords: Universal instructional design principles; mobile learning 


\section{Introduction}

In a previous article in this series, the current author discussed the value of Universal Instructional Design (UID) principles for use with the learning management system, Moodle. The current article extends the discussion by discussing the application of UID in mobile learning (mlearning). M-learning has been championed as "a personal, unobtrusive, spontaneous, 'anytime, anywhere' way to learn and to access educational tools and material that enlarges access to education for all” (Kukulska-Hulme \& Traxler, 2005, p.1). It also been described as having the potential to "reach people who live in remote locations where there are no schools, teachers, or libraries,” (Ally, 2009, p. 2). This ability to reach new audiences in new places is particularly relevant in the developing world where mobile cellular penetration has more than doubled since 2005 and the adoption of mobile devices has outpaced the use of personal computers and landline Internet access (ITU, 2010). Thus, mobile devices are rapidly becoming the key to making information "universally accessible" (Wellman, 2007). In order to realise its potential, effective methods for offering high-quality and accessible m-learning are required.

Although a single definition of m-learning remains elusive, Traxler (2009) has stated:

Mobile learning exploits both handheld computers and mobile telephones and other devices that draw on the same set of functionalities. Mobile learning using handheld computers is obviously relatively immature in terms of both its technologies and its pedagogies, but is developing rapidly. It draws on the theory and practice of pedagogies used in technology enhanced learning and others used in the classroom and the community. (p.11-12)

To date, m-learning research in both the developed and developing world has focused on the use of handheld computers and smartphones (Kukulska-Hulme \& Traxler, 2005; Ally, 2009). In contrast, little research has concentrated on m-learning for simpler devices and/or those capable of running on limited networks (Trifonova \& Ronchetti, 2003). After a successful pilot using simply featured phones, Gregson \& Jordaan (2009) nonetheless referred to "the potential uses of the more recent smartphone and 3G handsets for supporting a broader range of academic activity within education in Africa” (p.225). Similarly, Ford \& Leinonen (2009) have identified

a desperate need for a new approach...particularly in the developing world environment. The model needs to take into account issues of usability, accessibility, and affordability, while ensuring that appropriate pedagogical models are adhered to... (p.198)

Thus, m-learning has much in common with traditional forms of face-to-face and online learning with respect both to its pedagogy and its use of technology. The current paper suggests that UID 
principles developed for other forms of learning can also be helpful in designing inclusive mlearning applications accessible to the largest possible audience from the simplest of devices.

\section{The Challenges and Opportunities of M-Learning}

M-learning design presents unique challenges.

1. Device variability. Nielson (2009) identified three categories of handheld mobile devices: feature phones with tiny screens and numeric keypads; smartphones that include an A-Z keypad and a mid-sized screen; and touch phones featuring a device-sized screen and activated by touch. Despite recent market excitement about the potential of higher-end smartphones and touch phones, feature phones continue to represent an estimated $85 \%$ of the mobile market. The significant challenges of m-learning are partly due to this diversity. As Stead (2010) has explained,

There is no single solution to push richly interactive mobile content onto every possible phone. Rather, there is a spectrum of possible solutions: On one side, going for the richest possible interactivities....and on the other side going for the widest possible phone coverage (para.3).

In many m-learning pilot projects, this challenge has been overcome by distributing to learners a specific mobile device and designing for that device. Students, however, generally want to learn on their own mobile devices (Bradley et al., 2010). Moreover, Herrington and Herrington (2009) point out that "using a learner's own device ensures that many of the features of the devices are well known and practiced" (p.136).

2. Slow download speed and limited Internet access. Despite advances in the delivery of mobile cellular broadband in North America and Europe, download speeds on mobile devices continue to present problems. These are compounded in regions of the world where highspeed broadband access is expensive and/or completely unavailable (ITU, 2010). To this point, most m-learning pilot projects have provided free access to the highest available level of mobile Internet access, although this approach is not in tune with the realities facing a large proportion of users, particularly in the developing world.

3. Small screen sizes with poor resolution, colour, and contrast. On hardware designed to fit in a pocket, small screen size continues to be a defining feature of handheld mobile devices. A typical screen size is $8-12$ centimetres long and 6-8 centimetres wide with the presentation usually being in portrait mode but sometimes in landscape. Resolutions vary and may or may not involve back-, front- or side-lit images with colour (JISC, 2010). Neilson (2009) estimated that the average success rate for accessing Web sites from feature phones was only $38 \%$. Smartphones and touch phones fared moderately better with success rates of 55 and $75 \%$ respectively. 
4. Awkward text input. Regardless of the device being used, inputting text data into small devices also presents challenges for the user. Inputting information into a device using a numeric (0-9) keypad on a feature phone continues to be tedious and time consuming. Again, the more sophisticated the device, the better its input capabilities.

5. Limited memory. Handheld phones have limited internal information storage capacity or memory. Extra random access memory (RAM) for the storage of programs and files may be added to devices from external memory sticks or cards (JISC, 2010), although these cannot be inserted into all handheld devices. Moreover, Kukulska-Hulme and Traxler (2005) pointed out that it takes slightly longer to retrieve data from external memory by comparison with internal memory - a fact that still applies five years later. In contrast, read-only memory (ROM), which runs the device operating system, cannot usually be increased (JISC, 2010).

But m-learning design also presents a distinctive set of opportunities.

1. Relatively inexpensive m-learning opportunities. Although cost remains a barrier to mlearning in many parts of the world, handheld mobile devices and cellular services are significantly less expensive than PCs and laptops with fixed Internet service (ITU, 2010). During a pilot project in Africa, Ford and Leinonen (2009) found that if "the phones used were basic models and only needed to support the ability to send an SMS, the cost factor for the handset was small” (p.225). Moreover, the size and inherent portability of the devices facilitates information sharing as a method of lowering access costs more easily. In fact, Kreutzer (2009) found that for many young South Africans, mobile phone handsets are quickly becoming the Internet platform and multimedia device of choice. Moreover, he noted that not owning a phone "does not seem to create a 'mobile divide' or automatically lead to exclusion from the possibilities of mobile Internet access” (Kreutzer, 2009, p.ii).

While the hardware devices themselves may be relatively inexpensive, network access can present additional challenges. Ramos et al. (2006) found in the Philippines that $81 \%$ of those surveyed would be willing to set aside a portion of their prepaid cell-phone credits for learning. Although cost will continue to present a barrier to m-learning for some populations, the entry point for this type of learning is potentially much lower than for forms of online learning.

2. Multimedia content delivery and creation options. Mobile devices allow sound, text, pictures, and video files to be downloaded to the device and uploaded from the device. In addition, they feature built-in speakers and, almost always, cameras. Ford and Leinonen (2009) used a mobile audio-wikipedia that supported increased access to information in a region "where the access to information, both paper-based and electronic, is limited" and built on "the strong African oral tradition" (p. 210).

3. Continuous and situated learning support. Mobile devices allow ongoing learning to occur in multiple locations, including the potential to offer scaffolded support (Saye \& Brush, 2002) to learners undertaking authentic tasks. Using these devices in a way that maximises these 
learning benefits has the potential to offer educational opportunities that are both more inclusive and of higher quality. As Nyíri (2002) has explained:

Mobile communication is enhanced everyday communication; and just as our everyday conversation is indifferent towards disciplinary boundaries, so, too, is m-learning. Situation dependent knowledge, the knowledge at which m-learning aims, by its nature transcends disciplines; its organising principles arise from practical tasks; its contents are multisensorial; its elements are linked to each other not just by texts, but also by diagrams, pictures, and maps” (p. 124).

\section{UID Recommendations for M-Learning}

UID principles have been developed to build flexibility of use into both the instructional design and operating systems of educational materials so that they will be appropriate to the widest range of students (Connell et al., 1997; Scott et al., 2002; Burgstahler, 2007). Elias (2010) extracted from these eight UID principles particularly useful in distance education (DE):

1. equitable use,

2. flexible use,

3. simple and intuitive,

4. perceptible information,

5. tolerance for error,

6. low physical and technical effort,

7. community of learners and support, and

8. instructional climate.

Although not specifically developed for m-learning environments, these are equally relevant to them. The relevance of almost all of these principles for designing inclusive online learning is further increased when designing inclusive m-learning. Table 1 compares the most relevant recommendations arising from UID principles for online learning with a series of additional recommendations for m-learning. 
Table 1

UID Recommendations for Inclusive M-Learning

\begin{tabular}{|c|c|c|}
\hline UID Principles & Online DE recommendations & M-learning recommendations \\
\hline 1. Equitable use & $\begin{array}{l}\text { - put content online } \\
\text { - provide translation }\end{array}$ & $\begin{array}{l}\text { - deliver content in the simplest } \\
\text { possible format } \\
\text { - Use cloud-computing file storage } \\
\text { and sharing sites }\end{array}$ \\
\hline 2. Flexible use & $\begin{array}{l}\text { - present content and accept } \\
\text { assignments in multiple formats } \\
\text { - offer choice and additional } \\
\text { information }\end{array}$ & $\begin{array}{l}\text { - Package content in small chunks } \\
\text { - consider unconventional } \\
\text { assignment options } \\
\text { - Leave it to learners to illustrate } \\
\text { and } \\
\text { animate courses }\end{array}$ \\
\hline $\begin{array}{l}\text { 3. Simple and } \\
\text { intuitive }\end{array}$ & $\begin{array}{l}\text { - simplify interface } \\
\text { - offer offline and text-only options }\end{array}$ & $\begin{array}{l}\text { - keep code simple } \\
\text { - use open-source software }\end{array}$ \\
\hline $\begin{array}{l}\text { 4. Perceptible } \\
\text { information }\end{array}$ & $\begin{array}{l}\text { - add captions, descriptors and } \\
\text { transcriptions }\end{array}$ & \\
\hline $\begin{array}{l}\text { 5. Tolerance for } \\
\text { error }\end{array}$ & $\begin{array}{l}\text { - allow students to edit posts } \\
\text { - issue warnings using sound and } \\
\text { text }\end{array}$ & $\begin{array}{l}\text { - scaffold and support situated } \\
\text { learning methods }\end{array}$ \\
\hline $\begin{array}{l}\text { 6. Low physical } \\
\text { and technical } \\
\text { effort }\end{array}$ & $\begin{array}{l}\text { - incorporate assistive technologies } \\
\text { - consider issues of physical effort } \\
\text { - check browser capabilities }\end{array}$ & $\begin{array}{l}\text { - use available SMS readers and } \\
\text { other mobile-specific assistive } \\
\text { technologies }\end{array}$ \\
\hline $\begin{array}{l}\text { 7. Community of } \\
\text { learners and }\end{array}$ & - include study groups and tools & - encourage multiple methods of \\
\hline
\end{tabular}




\begin{tabular}{|l|l|l|}
\hline support & - easy-to-find links to support & communication \\
& Services & $\begin{array}{l}\text { - group learners according to } \\
\text { technological access and/or } \\
\text { preferences }\end{array}$ \\
\hline $\begin{array}{l}\text { 8. Instructional } \\
\text { climate }\end{array}$ & - make contact and stay involved & $\begin{array}{l}\text { - push regular reminders, quizzes } \\
\text { and questions to students } \\
\end{array}$ \\
\hline
\end{tabular}

1. Equitable use. Course content should be accessible to people with diverse abilities and in diverse locations. With respect to m-learning, this involves developing content and assignments that can be accessed on a wide variety of devices. As a result, to develop accessible m-learning one ought to do the following.

- Deliver content in the simplest possible formats. Short Messaging Systems (SMS), or texting technology is cheap and given its high levels of penetration is almost universally accessible. Mitchell (2002) indentified "simplicity of use, relatively low cost and the asynchronous nature of SMS, which gives people time to reflect before responding to a message [as] undoubtedly part of its phenomenal success (Mitchell, 2002). Issham et al. (2010) found a high level of acceptance of SMS-learning as "safe, easy, effective and usable to help them in their studies” (p.14). JISC (2010) has described SMS as a classic example of an "m-learning accessibility model. Although it poses all kinds of physical and usability barriers to disabled learners the motivation for using it is sufficiently high that there are few who do not actively manage to master it to some extent.”

There are numerous ways to address these accessibility issues (see item 6). Developing primary content using SMS can be a simple yet elegant way of ensuring that diverse learners have access to required materials. Wijayanto (2006), for example, designed an SMS-based public education system to both inform the public and to gather information regarding avian 'flu.

- Use cloud-computing file storage and sharing sites. Given the small storage capacity of most handheld devices, file-storage sites may offer users the same level of flexibility in completing assignments as is available to those with more sophisticated hardware and/or connectivity. A study at a South African high school, for example, indicated that only $33 \%$ of students had access to phones with substantial internal and flash-card memory. This led "to the regular deletion of older content in order to make room for new material" (Kreutzer, 2009, p.69). Using external storage sites would enable these students to save more information, develop more complex projects, and engage more fully in learning. 
2. Flexible use. According to this UID principle, course design should accommodate a wide range of individual abilities, preferences, schedules, levels of connectivity, and choices in methods of use. As with other forms of inclusive learning, inclusive m-learning should offer choice in how materials are used. SMS-based m-learning offers fast transmission of information to students who are bound to neither a computer nor a classroom. Whereas other types of education go to great lengths to simulate real-world situations and to bring the outside world into the classroom through the use case studies, role-plays, photographs, videos, and so on, m-learning has the potential to bring the learning out of the classroom to remote students. SMS-based solutions may often be more than adequate for this but will require significant adjustments.

- Package content in small bits. Clearly, the use of an SMS system, with its 160 character limit, forces content to be brief. The length of resources needs to be considered in taking download speed and costs into account. Bradley et al. (2009) divided materials into "manageable learning chunks" (p. 281) and separated text over several screens. Although, seeking out such ways to package content may present challenges, it may also have pedagogical advantages for all learners owing to the elimination of dead wood information that is not essential for attaining a learning goal (Ragan \& Smith, 2005).

- Consider unconventional assignment options. Suggesting and accepting unconventional assignments allows learners to look for unique ways to use the multimedia features of their devices and to compensate for the hardware's shortcomings. In the South African project, for example, the inclusion of multimedia options led to audiocasts that "were passionate and uninhibited and included spontaneous harmonizing of songs, including rap songs” (Ford \& Leinonen, 2010, p.207).

- Leave it to learners to illustrate and animate courses. In contrast to traditional teaching environments where instructors are predominantly responsible for incorporating the real world into the classroom, mobile devices have the potential to transfer that responsibility to the learners themselves. Using phones with cameras/video capabilities, students can capture their own material and instantaneously it them to other students and instructors and/or upload it for storage. Discussion could then revolve around real-world examples defined by the learners.

3. Simple and intuitive. Unnecessary complexity should be eliminated and course design rendered simple and intuitive. As already mentioned, the simplest mobile delivery system is currently SMS. To post and share their own multimedia content, however, learners must access multimedia messaging systems (MMS), email, and/or a mobile Internet service. When developing and/or selecting existing sites for use, the following guidelines are useful:

- Keep learners' interfaces simple. It should be ensured that they contain only information that can fit comfortably on the smallest of screens. 
- Keep code simple. Sites that use HTML provide a simple and relatively accessible content delivery system with useful features including the ability to link between pages and sites. Use of simple coding minimises files sizes, increases download speeds, and is better supported on feature phones that may not give good support for cascading style sheets and other advanced programming functions.

- Use open sites and software. Open sites and software help to ensure that learners have ongoing access to resources and lower costs. Ford and Leinonen (2009) state that this facility "stimulates the local IT sector in a country, which is crucial in developing countries to ensure full participation in the information society" and "allows software to be customized to local conditions by the communities themselves” (p. 199). The use of open-source products, therefore, advances not only simple access to content but also (relatively) simple access to m-learning development tools.

4. Perceptible information. With respect to this UID principle, one of the recommendations for online learning is to add captions, descriptors, and transcriptions (Elias, 2010). SMS-based materials would not require these added features. Instructors may encourage learners to include them, however, when their assignments include media elements. Nevertheless, it is likely that not all student-posted materials will be accessible to all users. Strategies are suggested to mitigate these issues (see item 7).

5. Tolerance for error. UID principles also minimise hazards and adverse consequences of errors in software operation by designing learning environments with a tolerance for error. While m-learning errors are likely to be similar to those encountered in traditional online learning, an additional m-learning-specific recommendation may be identified:

- Scaffold and support situated learning. M-learning is uniquely positioned to support situated learning (Lave \& Wenger, 1990). In many settings it may be valuable for learners to be able to access learning materials via their mobile device while performing a task or skill. In these cases, job performance aids included in the learning package may reduce learner errors by providing just-in-time training and support as and when required. Providing simple, short text-based support in rich learning contexts has an excellent educational potential.

6. Low physical and technical effort. As with online learning, m-learning should be developed requiring a low technical and physical effort. The physical effort related to inputting text into devices is therefore a primary concern. Clearly answering test essay questions on such a device would be tedious if not impossible. As indicated in relation to SMS usage, the difficulties associated with inputting text data into mobile devices poses the challenge of developing new, authentic, and inclusive forms of assessment. In addition, inclusive mlearning should seek out opportunities to do the following: 
- Use available SMS reader software and other mobile-specific assistive technologies. Several SMS readers are freely available with potential value to learners who are visually impaired, who are auditory learners, or who are studying while driving. A clip-on magnifier can easily be attached to increase font size and visibility (JISC, 2010). An external device to convert SMS to Braille was developed in the Philippines (Estopace, 2004) but may not be commercially available today.

7. Community of learners and support. As in other forms of learning, community support for learning should be facilitated through the development of groups and support from appropriate tools.

- Encourage multiple methods of communication. Learners should be encouraged to experiment with the standard communication options of mobile devices (SMS, email, instant messaging, and voice communication) in developing relationships with and support for one another. Using these features, they can scaffold one another (Saye \& Brush, 2002) in working collaboratively to theorise and solve ill-structured realworld problems.

- Group learners according to technological access and/or preferences. In the development of inclusive m-learning, it is likely that diverse learners will have differing levels of access to and interest in multimedia technologies. It may be preferable to combine learners into groups along these lines. For example, if some learners use only SMS text in a course, they may prefer to work together rather than with learners who have access to MMS and/or Internet. Grouping students in such a way may reduce their sense of "missing out” on specific delivery features.

8. Instructional climate. This UID principle focuses on the instructor's impact in course delivery as opposed to course design. M-learning instructors can send regular SMS messages to interact with learners in various ways. For example, they can do the following:

- Push regular reminders, requests, quizzes, and questions. Instructors can easily generate and send reminders about assignments, weekly expectations, and interactive quizzes using SMS (Ramos et al., 2010). Such systems can be effective in generating discussion and in inviting various forms of student feedback.

- Pull in learner-generated content. As instructors push their content out, they can continuously pull in student-generated content in various forms (SMS and MMS, audio files, pictures, videos, etc.). Regardless of the hardware, the key is for the instructor to foster an inclusive environment that supports learning through sharing and collaboration in which the contributions of all learners are valued. 


\section{Conclusions}

Inclusive and accessible education should aspire to include all learners. Mobile learning appears to have the potential to do that. SMS and MMS technologies offer excellent opportunities to open up education to many who have long been excluded from it. This effort, however, will involve the development of creative techniques for relatively simple technologies and the design of universally accessible educational materials for them. The challenge will force educators to rethink their current approaches to teaching. They should not look exclusively for the next great technological advance but rather should focus on the accessible design of materials using tools that are currently available. Intensive research is needed to consider the ways in which appropriate technologies and solid pedagogical approaches can remove the barriers to educational diversity. The principles of universal instructional design will play a valuable role in this process. 


\section{References}

Ally, M. (2009). Mobile learning: Transforming the delivery of education and training. Edmonton, AB: Athabasca University Press.

Burgstahler, S. (2007). Universal design of instruction: Definition, principles, and examples. University of Washington. Retrieved from http://www.washington.edu/doit/Brochures/Academics/instruction.html

Connell, B., Jones, M., Mace, R., Mueller, J., Mullick, A., Ostroff, E., Sanford, J., Steinfeld, E., Story, M., \& Vanderheiden, G. (1997). The principles of universal design. Raleigh, NC: Center for Universal Design, North Carolina State University.

Bradley, C., Haynes, R., Cook, J., Boyle, T., \& Smith, C. (2009). Design and development of multimedia learning objects for mobile phones. In M. Ally (Ed.) Mobile learning: Transforming the delivery of education and training (pp. 157-182). Edmonton, AB: Athabasca University Press.

Elias, T. (2010). Universal instructional design principles for Moodle. International Review of Research in Open and Distance Learning 11(2). Retrieved from http://www.irrodl.org/index.php/irrodl/article/view/869

Estopace, E. (2004). Text messaging for the blind: Proudly Filipino. Philippine Headline News Online. Retrieved from http://www.newsflash.org/2004/02/si/si001957.htm

Ford, M., \& Leinonen , T. (2009). MobilED - mobile tools and services platform for formal and informal learning. In M. Ally (Ed.) Mobile learning: Transforming the delivery of education and training (pp. 195-214). Edmonton, AB: Athabasca University Press.

Gregson, J., \& Jordaan, D. (2009). Exploring the challenges and opportunities of m-learning within an international distance education programme. In M. Ally (Ed.) Mobile learning: Transforming the delivery of education and training (pp. 215-246). Edmonton, AB: Athabasca University Press.

Herrington, A, Herrington, J., \& Mantei, J. (2009). Design principles for mobile learning. In J. Herrington, A. Herrington, J. Mantei, I. Olney \& B. Ferry (Eds.), New technologies, new pedagogies: Mobile learning in higher education. University of Wollongong. Retrieved from http://ro.uow.edu.au/edupapers/88/

Lave, J., \& Wenger, E. (1990). Situated learning: Legitimate peripheral participation. Cambridge: Cambridge University Press.

International Telecommunications Union (2010). Measuring the information society 2010. Geneva, Switzerland: ITU. 
Issham, I., Siti, S. Johari, M., \& Rozhan, I. (2010). Acceptance on mobile learning via SMS: a Rasch model analysis. International Journal of Interactive Mobile Technologies 4(2). Retrieved from http://www.scribd.com/doc/29729105/Acceptance-on-Mobile-Learningvia-SMS-A-Rasch-Model-Analysis

Joint Information Systems Committee (JISC) (2010). JISC TechDis advice and guidance on mlearning. Retrieved from http://www.techdis.ac.uk/index.php?p=9_5

Kreutzer, T. (2009). Generation mobile: Online and digital media usage on mobile phones among low-income urban youth in South Africa. Retrieved from http://tinokreutzer.org/mobile/

Kukulska-Hulme, A., \& Traxler, J. (2005). Mobile learning in developing countries. Vancouver: Commonwealth of Learning. Retrieved from http://www.col.org/resources/publications/trainingresources/knowledge/Pages/mobileLea rning.aspx

Mitchell, A. (2002). Translating mobile technologies into learning technologies: creating a microportal layer for the m-learning project. Online Educa Berlin (28 November). Retrieved from http://www.mlearning.org/docs/Online\%20Educa\%20paper\%2028\%20Nov\%2002.rtf

Neilsen, J. (July 20, 2009). Mobile usability [blog post]. Retrieved from http://www.useit.com/alertbox/mobile-usability.html

Nyíri, K. (2002). Towards a philosophy of m-learning. Proceedings of Wireless \& Mobile Technologies in Education. from http://academic.research.microsoft.com/Paper/4325835.aspx

Ramos, A., Trinoña, J., \& Lambert, D. (2006). Viability of mobile SMS technologies for nonformal distance education. In J. Baggaley (Ed.), Information and communication technology for social development (pp. 69-79). Jakarta: ASEAN Foundation.

Ramos, A., \& Triñona, J. (2010). Mobile technology in non-formal distance education. In J. Baggaley \& T. Belawati (Eds.), Distance education technologies in Asia. New Delhi: Sage India.

Saye, J., \& Brush, T. (2002). Scaffolding critical reasoning about history and social issues in multimedia-supported learning environments. Educational Technology Research \& Development 50(3), 77-96.

Scott, S., McGuire, J., \& Shaw, S. (2003). Universal design for instruction: A new paradigm for adult instruction in postsecondary education. Remedial and Special Education 24(6), 369-379. 
Smith, P., \& Ragan, T. (2005). Instructional design ( $3^{\text {rd }}$ ed.). Hoboken, NJ: Wiley.

Stead, G. (2010). Moblearn: The mobile generation is learning. Retrieved from http://moblearn.blogspot.com/2010/06/can-my-m-learning-course-run-same-on.html

Traxler, J. (2009). Learning in a mobile age. International Journal of Mobile and Blended Learning 1(1), 1-12.

Trifonova, A., \& Ronchetti, M. (2003). Where is mobile learning going?. In A. Rossett (Ed.), Proceedings of World Conference on E-Learning in Corporate, Government, Healthcare, and Higher Education, pp. 1794-1801. Chesapeake, VA: AACE. Retrieved from http://www.editlib.org/p/12226

Wijayanto, B. (2006). Using SMS methods to combat avian flu. In J. Baggaley (Ed.) Information and communication technology for social development (pp. 81-92). Jakarta: ASEAN Foundation.

Wellman, S. (2007). Google lays out its mobile user experience strategy (11 April). Retrieved from

http://www.informationweek.com/blog/main/archives/2007/04/google_lays_out.html

\section{Athabasca University $\mathbf{A}$}




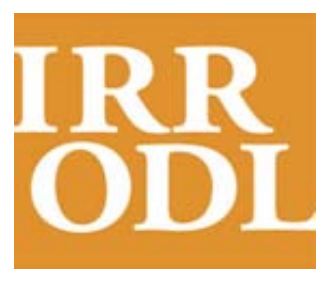

International

Review of

Research in Open

and Distance

Learning

Vol. 12.2

February - 2011

\section{Online Videoconferencing Products: Update}

\author{
Douglas Burton and Tim Kitchen
}

Athabasca University, Canada

\begin{abstract}
Software allowing real-time online video connectivity is rapidly evolving. The ability to connect students, staff, and guest speakers instantaneously carries great benefits for the online distance education classroom. This evaluation report compares four software applications at opposite ends of the cost spectrum: DimDim, Elluminate VCS, TokBox, and Vyew. Their benefits and shortcomings are contrasted, and efficient educational scenarios for them are suggested.
\end{abstract}

Keywords: Web-conferencing; online learning; synchronous communication; distance education; audio; video 


\section{Introduction}

Since the original review of videoconferencing software in this evaluation series (Craven, Keppy, \& Baggaley, 2002), tools for online conferencing have evolved dramatically. Many of the 10 products compared on the previous occasion no longer exist. New ones have taken their place and have been reviewed under integrated software headings in the series, including a new product, Elluminate VCS, which focuses on high-quality video and platform interoperability with dedicated videoconferencing equipment. This updated product is compared in the current report with three freeware applications: DimDim, TokBox, and Vyew.

Until recently, many factors kept real-time desktop videoconferencing from being a practical solution for connecting distance learners. The most obvious of these were the lack of adequate bandwidth availability and the high cost of the tools and equipment they require. With highspeed bandwidth increasing in many regions of the world, however, and with reduced costs of built-in and external computer webcams and microphones, this means of online collaboration is becoming more prevalent. According to Schenker (2008), "the worldwide videoconferencing systems and services market, which reached $\$ 1.6$ billion in 2007, is expected to grow to $\$ 4.2$ billion by 2012.” As to the educational and training sector of this market, Wainhouse Research has reported that it "reached about $\$ 680$ million in 2009, and is projected to grow to more than $\$ 1$ billion by the end of 2014” (Tierney, 2010). The current report focuses on four different videoconferencing software products, highlighting the strengths and weaknesses of each and ways for educators to use them effectively.

\section{Product Trials}

This report does not present a strict apples-to-apples comparison but instead a store-boughtapples-to-free-roadside-apples comparison. By deliberate choice, a fully featured commercial application is compared with three freeware conferencing applications. The rationale for this selection is that in the open- and distance-learning field budget and a vast range of educational objectives need to be considered. The software applications selected for comparison here are DimDim, ElluminateVCS, TokBox, and Vyew. These applications all have commercial versions and the ability to share webcam video, but they differ greatly in other respects. Elluminate VCS is the only product of the four that does not also have a freeware version. This study compares the commercial Elluminate VCS with the free versions of TokBox, DimDim, and Vyew.

It must be stressed that the current comparison may have been affected by fluctuations in product stability due to Internet traffic and bandwidth capacity, computer processing and host server speed, microphone sensitivity, network accessibility, and operating systems. The authorreviewers used a consistent technical platform in relation to each of these variables for reviewing all four products. The products were reviewed in April, 2010 in terms of the following features:

- maximum participants - number of participants who can join the conference from individual computers;

- $\quad$ simultaneous webcams - number of cameras visible on the screen at any one time; 
- cross-platform - ability to use the software on multiple operating systems (as stated by software manufacturer, though not actually tested by the reviewers);

- file-sharing - ease with which participants can exchange computer files ( 1 = hard to use, 3 = moderate ease of use, and $5=$ data files and video clips easily shared);

- $\quad$ whiteboard - shared writing and drawing feature ( 1 = hard to use, $3=$ moderate ease of use, and 5 = very easy to use);

- $\quad$ shared desktop - ability to share an individual's screen image $(1=$ hard to use, $3=$ moderate ease of use, and 5 = very easy to use);

- $\quad$ email messaging - ability to send and receive email within the product ( 1 = hard to use, 3 $=$ moderate ease of use, and 5 = very easy to use);

- $\quad$ voice/video messaging - ability to send and receive voice messages ( 1 = hard to use, $3=$ moderate ease of use, and 5 = very easy to use).

- Web-tour - ability to lead other participants on a co-surfing or shared browsing experience by taking over their computer displays.

- Web tools integration - ability to work with other communication applications; some products have a built-in feature for sending email, instant text messages, attachment files, and voicemail, but fulfill these functions solely within their own environment; other products can be used in conjunction with external email applications on a convenient, integrated basis ( 1 = hard to use, $3=$ moderate ease of use, and 5 = very easy to use).

These features of the four conferencing products are compared in Table 1.

Table 1

The Four Products' Features

\begin{tabular}{|c|c|c|c|c|}
\hline & DimDim & Elluminate VCS & TokBox & Vyew \\
\hline $\begin{array}{l}\text { Licensing cost } \\
\text { (USD) }\end{array}$ & $\begin{array}{l}\text { - Free to } 20 \text { users } \\
\text { - Pro: } \$ 25 \text { month for } \\
50 \text { users } \\
\text { - Webinar: } \$ 75 / \\
\text { month (to } 1,000 \\
\text { users, view only) }\end{array}$ & $\begin{array}{l}\text { Server-based } \\
\text { starting at } \\
\$ 70,000 \text { p.a. for } \\
150 \text { user seats } \\
\text { (average over } 3 \\
\text { years = \$20.80/ } \\
\text { per seat) }\end{array}$ & $\begin{array}{l}\text { - Free to } 20 \\
\text { users } \\
\text { - } \$ 9 / 99 / \text { month, } \\
\text { with } \\
\text { moderation + } \\
\text { scheduling }\end{array}$ & $\begin{array}{l}\text { - Free to } 10 \\
\text { users }+20 \text { Vyew } \\
\text { books } \\
\text { - } \$ 6.95 / \text { month } \\
\text { w/ } 50 \text { Vyew } \\
\text { books } \\
\text { - } \$ 13.95 / \text { month } \\
\text { w/ } 150 \text { Vyew } \\
\text { books }\end{array}$ \\
\hline $\begin{array}{l}\text { Maximum } \\
\text { participants }\end{array}$ & 10 (1 video) & 25 (6 video) & 20 (all video) & 10 (5 video) \\
\hline $\begin{array}{l}\text { Simultaneous } \\
\text { webcams }\end{array}$ & 0 & 6 & 20 & 5 \\
\hline Cross-platform & PC, Mac, Linux & $\begin{array}{l}\text { PC (Mac due in } \\
\text { 2010) }\end{array}$ & PC, Мac & PC, Mac, Linux \\
\hline File-sharing & PowerPoint + PDF & Any document & $\begin{array}{l}\text { EtherPad, } \\
\text { Flickr, Picasa, }\end{array}$ & $\begin{array}{l}\text { Any document } \\
\text { (extra small }\end{array}$ \\
\hline
\end{tabular}




\begin{tabular}{|c|c|c|c|c|}
\hline & & & $\begin{array}{l}\text { SlideShare, } \\
\text { YouTube }\end{array}$ & $\begin{array}{l}\text { fonts difficult to } \\
\text { use) }\end{array}$ \\
\hline Whiteboard & Yes & Yes & No (Etherpad) & Yes \\
\hline Shared desktop & Yes & Yes & No & Yes \\
\hline $\begin{array}{l}\text { Email } \\
\text { messaging }\end{array}$ & No & SMS & No & Yes \\
\hline $\begin{array}{l}\text { Voice/video } \\
\text { Messaging }\end{array}$ & No & No & Both & No \\
\hline Web-tour & $\begin{array}{l}\text { Yes (participants } \\
\text { control own } \\
\text { navigation) }\end{array}$ & Yes & No & Desktop-sharing \\
\hline $\begin{array}{l}\text { Web tools } \\
\text { integration }\end{array}$ & No & No & $\begin{array}{l}\text { EtherPad, } \\
\text { Flickr, Picasa, } \\
\text { SlideShare, } \\
\text { YouTube }\end{array}$ & $\begin{array}{l}\text { Plug-ins } \\
\text { available (see } \\
\text { list below) }\end{array}$ \\
\hline
\end{tabular}

The following product features were also rated by the reviewers on the basis of their April, 2010 trials:

- $\quad$ video clarity - visual precision $(1=$ barely visible, $2=$ obvious pixilation, $3=$ minor pixilation, 4 = clear with no obvious pixilation, 5 = DVD quality);

- $\quad$ video delay - lag and unintended pauses in the visual feed, resulting in jerky images $(1=$ major lag, $2+$ secs., 2 = lag, $1-2$ secs., 3 = lag $<1$ sec., 4 = barely perceptible delay, and 5 = real-time motion, no discernable lag);

- $\quad$ screen scalability - capacity to increase or decrease screen size $(1=$ no adjustment possible, 2 = some adjustment possible with decrease in clarity, 3 = adjustment possible to small, medium, or full screen with decrease in clarity, $4=$ some adjustment possible with no decrease in clarity, and 5 = adjustment possible to small, medium, or full screen with no decrease in clarity);

- $\quad$ audio clarity - clearness of the sound (e.g., the ability to hear a voice without background noise, white noise, crackling, interference from nearby electronic devices, etc.) (1 = barely audible, 3 = reasonably clear, and 5 = studio-quality recording);

- $\quad$ Echo - ringing and feedback, requiring the use of external headset and microphone $(1=$ major, 3 = moderate, and 5 = non-existent;

- $\quad$ audio/video synchronization - delay and lag between sound and visual $(1=$ major, $3=$ minor, and 5 = real-time synchronisation);

- help tools - built-in or downloadable user manuals, tutorials, FAQs, search, help by email/ fax/telephone/webinars, etc. ( 1 = minimal help available, 3 = moderate amount of relatively clear help, and 5 = numerous clear and easy-to-use help tools);

- intuitiveness - user-friendliness compared with more familiar media (telephone, text chat, etc.); some products try to replicate familiar web-page or software navigation styles, others augment styles of use to which their subscribers have become accustomed, and 
still others create an original environment that requires new learning ( $1=$ hard to use, not intuitive, $3=$ moderate ease of use, and 5 = very easy to use).

- stability - availability of a constant standard of operation for the software (e.g., no freezing or crashing) ( $1=$ unstable, $3=$ minimal freezing or crashing, and $5=$ uninterrupted use).

The reviewers' ratings of these product features are given in Table 2.

Table 2

Ratings of Product Audio/Video Quality (1 - negative; 5 = positive)

$\begin{array}{lcccc} & \text { DimDim } & \begin{array}{c}\text { Elluminate } \\ \text { VCS }\end{array} & \text { TokBox } & \text { Vyew } \\ \text { A. VIDEO QUALITY (Note: each } & \text { attribute relates to screen size) } & \\ \text { Clarity } & 3 & 5 & 3 & 3 \\ \text { Delay } & 3 & 5 & 3 & 5 \\ \text { Screen scalability } & 1 & 5 & 3 & 1 \\ \text { B. AUDIO QUALITY } & & & & \\ \text { Clarity } & 4 & 5 & 3 & 3 \\ \text { Echo } & 5 & 5 & 5 & 5 \\ \text { Audio/video } & 4 & 5 & 3 & 3 \\ \text { synchronisation } & & & & \\ \text { C. USABILITY } & & & & 1 \\ \text { Help tools } & 4 & 2 & 2 & 1 \\ \text { Intuitiveness } & 4 & 5 & 4 & 2 \\ \text { Stability } & 5 & 5 & 5 & \end{array}$

\section{Summary of Product Evaluations}

Overall, the four products gave adequate-to-good quality of service, summarised as follows.

1. DimDim is a free, open source web meeting platform with surprisingly rich features for up to 20 simultaneous attendees and a fee-for-service version allowing a larger number. The product's extensive list of basic services includes live screen-sharing, synchronised web browsing, whiteboard, and document-sharing. DimDim's help tools are without equal and include dial-in phone support. DimDim requires Flash installation and is supported on the Internet Explorer and Firefox browsers. Its lack of screen-size scalability and its support for only one webcam are major limitations. The product has limited application-sharing with the only shareable document types being PowerPoint and PDF formats. Microsoft Word is not supported, and there are limited desktop-sharing features. 
2. Elluminate VCS is a commercial product, which received the highest overall ratings in this review in all features except help tools. Elluminate VCS stands out from the other three products in relation to its high-quality video and audio. It is also the only product that features H323 interoperability, that is, the ability to connect to dedicated videoconferencing hardware end-points. This is a highly desirable feature for institutions with sites that need to connect to remote videoconferencing equipment. Elluminate VCS has an attractive and simple navigation interface, powerful sharing and collaboration tools, a "presence engine" that makes it easy to initiate spontaneous connections, and an effective meetings scheduling tool. Surprisingly, the product's help tools are limited, lacking the benefit of online tutorials, webinars, and a searchable database. It is to be hoped that this issue will be rectified in the next software release as the features for it are built into the user interface shell. Elluminate VCS is an institutional server-based solution and cannot be installed on individual computers by a lone, innovative teacher. This feature permits greater server-based control and increased security but requires substantial up-front expenditure. The license cost for a minimum of 150 users over three years averages $\$ 20.80$ per seat/month and represents a long-term commitment. The $\$ 70,000$ server, installation, and set-up costs for the initial year, plus an additional $17 \%$ service fee for each subsequent year, may put the product beyond the means of small institutions but make it a reasonable investment for medium-to-large institutions.

3. TokBox is a very useful tool with a number of unique features; the best feature is the ease with which it connects participants. The product is web-based and requires no download. Equally impressive is the fact that invitees do not need an account to use the product, which allows new participants to be invited into a session spontaneously. Another distinctive feature is that participants can email, video-mail, and instant message each other and can initiate a session by posting an invitation on a social networking site such as Twitter, Facebook, or MySpace. A single session can have up to 20 people sharing video, collaborating using an Ethernet Pad, and uploading HTML, Word, or RTF files. The use of EtherPad involves a "time slider" by which the collaboration can be reviewed and saved to various file formats. In addition, content can be shared through Flickr, Picasa, SlideShare, and YouTube. Audio and video quality is very good for a free tool, and easy adjustments of video size and switching between applications are possible.

4. Vyew is also a completely browser-based conferencing platform with no downloads or added services required. The developer claims that it is compatible with $95 \%$ of all browsers. Free for up to 10 participants, Vyew offers a wide range of features, including file-sharing, whiteboard, desktop-sharing, screen-capture, shared mouse cursors, and useful plug-ins, including MP3, Flash/YouTube players, and polling. Meeting setup is the most difficult of the features reviewed. With no integrated email messaging, inviting participants to a meeting requires contact addresses to be entered manually. The free Vyew version displays advertising banners.

An overall summary of the products' advantages and disadvantages is given in Table 3 . 


\section{Table 3}

Comparison of Product Advantages and Disadvantages

\begin{tabular}{|c|c|c|}
\hline & Advantages & Disadvantages \\
\hline \multirow{4}{*}{ DimDim } & Low cost & Lack of multi-camera support \\
\hline & Ease of use & Lack of screen-size scalability \\
\hline & Many basic features & Limited applications-sharing \\
\hline & Help tools & \\
\hline Elluminate & High-quality audio and video & Cost \\
\hline \multirow[t]{4}{*}{ vCS } & Easy applications-sharing & Lack of Help tools \\
\hline & Interoperability with dedicated & \\
\hline & videoconferencing equipment & \\
\hline & Good scheduling tool and presence engine & \\
\hline \multirow[t]{5}{*}{ TokBox } & Low cost & No whiteboard \\
\hline & Good-quality video & Most tools not integrated into \\
\hline & Can send video emails & the software \\
\hline & Simple meeting requests/set-up & \\
\hline & Can use various web applications & \\
\hline \multirow[t]{7}{*}{ Vyew } & Low cost & Lack of screen-size adjustment \\
\hline & Synchronous or & Banner advertising \\
\hline & asynchronous collaboration & \\
\hline & Voice recordings and sticky notes can be & \\
\hline & pasted into shared workspace & \\
\hline & Web-based plug-ins can easily be & \\
\hline & introduced into the workspace & \\
\hline
\end{tabular}

\section{Conclusion}

As open and distance education evolve, teachers, students, and administrators continue to seek effective ways to connect and collaborate. This review has considered several current products, based on desired outcomes, kinds of operational settings, and budget, especially important in times of economic hardship. No one conferencing tool is likely to satisfy the needs of all institutions and participants. Having reviewed several software products beyond the ones discussed here, the current reviewing team is encouraged to see the many new ways that participants can communicate and collaborate from wherever they may be in the world.

DimDim's many basic features make it a solid all-round product. It is a useful tool if one does not need multiple and flexible video as part of a collaboration and if the product needs to be free. DimDim's help tools and ease of use make it a good choice, but its lack of multi-camera support, lack of screen scalability, and limited application-sharing are major drawbacks. 
Elluminate VCS is a good product for an organisation that is looking for an institution-based solution with a minimum of 150 participants and for which cost is not the primary factor but for which connecting with existing videoconferencing equipment is paramount. The product is useful for formal presentations, guest speakers, and small meetings where high-quality audio and video are required.

Vyew's lack of screen-size adjustment and banner advertisements can be frustrating; otherwise, it is a fully featured product with solid collaboration features and is a strong candidate for any course requiring group work. Vyew would be an especially good choice for asynchronous collaboration across multiple time zones.

TokBox is the most fully featured tool of the freeware applications tested here. Its most unique feature is the ability to send video email. It gives good quality and scalable video for up to 20 participants at once. The product is appropriate for collaborative projects and for sending students personalised weekly messages and feedback.

It is hoped that these product reviews provide a starting point for comparing other products currently available to enhance the online learning experience. 


\section{References}

Craven, P., Keppy, B., \& Baggaley, J. (2002). Online videoconferencing products. International Review of Open \& Distance Learning, 3(2). Retrieved from http://www.irrodl.org/index.php/irrodl/article/view/88/167.

DimDim. (2010). Real-time collaboration made real easy. Retrieved from http://www.dimdim.com/.

Elluminate VCS. (2010). E-learning and collaboration solutions. Retrieved from http://www.elluminate.com/.

Schenker, J. L. (2008). Economic woes boost videoconferencing. Bloomberg Businessweek, (August 5). Retrieved from http://www.businessweek.com/globalbiz/content/aug2008/gb2008085_094217.htm.

Tierney, A. (2010). Education, training needs fuel web conference call market: Report. TMCnet.

TokBox. (2010). Free video chat platform and videoconferencing application. Retrieved from http://www.tokbox.com/.

Vyew. (2010). Free always-on collaboration and live web conferencing. Retrieved from http://vyew.com/.

\section{Athabasca University $\mathbf{Z}$}

